Savannah River

National Laboratory

\title{
3013 DE Inner Container Closure Weld Corrosion Evaluation
}

\author{
J. I. Mickalonis
}

September 2013

SRNL-STI-2013-00527, Revision 0 
SRNL-STI-2013-00527

Revision 0

\section{DISCLAIMER}

This work was prepared under an agreement with and funded by the U.S. Government. Neither the U.S. Government or its employees, nor any of its contractors, subcontractors or their employees, makes any express or implied:

1. warranty or assumes any legal liability for the accuracy, completeness, or for the use or results of such use of any information, product, or process disclosed; or

2. representation that such use or results of such use would not infringe privately owned rights; or

3. endorsement or recommendation of any specifically identified commercial product, process, or service.

Any views and opinions of authors expressed in this work do not necessarily state or reflect those of the United States Government, or its contractors, or subcontractors.

\section{Printed in the United States of America}

Prepared for

U.S. Department of Energy 


\section{ACKNOWLEDGEMENTS}

The author wishes to acknowledge the following for their assistance in this work: G.D.Creech, W. C. Crouch, J. Duffey, K. A. Dunn, M. R. Louthan, T. Reown, and V. B. Timmerman. 


\section{EXECUTIVE SUMMARY}

Destructive evaluation (DE) of 3013 containers is one part of the U. S. Department of Energy Integrated Surveillance Program. During standard DE of 3013 containers, visual examinations for pitting and stress corrosion cracking (SCC) are performed on the accessible surfaces of the outer, inner, and convenience containers, which make up the 3013 container. As a result of $3013 \mathrm{DE}$ additional analysis, the area near the inner container closure weld has been identified as being a region of increased corrosion susceptibility, which may provide a pathway for corrosive gases to the outer container. This area has a higher residual stress, an altered microstructure, and less corrosion resistant weld oxides as a result of the welding process as well as a lower temperature than other areas of the container, which may increase the absorption of moisture on the surface. The deposition of moisture in this stressed region could lead to pitting and stress corrosion cracking.

During FY2013, the inner container closure weld area was more closely evaluated on several archived samples from DE containers. These containers included FY09 DE2, FY12 DE4, FY12 DE6 and FY12 DE7 and the Hanford High Moisture Container. The additional examinations included visual observations with a stereomicroscope, scanning electron microscopy along with energy dispersive spectroscopy for chemical analysis, and serial metallography of the sidewall and lid that are part of the inner container closure weld region.

Pitting was observed in all the samples taken from the closure weld regions of the examined inner containers. This pitting was generally less $20 \mu \mathrm{m}$ with most less than $5 \mu \mathrm{m}$. These pits were similar in depth to those observed in the vapor exposed surfaces of teardrops in the shelf life corrosion testing. Cracking was not observed on either the vapor-exposed surfaces of the teardrop coupons or the inner container closure weld region. Further testing is necessary to determine if the conditions in the welded inner container could support SCC during the 50 year life time for the 3013 container. 


\section{TABLE OF CONTENTS}

LIST OF TABLES vii

LIST OF FIGURES vii

LIST OF ABBREVIATIONS xii

1.0 Introduction 1

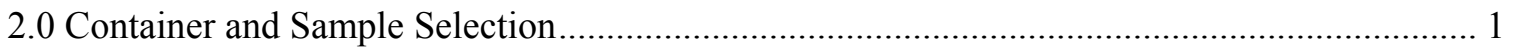

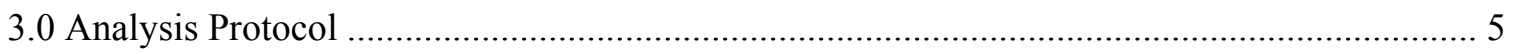

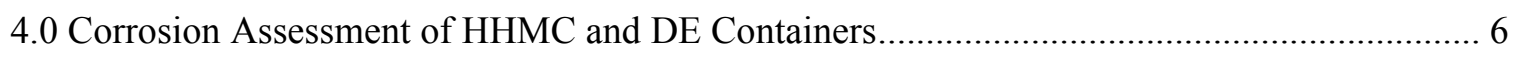

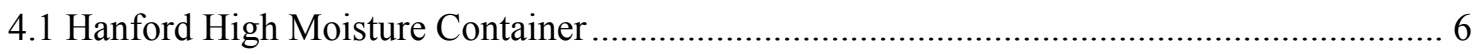

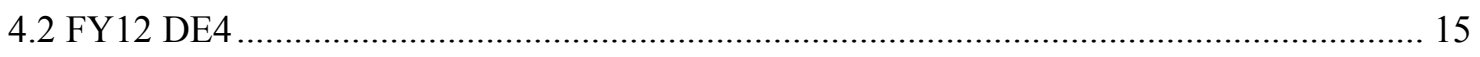

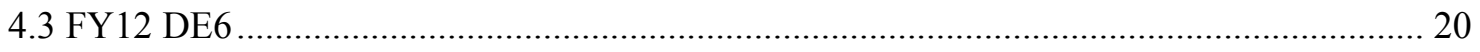

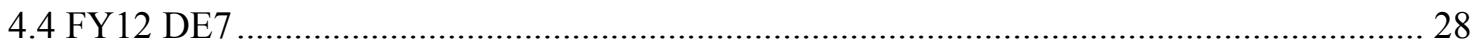

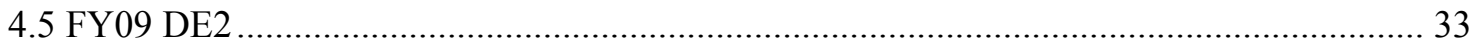

5.0 SRNL Shelf Life Corrosion Test Results Summary................................................................ 40

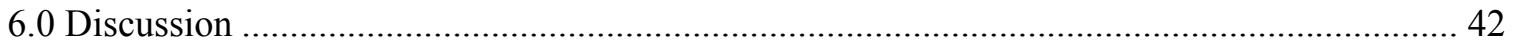

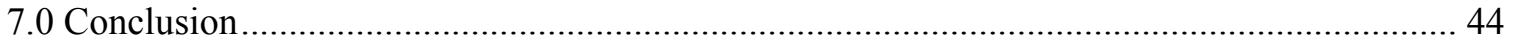

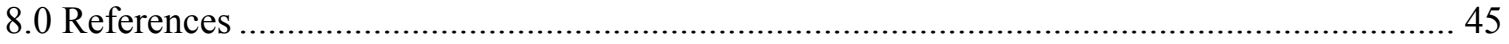

\section{LIST OF TABLES}

Table 1 Measured Parameters for Packaged 3013 Containers. 44

\section{LIST OF FIGURES}

Figure 2-1 Pictures showing the container condition of HHMC: A) convenience container, interior surface; B) inner container lid, interior surface; C) a material resembling corrosion products outside the inner container closure weld gap

Figure 2-2 Schematic drawing showing surfaces of the inner container closure weld gap formed between the container sidewall and lid

Figure 2-3 HHMC inner container lid: A) removal of pie section from for additional examination and $\mathrm{B}$ ) side view of the closure weld gap 3

Figure 2-4 FY12 DE4 as observed during DE: A) convenience container, interior surface; B) inner container lid, interior surface; and C) borescope image of a material resembling corrosion product outside the inner container closure weld gap....

Figure 2-5 Interior surfaces of container observed during DE: A) FY12 DE6 convenience container; B) FY12 DE6 inner container lid; C) FY12 DE7 convenience container; and D) FY12 DE7 inner container lid 
Figure 2-6 FY09 DE2 as observed during DE: A) convenience container, interior surface; B) inner container lid, interior surface; and C) stereomicrograph of surface outside inner container closure weld gap, $25 \mathrm{x}$........4

Figure 3-1 Schematic drawing showing the planes that are viewed during serial metallography of a sample mounted in cross section

Figure 4-1 Sidewall and lid pieces from the $90^{\circ}$ pie section of the HHMC inner container closure weld region after removal of the closure weld

Figure 4-2 Sidewall (A) and lid (B) pieces from the $90^{\circ}$ pie section of the HHMC inner container closure weld region after removal of the closure weld $(25 \mathrm{x})$

Figure 4-3 SEM micrographs of the sidewall and lid pieces of the $90^{\circ}$ pie section from HHMC inner container closure weld gap: A) sidewall, SE; B) sidewall, QB; C) lid, SE; and D) lid, QB

Figure 4-4 EDS spectrum from a raster scan for the sidewall piece from the $0^{\circ}$ pie section of the HHMC prior to cleaning.

Figure 4-5 Surface of the sidewall piece from the $0^{\circ}$ pie section of the HHMC showing the locations for the EDS point analysis of various surface features

Figure 4-6 EDS spectra from point analysis of surface features on the sidewall piece from the $0^{\circ}$ pie section of the HHMC: A) spot 3, multi-elemental feature; B) spot 1, iron-rich oxide; and C) spot 4, chromium-rich oxide (see Figure 4-5 for the location of the point analyses).

Figure 4-7 SEM micrographs of the sidewall from the $90^{\circ}$ pie section for the HHMC after cleaning: A) micrograph showing overall surface of the sidewall, 17x; B) micrograph from ROI1, 250x; and C) micrograph from ROI2, 251x

Figure 4-8 SEM micrographs of the sidewall gap surface for the HHMC after cleaning: A) $90^{\circ}$ pie section, 100x; B) $90^{\circ}$ pie section, 200x; C) $270^{\circ}$ pie section, $300 \mathrm{x}$; and D) $270^{\circ}$ pie section, $745 \mathrm{x}$

Figure 4-9 Cross sectional micrographs from different location along the sidewall for each pie section from the HHMC: A) $270^{\circ}$ pie section, $500 \mathrm{x}$; B) $90^{\circ}$ pie section, $500 \mathrm{x}$; C) $0^{\circ}$ pie section, $500 \mathrm{x}$; D) $180^{\circ}$ pie section, 500x; and E) cross section of sidewall showing location of micrographs, $12.5 x$ (i.e. micrograph in A comes from location A on sidewall)

Figure 4-10 Cross sectional micrographs from different location along the lid of the $90^{\circ}$ pie section from the HHMC: A-D) pit locations along lid gap surface, 500x; and E) overview of lid showing locations for micrographs in (A) through (D), 12.5x 
Figure 4-11 Cross sectional micrographs showing the location of the dendritic microstructure in the HHMC inner container closure weld region (indicated by arrows): A) lid from $90^{\circ}$ pie section, 50x; B) sidewall from $270^{\circ}$ pie section, $12.5 \mathrm{x}$; C) sidewall from $270^{\circ}$ pie section showing pits forming at interdendritic regions, $500 \mathrm{x}$

Figure 4-12 Secondary electron images of the sidewall and lid pieces from the inner container lid of FY12 DE4 prior to cleaning: A) sidewall from A pie section, 17x; B) sidewall from $B$ pie section, 40x; C) lid from $A$ pie section, 19x; and D) lid from $B$ pie section, 50x

Figure 4-13 EDS spectrum for the lid piece from the A pie section for FY12 DE4 inner container showing the relative size of the chloride signal

Figure 4-14 Secondary electron micrographs of the sidewall (A, 150x) and lid (B, 250x) pieces from the A pie section for FY12 DE4 showing the layer of oxides and corrosion products on the sample

Figure 4-15 Secondary electron micrographs for FY12 DE4 inner container closure weld gap surfaces showing the observed pitting: A) sidewall from A pie section, 500x; B) sidewall from $B$ pie section, 600x; C) lid from A pie section, 500x; and D) lid from $\mathrm{B}$ pie section, 450x

Figure 4-16 Cross sectional micrograph (200x) of the inner container lid for FY12 DE4 showing no degradation along the gap and bottom surfaces for the first (A), second (B), and third (C) planes

Figure 4-17 Cross sectional micrographs of the sidewall piece for FY12 DE4 for the first (A, 200x), second (B, 200x), and third ((C, 200x) and (D, $500 x)$ planes of observation

Figure 4-18 SEM micrograph (backscattered electron image, 15x) of the surface of FY12 DE6 sidewall from the $0^{\circ}$ pie section

Figure 4-19 SEM micrographs (100x) showing the locations of EDS spectra for the heavily oxidized surface (A) near the weld and the particle-covered surface (B) nearer the gap opening

Figure 4-20 EDS spectra of spots shown in Figure 4-19: 1 (A), 2 (B), 4 (C) and 6 (D); and a base metal spectrum is shown in (E)

Figure 4-21 Stereomicroscope images of the sidewall (A, 25x and C, 63x) and lid $(\mathrm{B}, 10 \mathrm{x}$ and $\mathrm{D}, 50 \mathrm{x})$ pieces from the $0^{\circ}$ pie section of FY12 DE6

Figure 4-22 Mounted sidewall and lid pieces from the $0^{\circ}$ (A and B, respectively) and $90^{\circ}$ (C and D, respectively) pie sections of FY12 DE6

Figure 4-23 Progressive changes with grinding and polishing in the crevice at the top of the $0^{\circ}$ pie section from the inner container closure weld gap for FY12 DE6; (A), (B), and (C) are different planes with (A) being closest to the edge of the pie section, 200x. 
Figure 4-24 Pitting observed in the sidewall surface of the $90^{\circ}$ pie section from the inner container closure weld gap for FY12 DE6 (A-D, first plane; E-F, second plane; G-H, third plane): (A) 50x; (B) 200x; (C) 500x; (D) 500x; (E) 100x; (F) 200x, (G) 200x, and (H) 500x

Figure 4-25 Microstructure near the pit observed in the sidewall of the $90^{\circ}$ pie section for FY12 DE6 (200x, electrolytically etched 10\% oxalic acid) ....28

Figure 4-26 Stereomicroscope photographs of the sidewall and lid pieces from the $0^{\circ}$ pie section for FY12 DE7: (A) sidewall, 10x; (B) sidewall, 50x; (C) sidewall, 50x; and (D) lid, 10x

Figure 4-27 SEM micrographs (15x) of the sidewall from the $0^{\circ}$ pie section for FY12 DE7: (A) secondary electron image and (B) backscattered image

Figure 4-28 SEM micrographs showing the locations of EDS spectra for the heavily oxidized sidewall surface near the weld $(\mathrm{A}, 175 \mathrm{x})$ and the particle-covered surface close to the gap opening $(\mathrm{B}, 75 \mathrm{x})$ from the $0^{\circ}$ pie section for FY12 DE7

Figure 4-29 EDS spectra of the sidewall from the $0^{\circ}$ pie section for FY12 DE7; spots identified in Figure 4-28: (A) base metal raster scan; (B) spot 1, Cr-rich oxide; (C) spot 2, $\mathrm{Al} / \mathrm{Si} / \mathrm{Mg} / \mathrm{Ca}$ from particulate heavy area; (D) spot 7, Fe-rich oxide; (E) spot 8 oxide of nominal composition (compare to base metal scan).

Figure 4-30 Micrographs (200x) showing progressive changes with grinding and polishing in the crevice at the top of the $0^{\circ}$ pie section closure weld gap for FY12 DE7; (A), (B), and (C) are different planes with (A) being closest to the edge of the pie section (shown by red arrow in Figure 4-26 (A))

Figure 4-31 Micrographs (200x) showing progressive changes with grinding and polishing in the crevice at the top of the $90^{\circ}$ pie section closure weld gap for FY12 DE7; (A), (B), and (C) are different planes with (A) being closest to the edge of the pie section.

Figure 4-32 Sectioning of the FY09 DE2 inner container closure weld region: (A) remainder of sectioned lid; (B) $0^{\circ}$ and $90^{\circ}$ pie sections; (C) all pie sections

Figure 4-33 Schematic drawing showing the different cut lines used for removing pieces of the sidewall from the pie sections for FY09 DE2

Figure 4-34 SEM micrographs (25x) of the sidewall surface from the inner container closure weld gap for the $90^{\circ}$ pie section from FY09 DE2 35

Figure 4-35 Stereomicroscope micrograph (25x) of the sidewall surface from the inner container closure weld gap for the $90^{\circ}$ pie section from FY09 DE2 (same as that shown in Figure 4-34 (B)) 
Figure 4-36 Stereomicroscope micrographs of the inner container closure weld region for FY09 DE2: (A) gap surface of the lid from the $90^{\circ}$ pie section, 20x; (B) lid outside the gap from $180^{\circ}$ pie section, $25 \mathrm{x}$; and (C) sidewall surface outside the gap from the $180^{\circ}$ pie section.

Figure 4-37 SEM micrograph (100x) showing the location of EDS point analysis for the sidewall surface for FY09 DE2 $90^{\circ}$ pie section (spectra are shown in Figure 4-38)

Figure 4-38 EDS spectra from spot analysis of the sidewall gap surface for the $90^{\circ}$ pie section from FY09 DE2 (see Figure 4-37 for location of spots): 1 (A), 3 (B), 4 (C) and 5 (D); and 6 (E)

Figure 4-39 Closure weld gap region for the $180^{\circ}$ pie section from FY09 DE2: (A) gap region, 12.5x; (B) pitting at the gap opening on the lid, 500x; (C) pitting on the sidewall, 500x; and (D) top of gap showing a crevice, 200x (arrows in A show the location of the other micrographs)

Figure 5-1 Cross-sectional micrographs (200x) showing pit morphology for teardrop-shaped coupon after exposure to plutonium oxide/chloride salt mixture loaded with $0.5 \mathrm{wt} \%$ water: A) 85 days and B) 175 days

Figure 5-2 Corrosion observed in the closure weld region of teardrop-shaped coupons after exposure to a plutonium oxide/chloride salt mixture with $0.5 \mathrm{wt} \%$ water: A) teardrop-shaped coupon exposed to vapor only after 85 days; B) cross-sectional micrograph (200x) of pitting in coupon after 85-days exposure; and C) SEM micrograph (19x) of pitting on TIG weld surface after 340-day exposure, sample was cleaned....

Figure 6-1 Cross-sectional micrograph (12x) of the inner container closure weld region for FY08 DE7: A) $90^{\circ}$ pie section and B) $270^{\circ}$ pie section 


\section{LIST OF ABBREVIATIONS}

$\begin{array}{ll}\text { CWG } & \text { Corrosion Working Group } \\ \text { DE } & \text { Destructive Evaluation } \\ \text { DOE } & \text { Department of Energy } \\ \text { EDS } & \text { Energy Dispersive Spectroscopy } \\ \text { FY } & \text { Fiscal Year } \\ \text { HHMC } & \text { Hanford High Moisture Container } \\ \text { MIS } & \text { Materials Identification and Surveillance } \\ \text { QB } & \text { Backscattered Electrons } \\ \text { SCC } & \text { Stress Corrosion Cracking } \\ \text { SE } & \text { Secondary Electrons } \\ \text { SEM } & \text { Scanning Electron Microscope }\end{array}$




\subsection{Introduction}

Destructive evaluation (DE) of 3013 containers is one part of the U. S. Department of Energy (DOE) Integrated Surveillance Program, which is specified by DOE-STD-3013 [1] and overseen by the Materials Identification Surveillance (MIS) working group. During the DE of 3013 containers, visual examinations for pitting and stress corrosion cracking (SCC) are performed on the outer, inner, and convenience containers, which make up the 3013 container. Additional examinations including high magnification microscopy and chemical characterization may be used depending on the container condition.

The Corrosion Working Group (CWG), which is a component of the larger MIS working group, reviews the DE results and the extent of observed corrosion to better understand the principle factors driving the corrosion and the pathway for possible container failure. The areas of primary interest during DE have evolved since 2007 when DE began. Over the last year, the area near the inner container closure weld has been identified as being a region of increased corrosion susceptibility, which may provide a pathway for corrosive gases to the outer container. This area has a higher residual stress, an altered microstructure, and less corrosion resistant weld oxides as a result of the welding process as well as a lower temperature than other areas of the container, which may increase the absorption of moisture on the surface. These conditions could lead to pitting corrosion as well as stress corrosion cracking via a vapor/gas transport mechanism.

During FY13, the inner container closure weld area was more closely evaluated on several archived samples from DE containers. These containers include the Hanford High Moisture Container (HHMC), FY09 DE2, FY12 DE4, FY12 DE6 and FY12 DE7, which are all Hanford container types. The evaluation or additional examinations included visual observations with a stereomicroscope, scanning electron microscopy (SEM) along with energy dispersive spectroscopy (EDS) for chemical analysis, and serial metallography. The results from the additional evaluations of the archived container sections were analyzed in line with the knowledge obtained from the shelf life corrosion testing.

\subsection{Container and Sample Selection}

The corrosion observed in the HHMC was far greater than any observed in containers examined during DE. The HHMC was examined during FY11 using the standard DE procedure. The standard DE would include a visual evaluation of the interior and exterior surfaces of both the lid and container body. Figure 2-1 shows the condition of the convenience container and inner container lid. Because of the presence of material observed on the inner container lid near the closure weld region, a decision was made to section the inner container lid so as to examine the surfaces in the gap between the lid and sidewall near the closure weld. This gap region, which is shown schematically in Figure 2-2, cannot be readily examined during the standard visual evaluation performed during DE. Figure 2-3 shows a side view of the inner container closure weld gap of the HHMC as well as the pie sections cut from the inner container lid. After observing corrosion in this gap, the decision was made to examine the inner container closure weld gaps in other DE containers because a through wall crack in this region would provide a path for corrosive gases to contact the interior surfaces of the outer container and potentially jeopardize the primary barrier [2]. Several DE containers that were being processed from FY12 had pieces from the inner container closure weld gap archived for closer examination along with the previously archived inner container pie sections from FY09 DE2. 

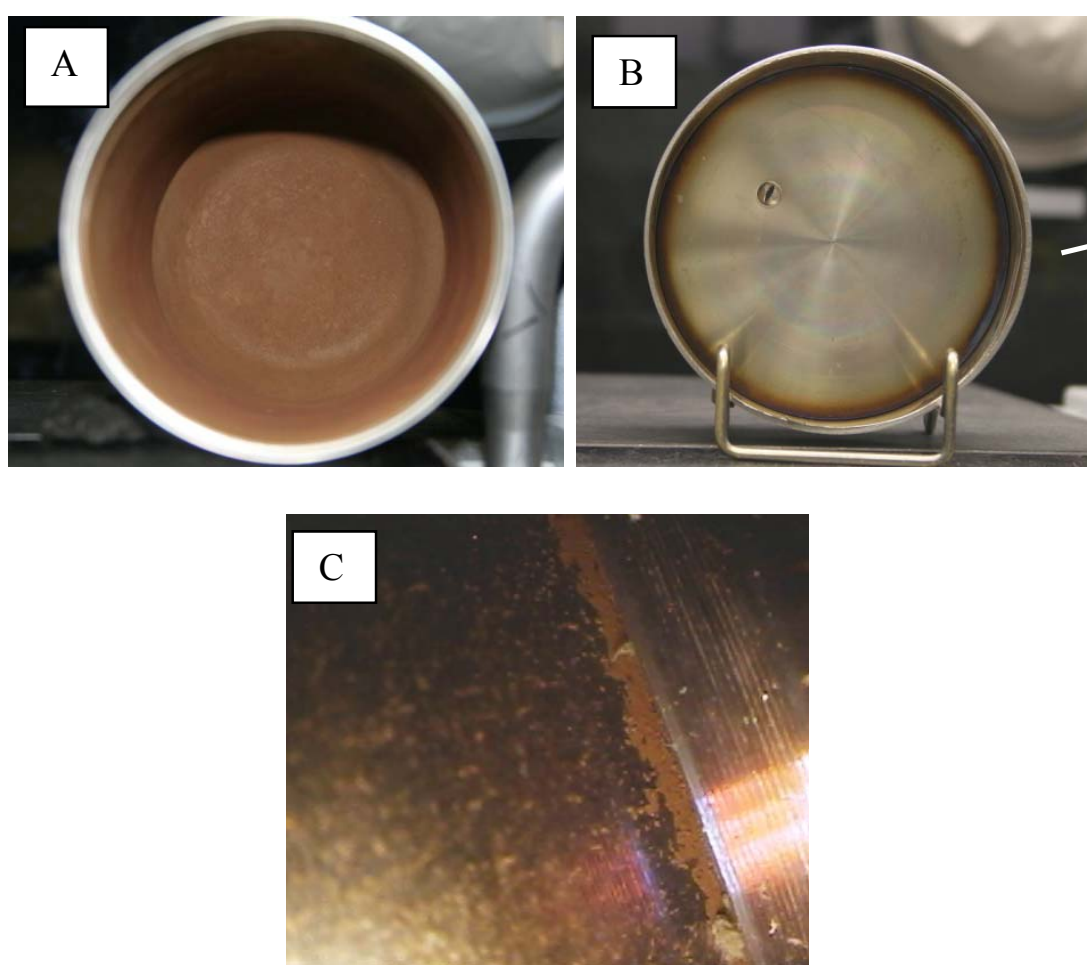

Figure 2-1 HHMC as observed during DE: A) convenience container, interior surface; B) inner container lid, interior surface; $C$ ) a material resembling corrosion product outside the inner container closure weld gap

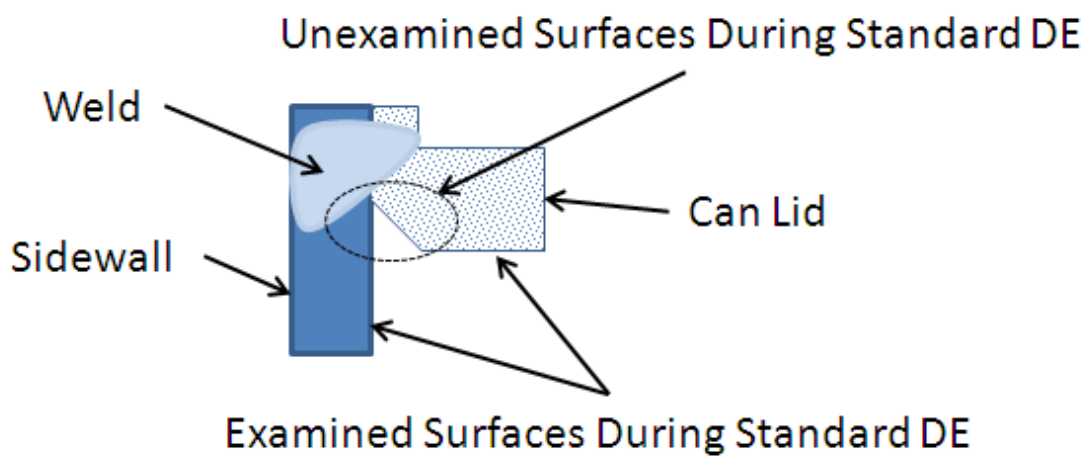

Figure 2-2 Schematic drawing showing surfaces of the inner container closure weld gap formed between the container sidewall and lid 

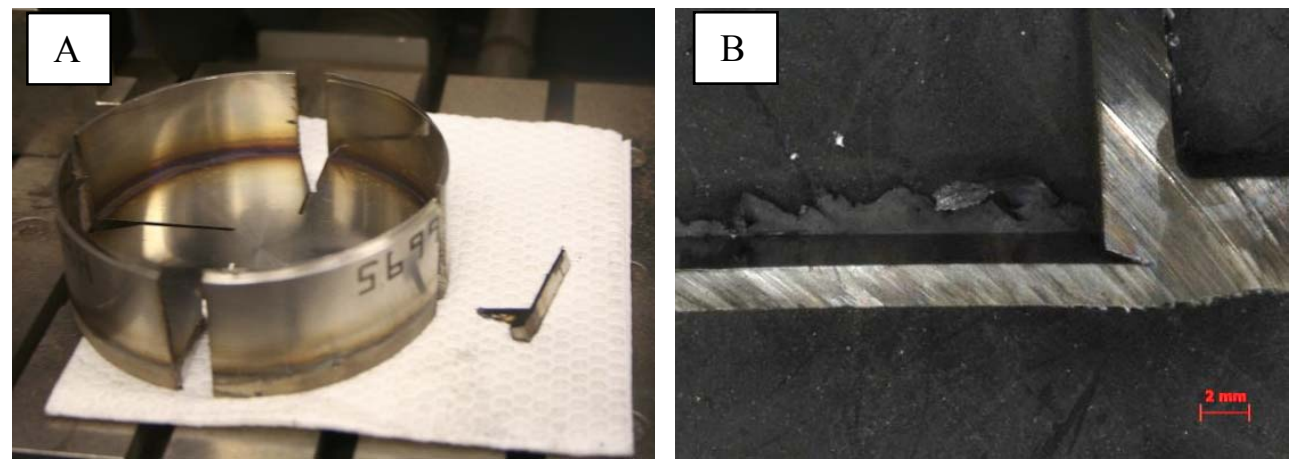

Figure 2-3 HHMC inner container lid: A) removal of pie section from for additional examination and $B$ ) side view of the closure weld gap

The three containers from FY12 DE that were chosen for examination had convenience containers with different surface conditions. The convenience container condition on opening is one factor being evaluated as an indicator of the closure weld gap surface condition. On DE4, an adherent coating was found in the vapor region of the convenience container and lid as well as pitting on the container lid and possible pitting on the container sidewall. A material was found at a few locations near the gap opening of the inner container lid, similar to the HHMC. Two samples were cut from the lid in areas where the material was located. Figure 2-4 shows the condition of the convenience container and inner container lid surfaces as well as a borescope image of a material resembling corrosion products outside the inner container closure weld gap.
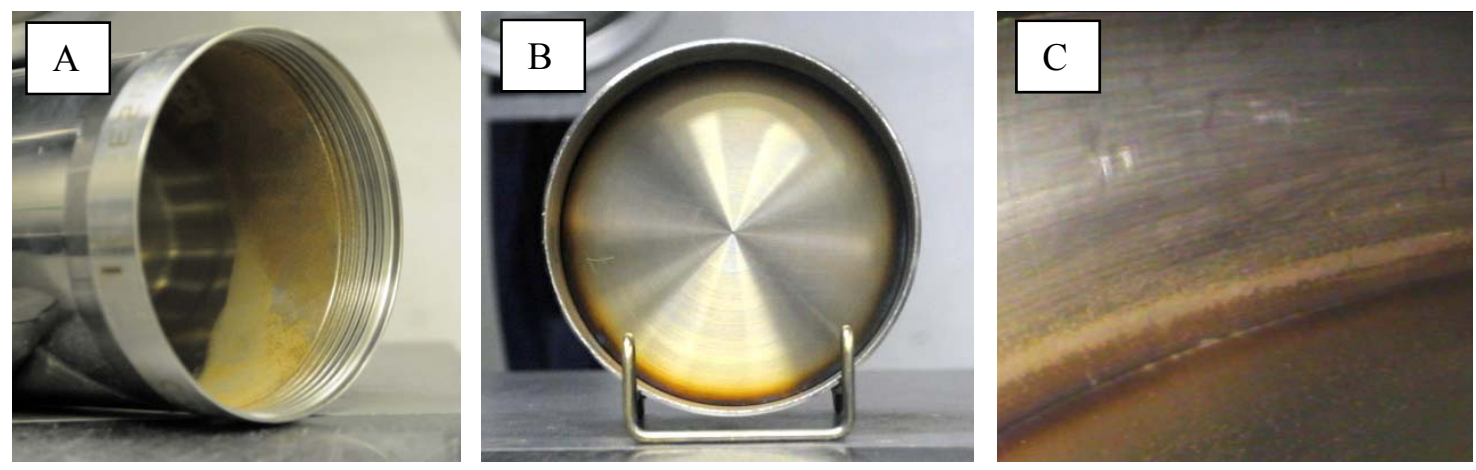

Figure 2-4 FY12 DE4 as observed during DE: A) convenience container, interior surface; B) inner container lid, interior surface; and $\mathrm{C}$ ) borescope image of a material resembling corrosion product outside the inner container closure weld gap

The DE containers, FY12 DE6 and DE7, were chosen initially to be baseline investigations. The baseline investigations were to establish the as-welded condition of the surfaces in this gap. This baseline was to be used to better understand the observed corrosion as well as the corrosion process. DE6 and DE7 were found to have some change in the convenience container surfaces, but nothing on the inner container lid. Figure 2-5 shows the condition of these surfaces as observed during DE.

The convenience container of DE6 had a coating that could be wiped; no suspect pits were observed. For DE7, suspect pitting was observed both on the container threads and the interior 
surface of the convenience container lid. For both containers, no material was found at the entrance to the gap of the inner container closure weld as was found for the HHMC and FY12 DE4. Four pie sections at orthogonal positions were cut from each inner container lid with the $0^{\circ}$ point being at the end point of the weld as observed on the exterior surface.
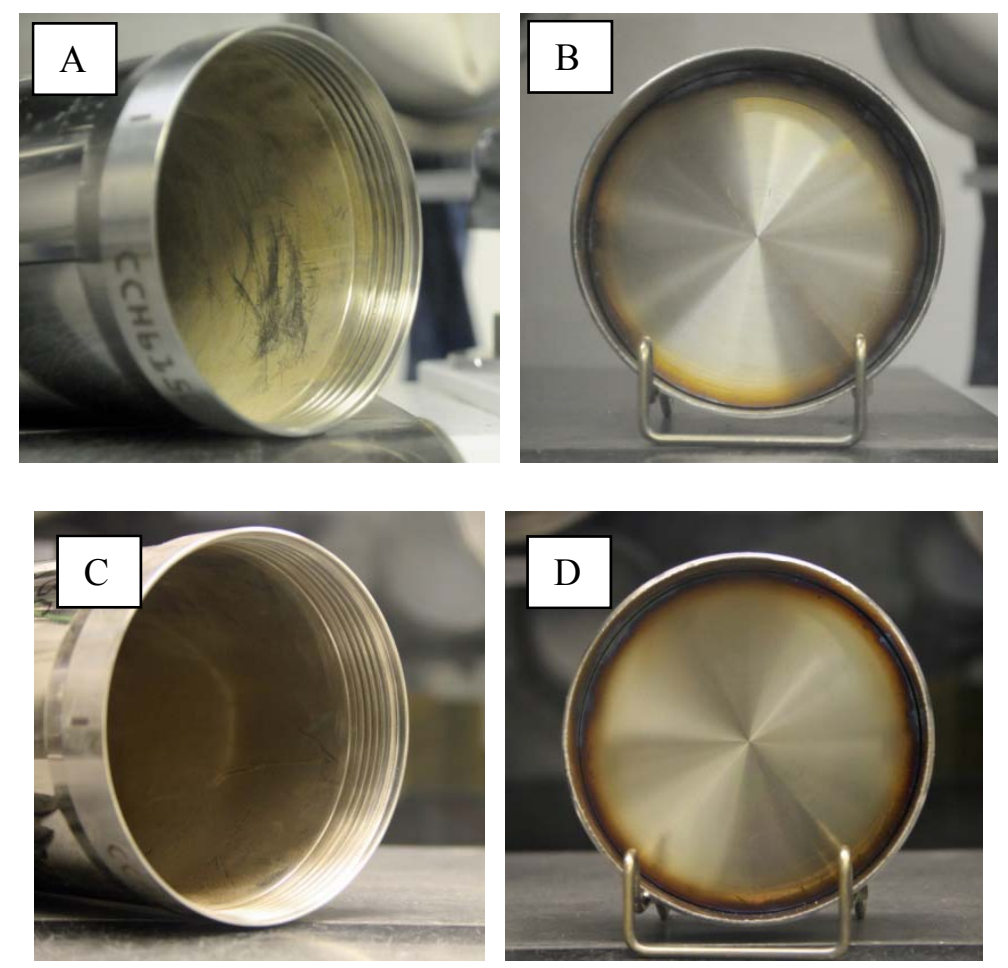

Figure 2-5 Interior surfaces of container observed during DE: A) FY12 DE6 convenience container; B) FY12 DE6 inner container lid; C) FY12 DE7 convenience container; and D) FY12 DE7 inner container lid

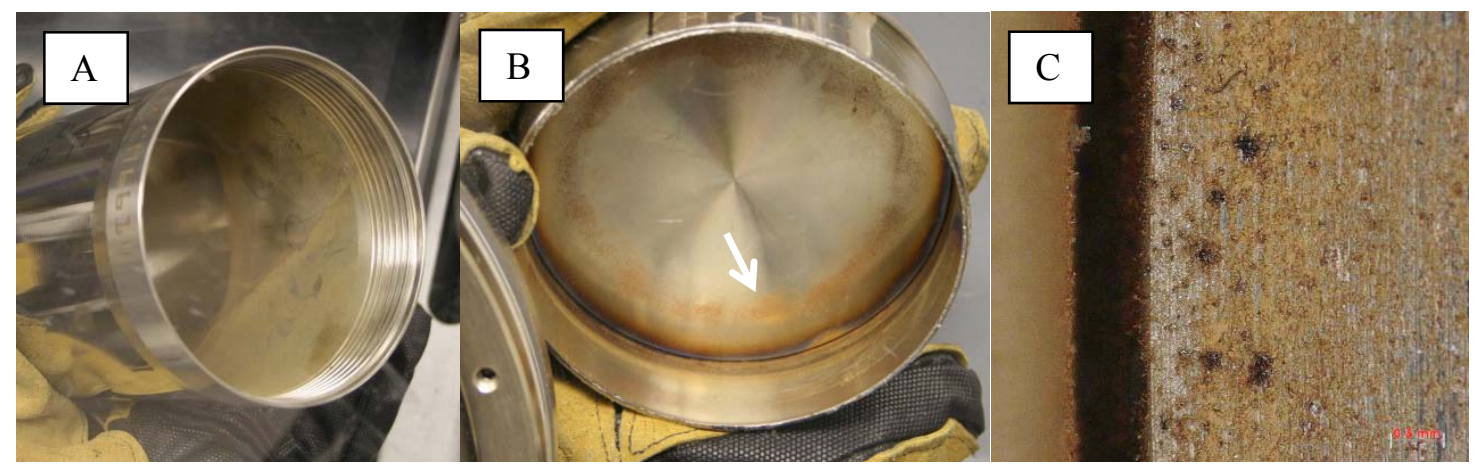

Figure 2-6 FY09 DE2 as observed during DE: A) convenience container, interior surface; B) inner container lid, interior surface; and C) stereo-micrograph of surface outside inner container closure weld gap, $25 x$

FY09 DE2 was a container that had pitting on the interior surface of the inner container lid as well as on the convenience container as shown in Figure 2-6. Pit depths on the interior surface of the inner container lid (see arrow in Figure 2-6 (B)) were measured to be approximately 20 
mils using the SEM [3]. Four pie sections at orthogonal positions were cut from the inner container lid with the $0^{\circ}$ point being at the end point of the weld as observed on the exterior surface.

\subsection{Analysis Protocol}

The analysis protocol was established based on the available equipment for examination of contaminated material surfaces. The equipment included a stereomicroscope (magnification up to 63x); a scanning electron microscope (SEM) with an energy dispersive spectrometer for chemical analysis; a metallograph for examination of metallographic samples, i.e. mounted with polished surfaces; and a borescope.

The general protocol followed for the samples cut from the inner container closure weld region were examination using the SEM and the stereomicroscope followed by mounting the sample in cross section for serial examination using the metallograph. The SEM and stereomicroscope examinations were conducted to evaluate the surface and identify regions of corrosion, specifically pitting and cracking. Cracking at the inner container closure weld region has not been observed to date.

The serial metallography consisted of a systematic examination of the cross section of the sidewall and lid surfaces within the inner container closure weld gap to assess the pit geometry and depth and to determine if any cracks were initiating from pits. By grinding and polishing of the samples different planes can be viewed (See Figure 3-1). The distance between planes varies depending on numerous factors. For serial metallography of samples from the SRNL small scale shelf life corrosion testing, this distance was found to vary from approximately 0.1 to $1 \mathrm{~mm}$. For the inner container closure weld metallography, the measurement between metallographic planes was not made, but is expected to be similar to that measured previously.

Select metallographic samples for each 3013 container examined in this study were etched following an electrolytic procedure using 10\% oxalic acid. Etching the samples allowed for the underlying microstructure to be identified. 


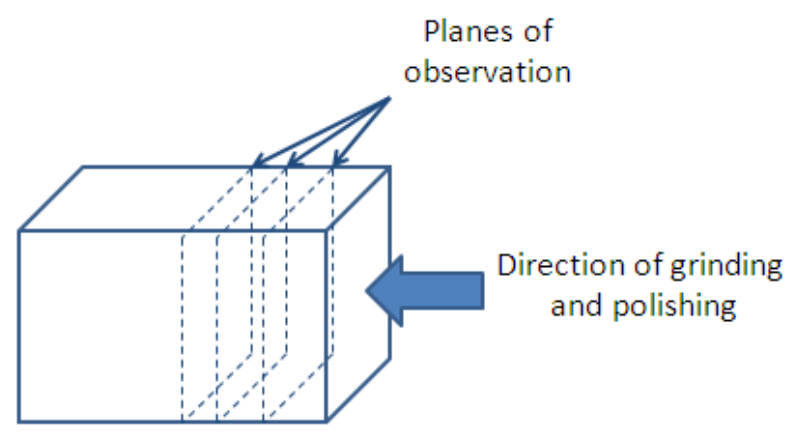

Figure 3-1 Schematic drawing showing the planes that are viewed during serial metallography of a sample mounted in cross section

\subsection{Corrosion Assessment of HHMC and DE Containers}

The evaluation of the inner container closure weld gap was performed at different times on DE containers, FY09 DE2, FY12 DE4, DE6 and DE7, and the HHMC. The results of the HHMC will be presented first since it had the most extensive analysis and the most extensive corrosion. In fact, the HHMC convenience and inner containers showed a marked difference in the observed corrosion from the other 3013 containers evaluated and discussed below.

\subsection{Hanford High Moisture Container}

The inner container lid was sectioned at the four orthogonal positions with the $0^{\circ}$ location being the endpoint of the welding. The quantity of material at the gap opening varied around the circumference of the lid. Once the sample was cut from the lid, the closure weld was cut off the sample and the lid piece was separated from the sidewall as shown in Figure 4-1. Compare this photograph with the side view shown in Figure 2-3 (B); note the absence of the weld section in Figure 4-1. The lid and sidewall surfaces within the gap were irregular with some corrosion products as shown by the stereo-micrograph images in Figure 4-2. The surface had a banded appearance, i.e. different surface morphologies at different locations moving from the weld towards the gap opening.

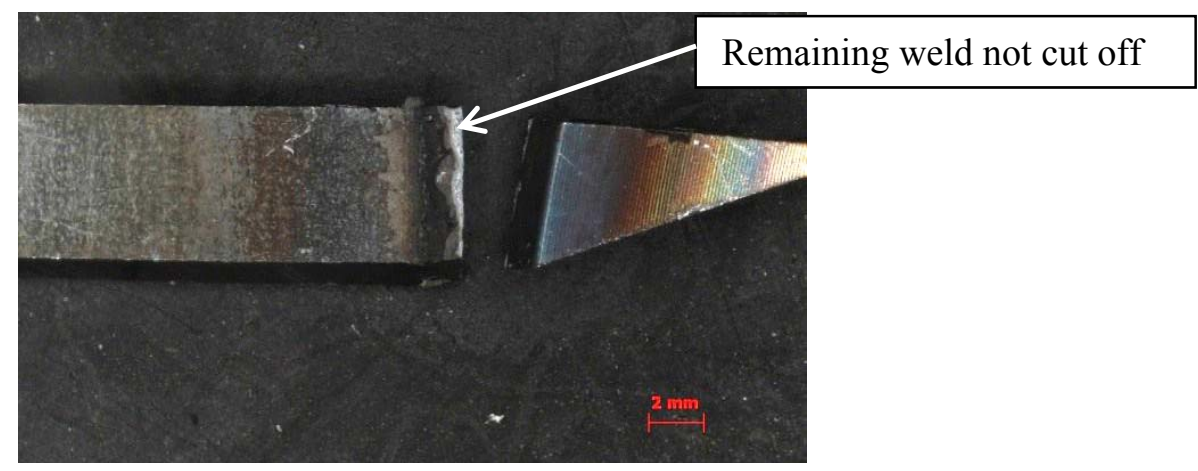

Figure 4-1 Sidewall and lid pieces from the $90^{\circ}$ pie section of the HHMC inner container closure weld region after removal of the closure weld 

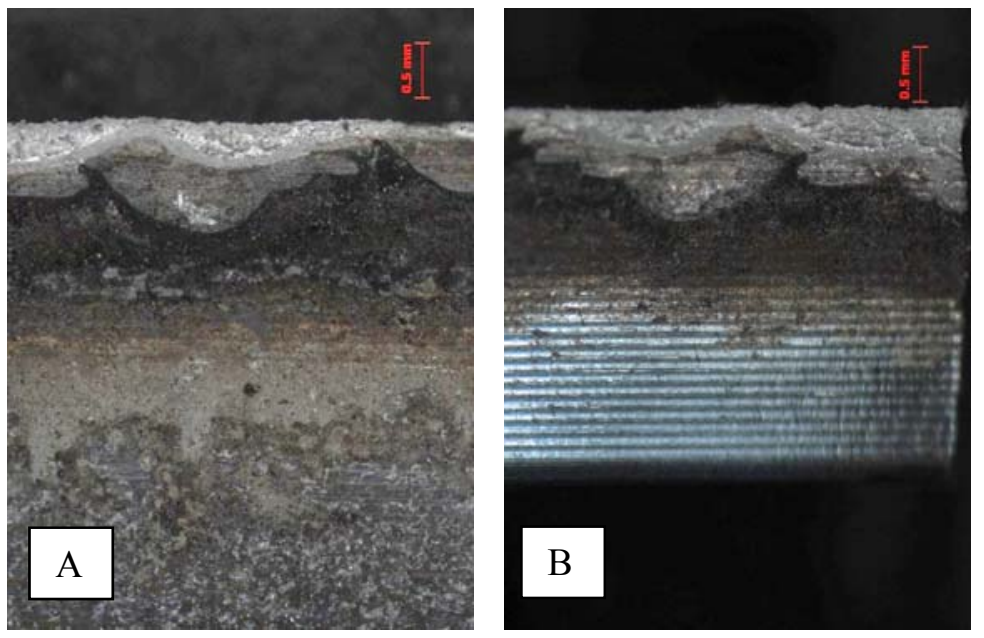

Figure 4-2 Sidewall (A) and lid (B) pieces from the $90^{\circ}$ pie section of the HHMC inner container closure weld region after removal of the closure weld $(25 x)$

The sidewall and lid surfaces that make up the weld gap were examined on the SEM for all orthogonal samples of the HHMC. Figure 4-3 shows the surface morphology for the sidewall and lid pieces of the $90^{\circ}$ pie section. The secondary (SE) images (Figure 4-3 (A) and (C)) show the topography, while the backscatter (QB) images (Figure 4-3 (B) and (D)) show the difference in atomic number for surface components. The three other pie sections had surfaces with similar appearances. A band of particulate can be seen on the sidewall which lies outside of the gap (note white arrow in image). The source of this particulate has not been identified. This particulate band and a band next to the weld are darker in color (Figure 4-3 (B)) indicating that low $\mathrm{Z}$ elemental compounds such as oxides and chlorides are present. 

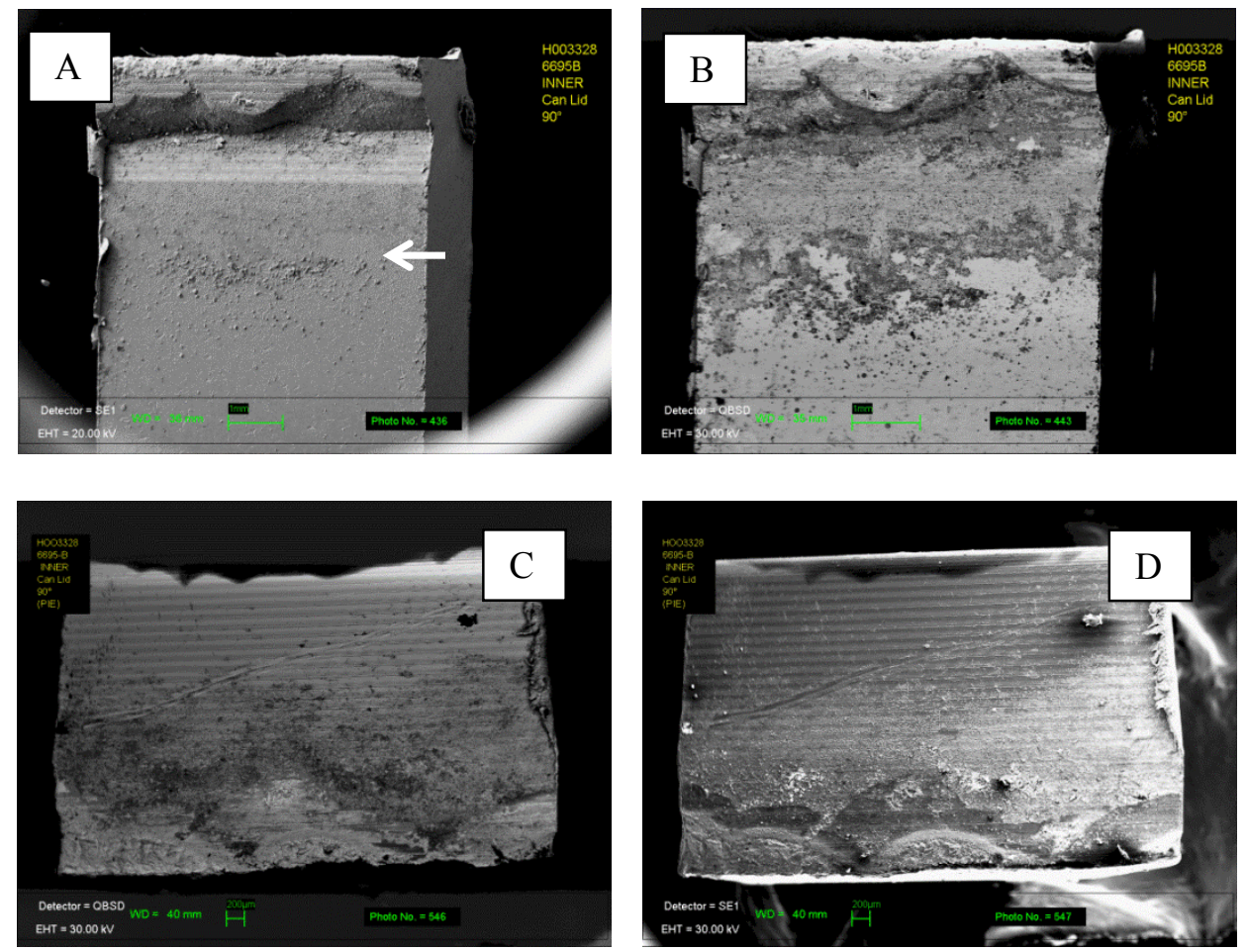

Figure 4-3 SEM micrographs of the sidewall and lid pieces of the $90^{\circ}$ pie section from $\mathrm{HHMC}$ inner container closure weld gap: A) sidewall, SE; B) sidewall, QB; C) lid, SE; and D) lid, QB

The surfaces were analyzed for the presence of chloride using EDS. A raster scan of the lid and sidewall pieces for each pie section showed chloride was present (See Figure 4-4). The chloride was found to be present with oxides and particulates that were analyzed. Chlorides were also found with these same surface features after cleaning the samples, although raster scans were not performed to evaluate the overall chloride content.

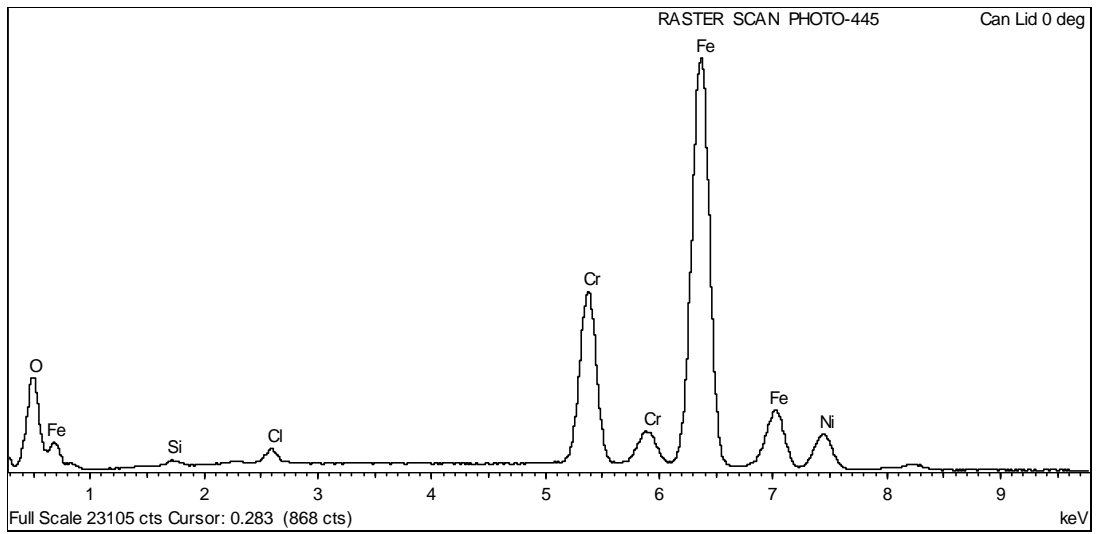

Figure 4-4 EDS spectrum from a raster scan for the sidewall piece from the $0^{\circ}$ pie section of the HHMC prior to cleaning 
A number of features were found that were common on many of the gap surfaces from the four orthogonal pie sections. The SEM micrograph from the sidewall piece from the $0^{\circ}$ pie section shown in Figure 4-5 is used as reference in describing the results of the EDS analysis. Aluminum, silicon and lead bearing compounds were found on many of the pieces (See Figure 46 (A)). The source of this material is unknown, but are not common constituents of the base metal (other than silicon). Sometimes calcium, potassium and magnesium were also associated with these features. Iron-rich and chromium-rich oxides were also identified (See Figure 4-6 (B) and $(\mathrm{C})$ ). These oxides may be associated with the welding process since iron-rich and chromium-rich oxides are formed [4]. Many oxides had chloride associated with them as shown in Figure 4-6 (C) and are probably associated with the observed corrosion.

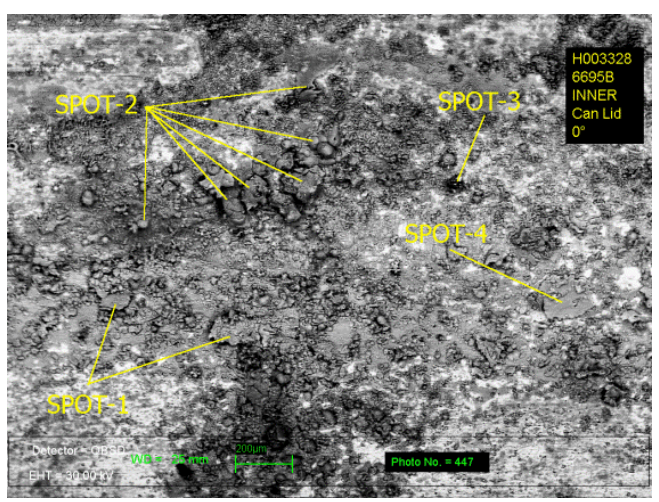

Figure 4-5 Surface of the sidewall piece from the $0^{\circ}$ pie section of the HHMC showing the locations for the EDS point analysis of various surface features

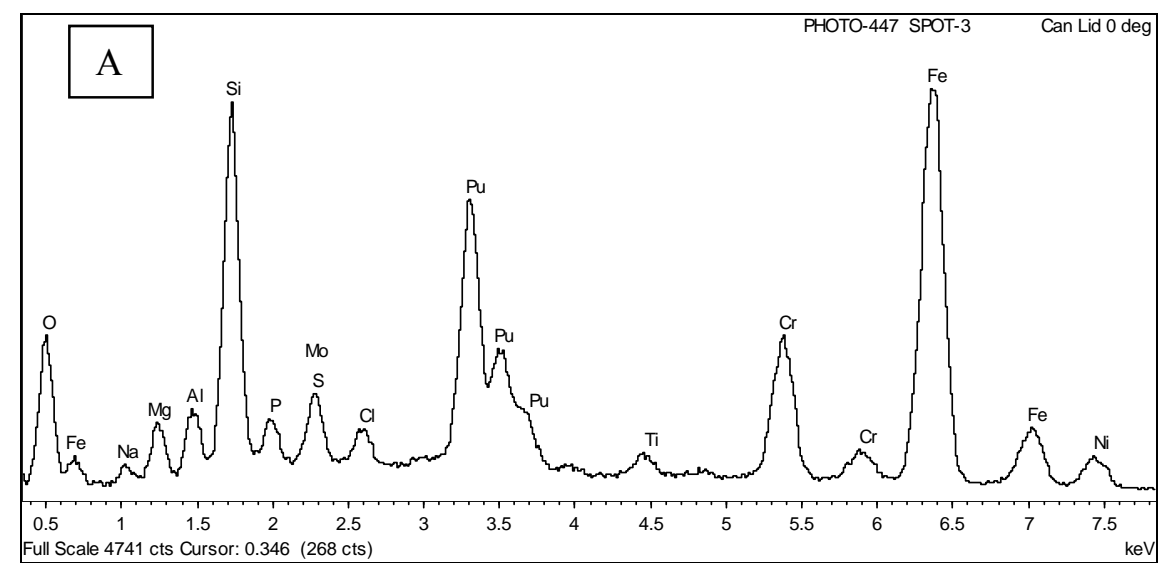

Figure 4-6 EDS spectra from point analysis of surface features on the sidewall piece from the $0^{\circ}$ pie section of the HHMC: A) spot 3, multi-elemental feature; B) spot 1 , iron-rich oxide; and C) spot 4, chromium-rich oxide (see Figure 4-5 for the location of the point analyses) 

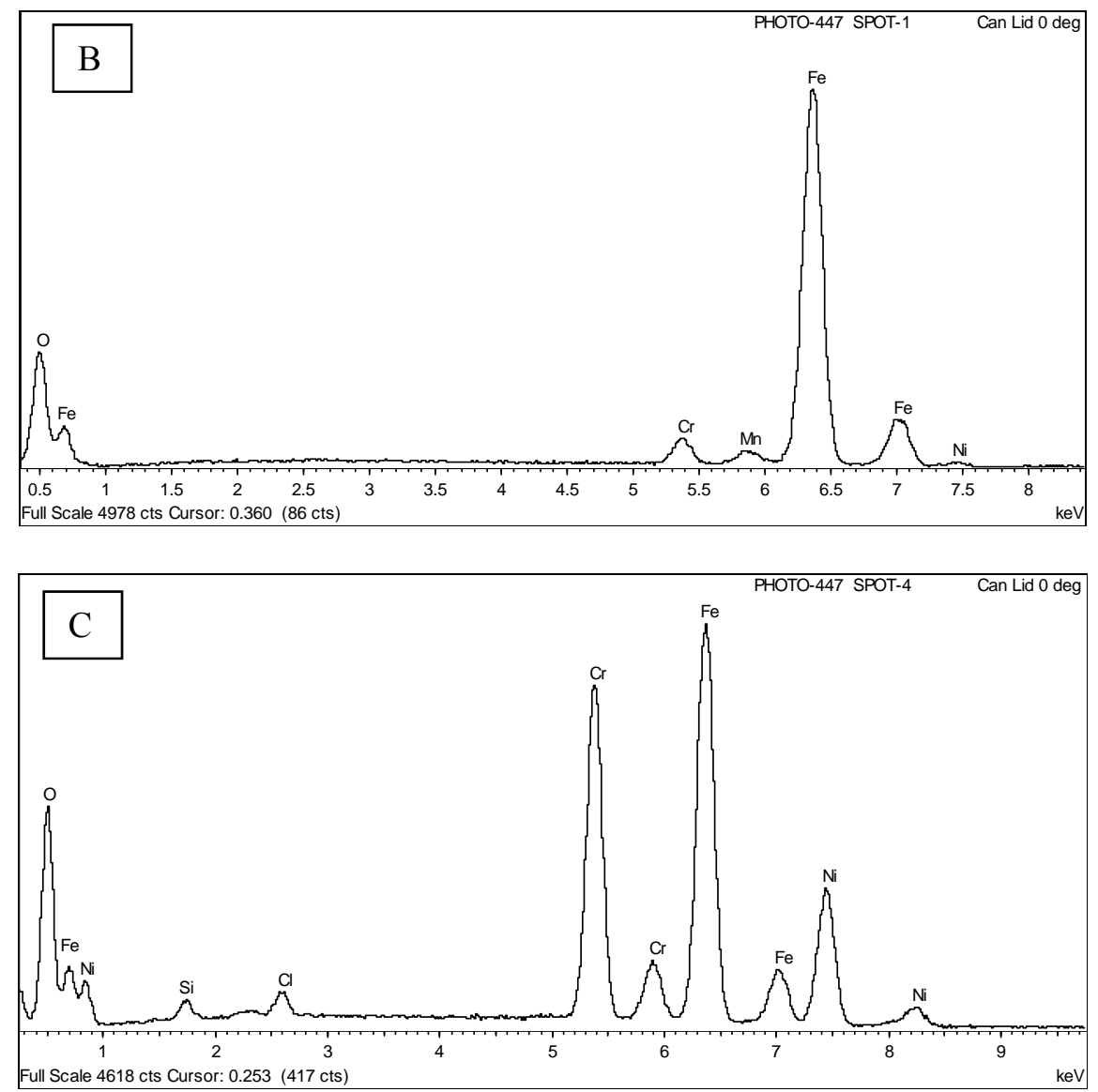

Figure 4-6 (Continued) EDS spectra from point analysis of surface features on the sidewall surface from the $0^{\circ}$ pie section of the HHMC: A) spot 3 , multi-elemental feature; B) spot 1, iron-rich oxide; and C) spot 4, chromium-rich oxide (see Figure 4-5 for the location of the point analyses)

The sidewalls from the $90^{\circ}$ and $270^{\circ}$ pie sections were cleaned in a commercial sonication cleaner to remove the particulate and any loose oxide so pitting or cracking could be observed if present. In Figure 4-7, an SEM micrograph shows the surface of the sidewall from the $90^{\circ}$ pie section after cleaning. Two regions of interest (ROI) are identified. The ROI closer to the weld, ROI1, continued to have a heavily oxidized surface as shown in Figure 4-7 (B). Similar areas were found for the sidewall from the $270^{\circ}$ pie section. In ROI2, the surface was not covered by oxide, although the degradation of the surface appears to form continuous circuits. Chloride was still present on the surface (spot 3 in (B) associated with a large oxygen and chromium peaks and spot 4 in (C) associated with a more typical chromium and iron peak distribution).

The corrosion morphology differed slightly between the two ROI, but may be a difference in severity and not mechanism. Figure 4-8 shows the morphologies which were found on both the $90^{\circ}$ and $270^{\circ}$ pie sections. Figure 4-8 (A) and (C) show a circuitous nature to the degradation, while Figure 4-8 (B) and (D) show a more pocked or pitted surface with some connectivity. 

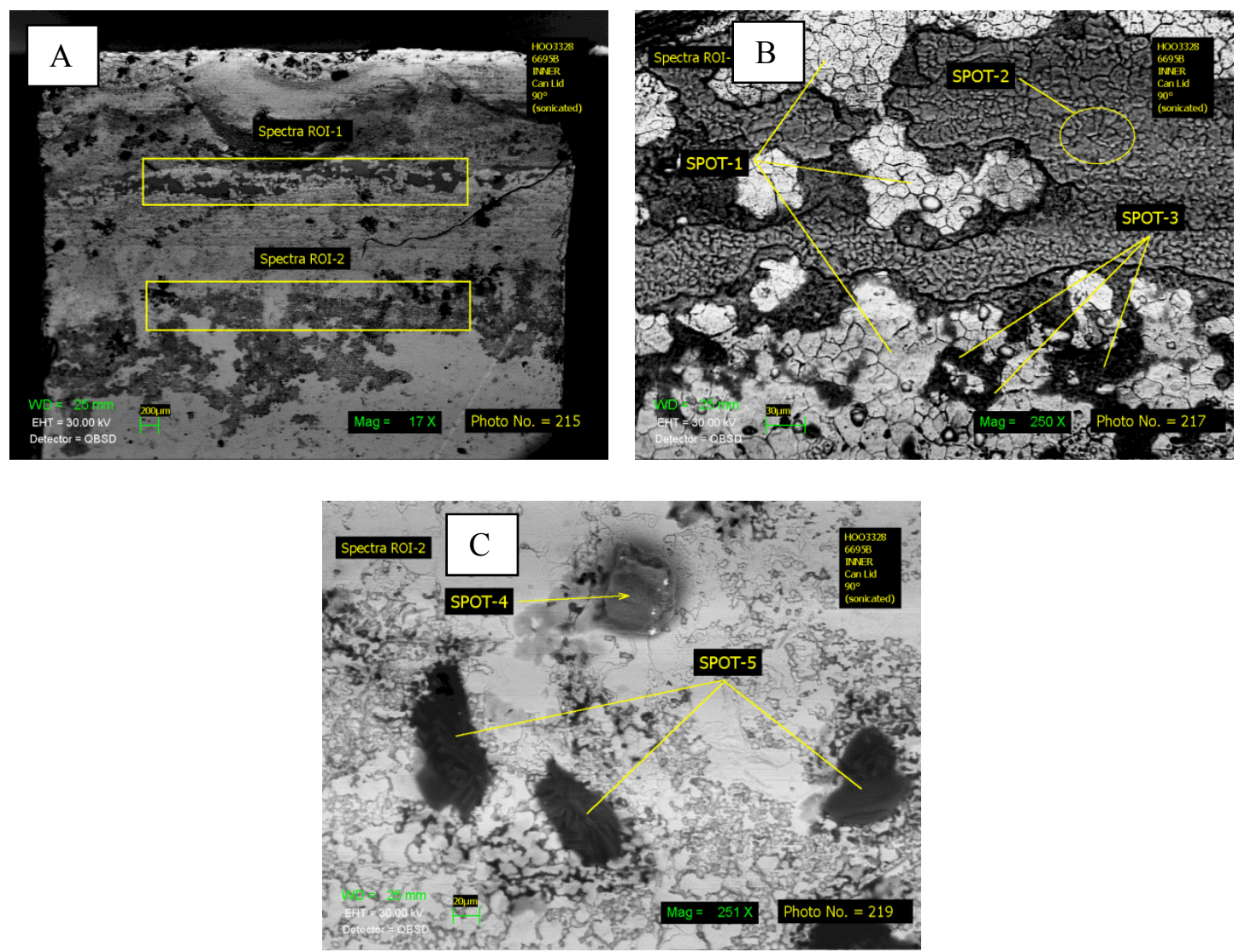

Figure 4-7 SEM micrographs of the sidewall from the $90^{\circ}$ pie section for the HHMC after cleaning: A) micrograph showing overall surface of the sidewall, 17x; B) micrograph from ROI1, 250x; and C) micrograph from ROI2, 251x 

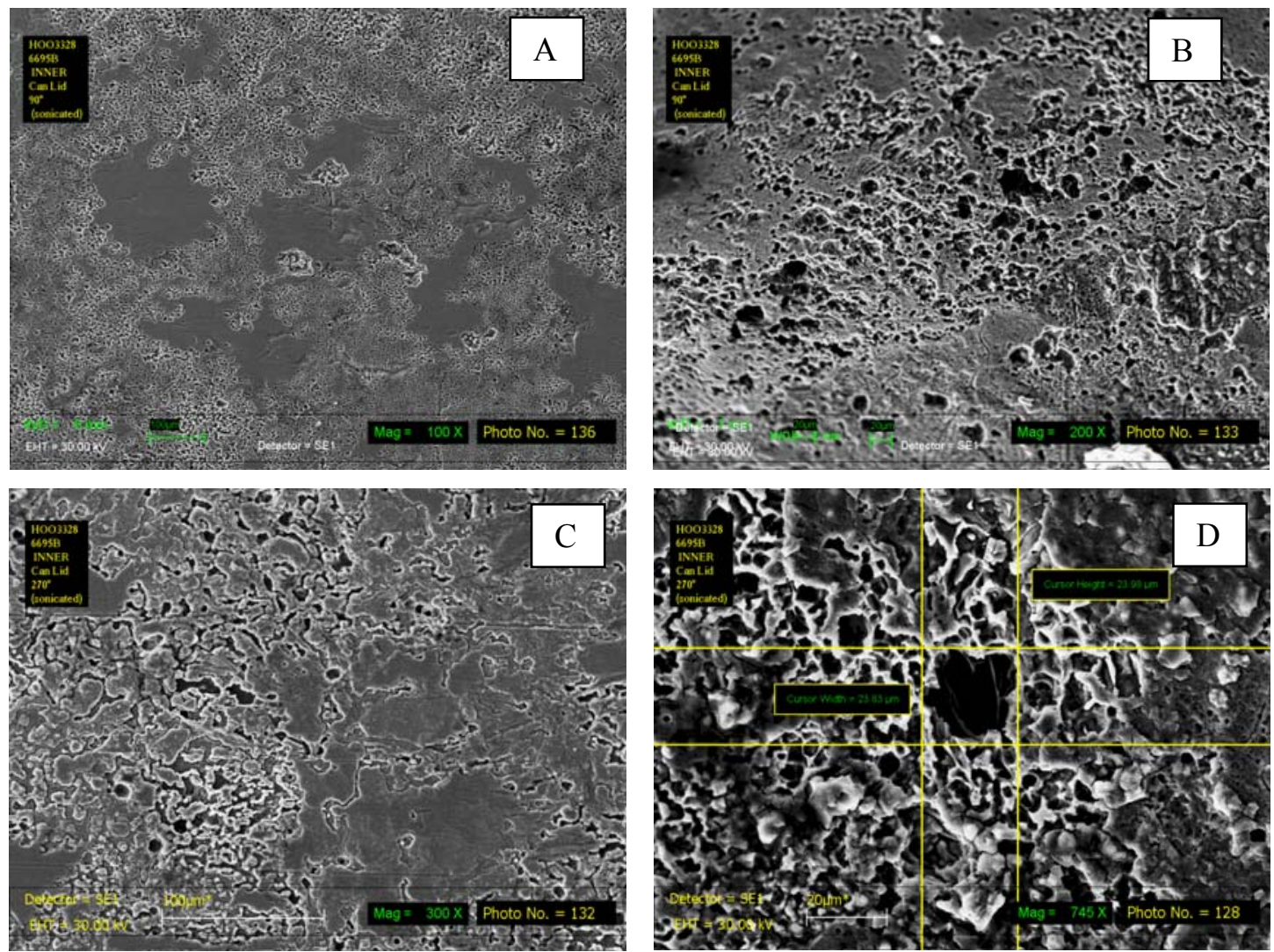

Figure 4-8 SEM micrographs of the sidewall gap surface for the HHMC after cleaning: A) 90 pie section, 100x; B) $90^{\circ}$ pie section, 200x; C) $270^{\circ}$ pie section, $300 x$; and D) $270^{\circ}$ pie section, $745 x$

The lid and sidewall pieces were placed into epoxy mounts and examined in cross section to evaluate the presence of pitting and any cracks. Figure 4-9 shows micrographs of the pitting for the sidewall surfaces from each pie section. Figure 4-10 shows micrographs of the pitting along the lid surface for the $90^{\circ}$ pie section. Pits were observed on all surfaces and ranged in depth from 5-10 $\mu \mathrm{m}$. The pits were both hemispherical as well as elongated. Some pits were irregular and jagged. Oxides, presumably a byproduct of corrosion, were found in the bottom of some pits (Figure 4-9 (D)). Some pits also had crack precursors that extended away from the pit (black arrows in Figures 4-9 (C) and 4-10 (C)). The transition from crack precursor to pit is not defined. The pit morphology was similar to those described by Sato for passive (smooth wall) and active (irregular wall) pits [5]. 

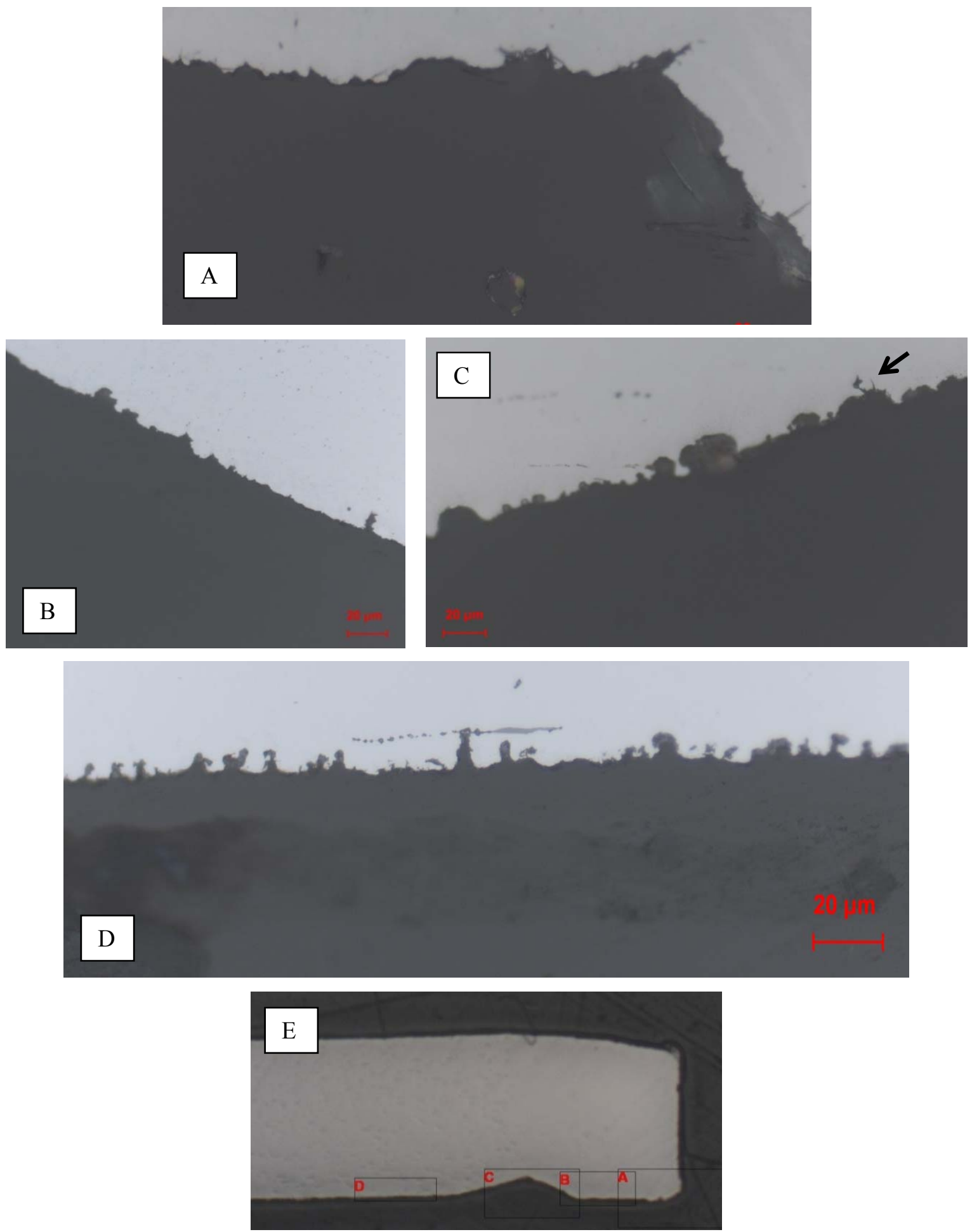

Figure 4-9 Cross sectional micrographs from different location along the sidewall for each pie section from the HHMC: A) $270^{\circ}$ pie section, $500 \mathrm{x}$; B) $90^{\circ}$ pie section, 500x; C) $0^{\circ}$ pie section, $500 x$; D) $180^{\circ}$ pie section, $500 x$; and $E$ ) cross section of sidewall showing location of micrographs, 12.5x (i.e. micrograph in A comes from location A on sidewall) 

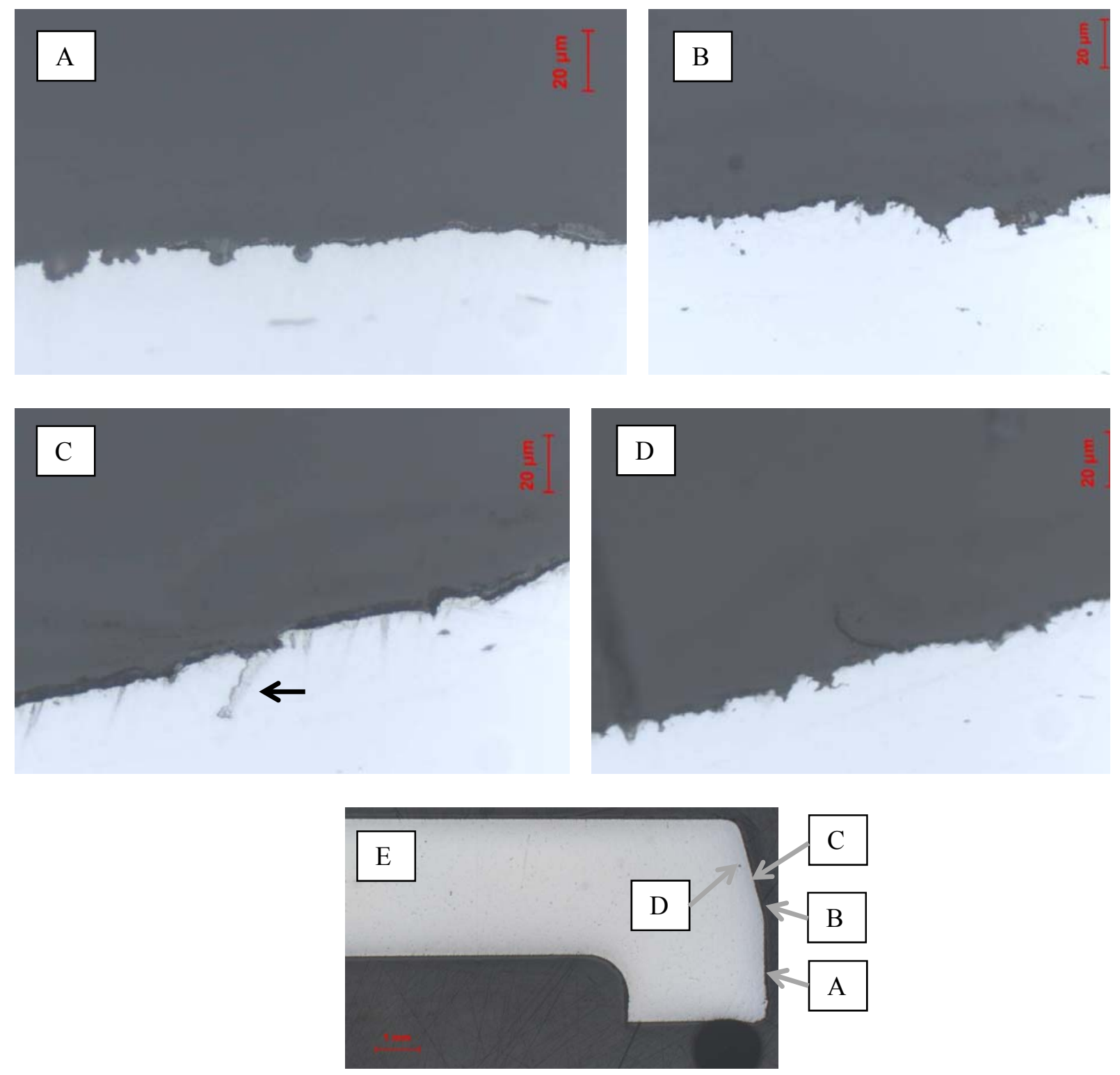

Figure 4-10 Cross sectional micrographs from different location along the lid of the $90^{\circ}$ pie section from the HHMC: A-D) pit locations along lid gap surface, 500x; and E) overview of lid showing locations for micrographs in (A) through (D), 12.5x

The mounted samples were etched to determine the parts of the sidewall and lid that had a dendritic microstructure resulting from the welding process or maintained their original microstructure. The lid was found to have only a small portion that had a dendritic microstructure, which was located near the top of the weld gap (See Figure 4-11 (A)). On the sidewall, the dendritic microstructure extended to the top of the bevel apex as shown in Figure 411 (B). A significant portion of the gap sidewall surface was dendritic. From this analysis there is some indication that the pitting was associated with the interdendritic regions (See Figure 4-11 (C)). Pitting in 304L is known to be associated with manganese sulfide inclusions although there was no specific evidence of this association [6]. 

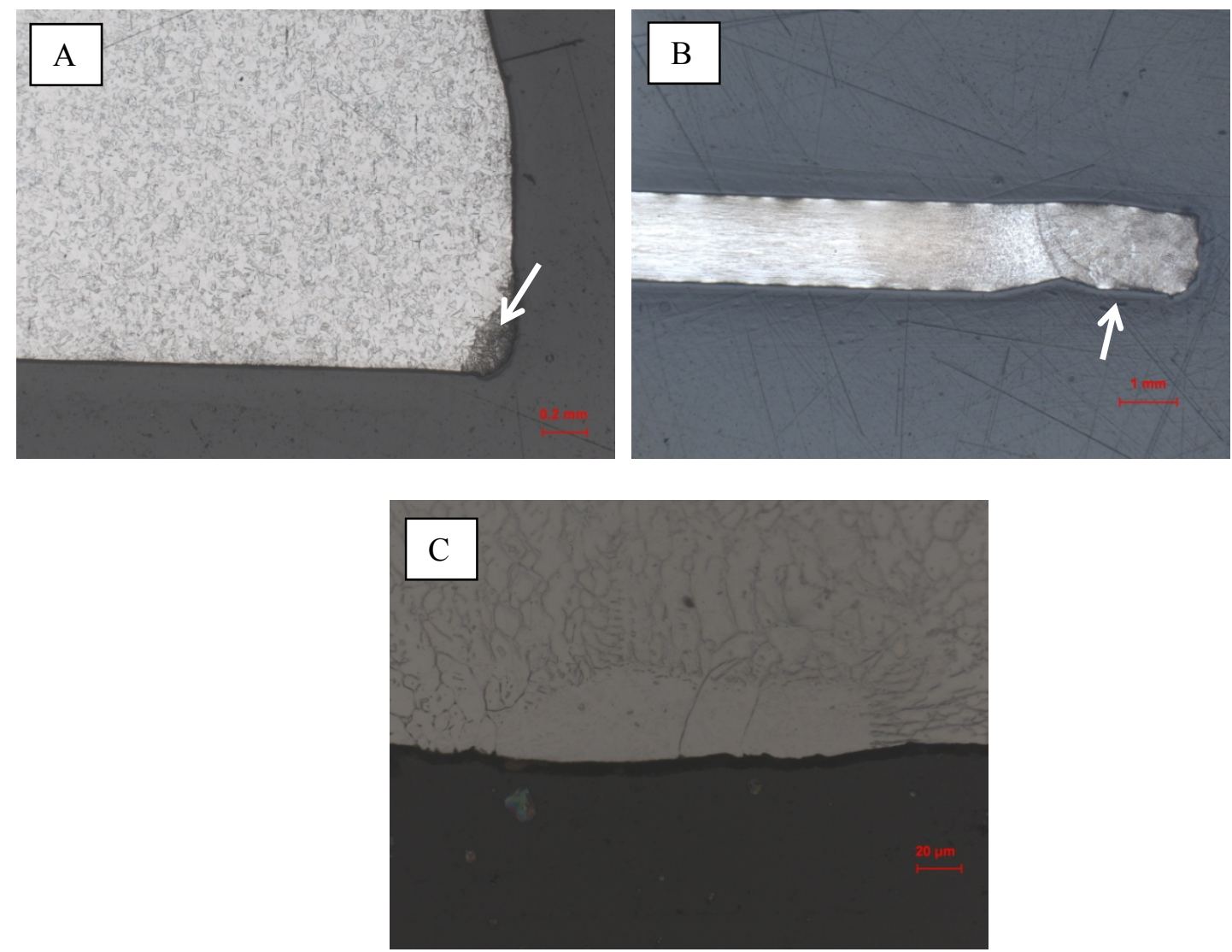

Figure 4-11 Cross sectional micrographs showing the location of the dendritic microstructure in the HHMC inner container closure weld region (indicated by arrows): A) lid from $90^{\circ}$ pie section, $50 x$; B) sidewall from $270^{\circ}$ pie section, $12.5 x ; C$ ) sidewall from $270^{\circ}$ pie section showing pits forming at interdendritic regions, $500 \mathrm{x}$

\subsection{FY12 DE4}

For FY12 DE4, a band of corrosion, material or mechanical damage was identified outside the inner container lid closure weld gap as shown in Figure 2-4 (C). Pie sections of the inner container lid, identified as $\mathrm{A}$ and $\mathrm{B}$, were taken from locations with this material. The initial analysis of the A and B pie sections consisted of SEM/EDS to evaluate the type of degradation and what elemental species were associated with it. The sidewall and lid pieces showed a slightly banded appearance moving away from the weld down towards the gap opening as shown in Figure 4-12 (note white arrow shows direction of gap opening).

On the sidewall piece from the B pie section shown in Figure 4-12 (B), small worm-like structures were observed similar to those observed previously on some convenience containers. EDS spectra were not taken of them, but previously these features were found to be chloride bearing. However, EDS analysis found chloride in the particulate on top of the surface, mostly near the machine marks (shown by black arrow in Figure 4-12 (A)). An EDS spectrum is shown in Figure 4-13 to show the relative magnitude of the chloride signals. 

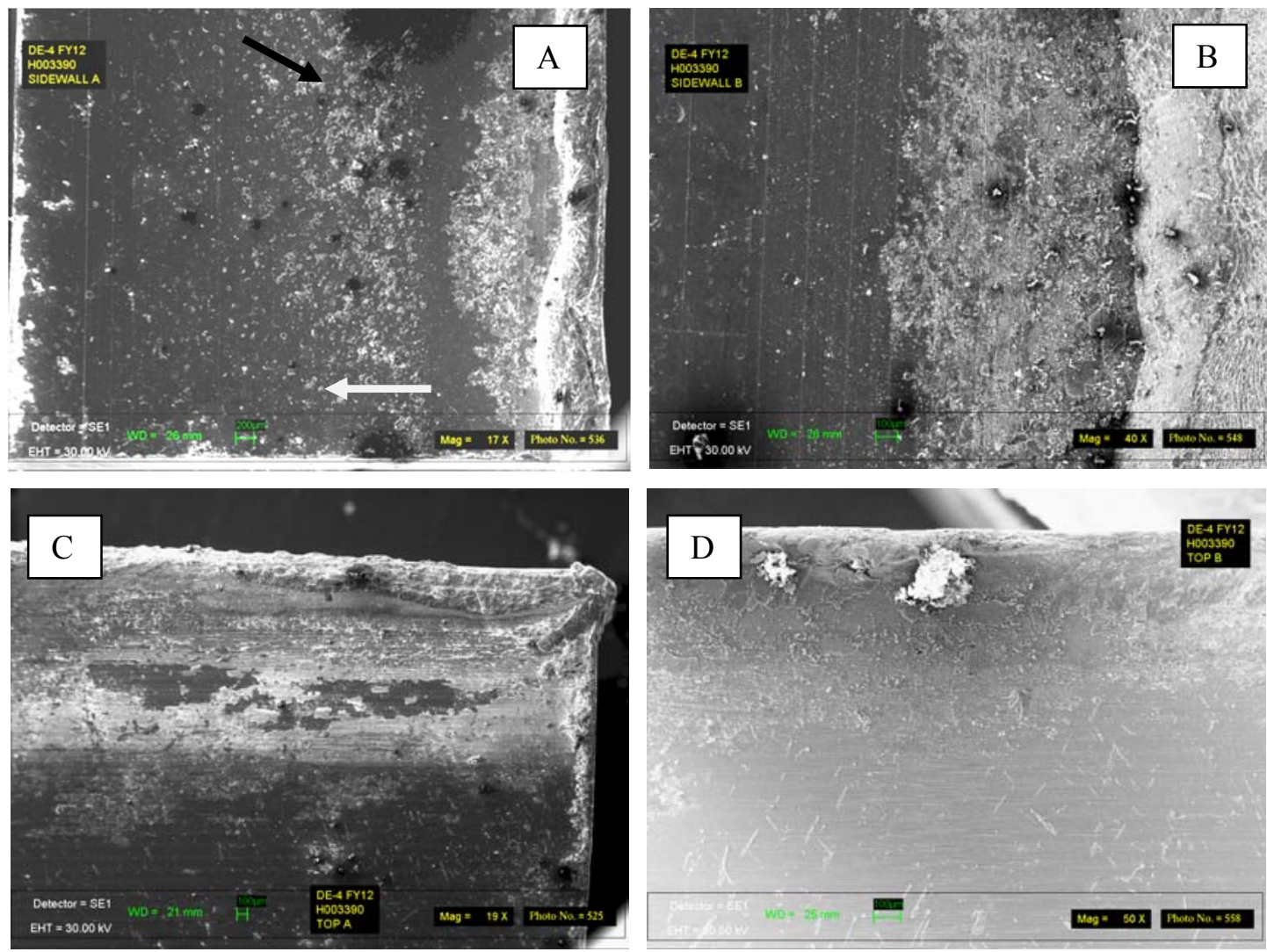

Figure 4-12 Secondary electron images of the sidewall and lid pieces from the inner container lid of FY12 DE4 prior to cleaning: A) sidewall from A pie section, 17x; B) sidewall from $B$ pie section, 40x; C) lid from A pie section, 19x; and D) lid from B pie section, $50 x$

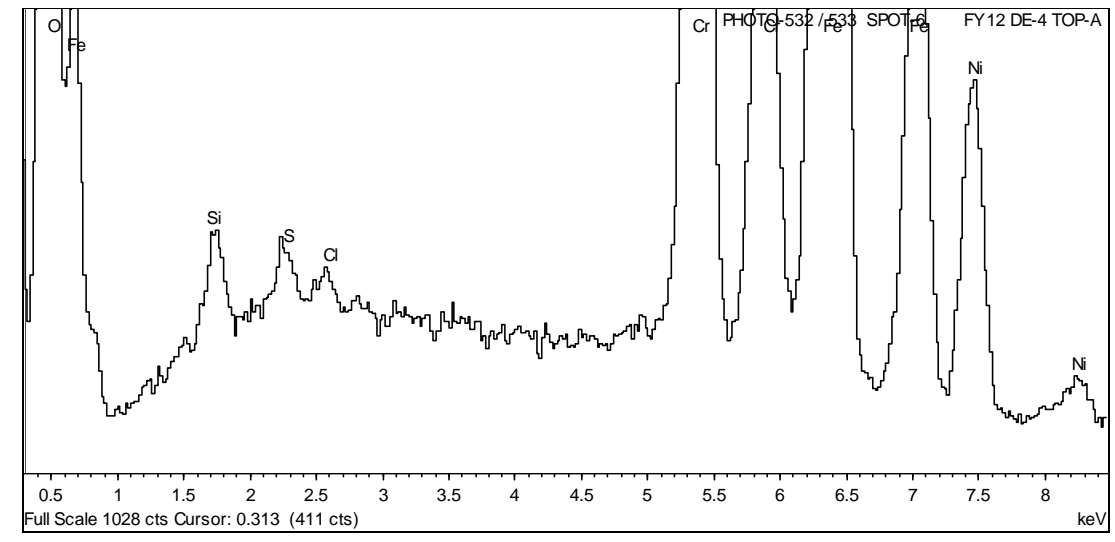

Figure 4-13 EDS spectrum for the lid piece from the A pie section for FY12 DE4 inner container showing the relative size of the chloride signal

EDS analysis also showed that near the weld on two pieces (sidewall A and lid B) material containing $\mathrm{Al}, \mathrm{Si}, \mathrm{Mg}$, and $\mathrm{Ca}$ were identified. On all pieces but the lid piece from the A pie section, iron-rich and chromium-rich oxide were each identified. The chromium-rich layer was 
identified as the outermost layer, which has been noted for weld oxides [4]. All pieces showed a layering of the oxides/corrosion products as shown in Figure 4-14 for the sidewall and lid pieces from the A pie section. Opened pits were not observable prior to cleaning.
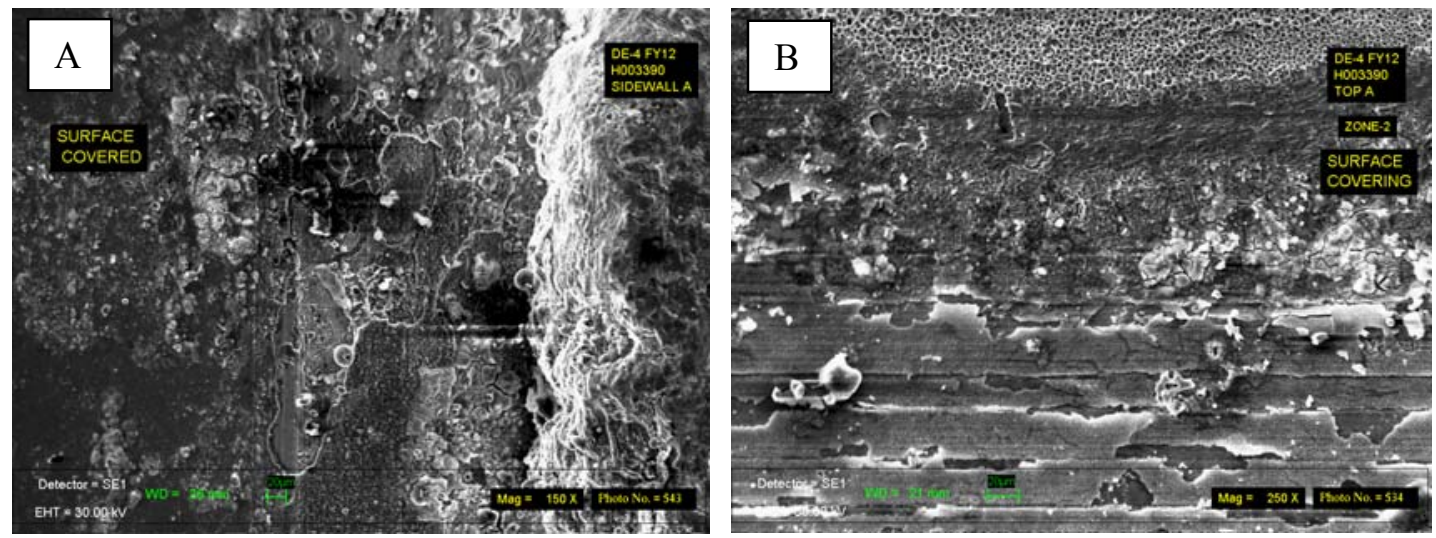

Figure 4-14 Secondary electron micrographs of the sidewall (A, 150x) and lid (B, 250x) pieces from the A pie section for FY12 DE4 showing the layer of oxides and corrosion products on the sample

After cleaning, much of the corrosion products were removed, but oxides still remained. This oxide is probably associated with the initial weld oxide formed when the inner container was welded since the cleaning procedure was not sufficiently aggressive to remove this oxide. Pitting was now clearly observable on all pieces as shown in Figure 4-15. The largest pit was measured on the sidewall piece from the A pie section with a length of approximately $60 \mu \mathrm{m}$ (40 $\mu \mathrm{m}$ at widest point). Pits sizes for both the lid and sidewall varied from less than $10 \mu \mathrm{m}$ to approximately $30 \mu \mathrm{m}$. Pitting was located both near the weld as well as closer to the gap opening as shown in Figure 4-15. Cracking was not observed. 

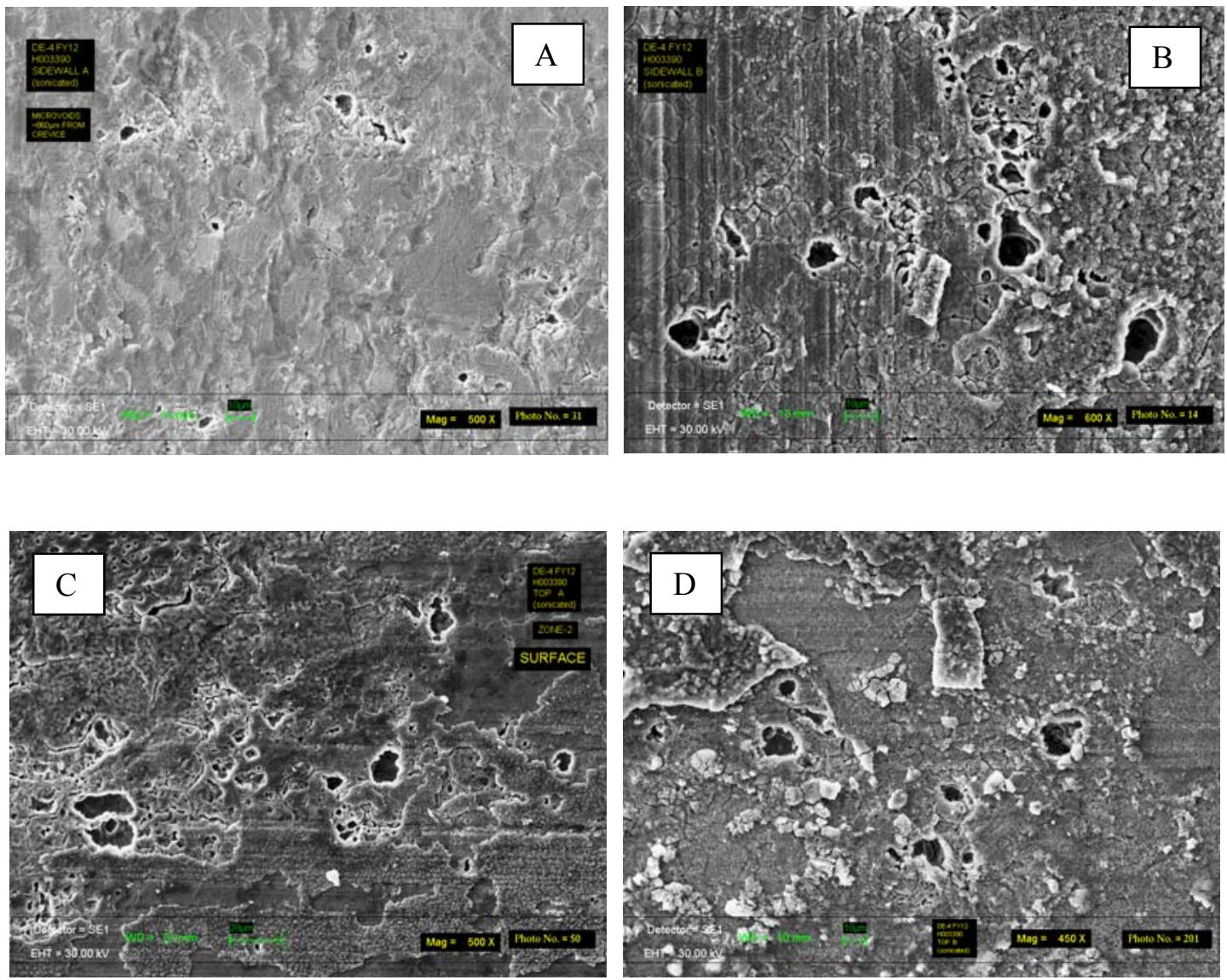

Figure 4-15 Secondary electron micrographs for FY12 DE4 inner container closure weld gap surfaces showing the observed pitting: A) sidewall from A pie section, 500x; B) sidewall from $B$ pie section, $600 x$; $C$ ) lid from A pie section, 500x; and D) lid from B pie section, 450x

For the serial metallography three planes were examined for one pie section. For the lid piece, pitting was not observed in any plane as shown by the micrographs in Figure 4-16. Degradation also was not noted along the bottom surface of the lid which faces the interior of the inner container. 

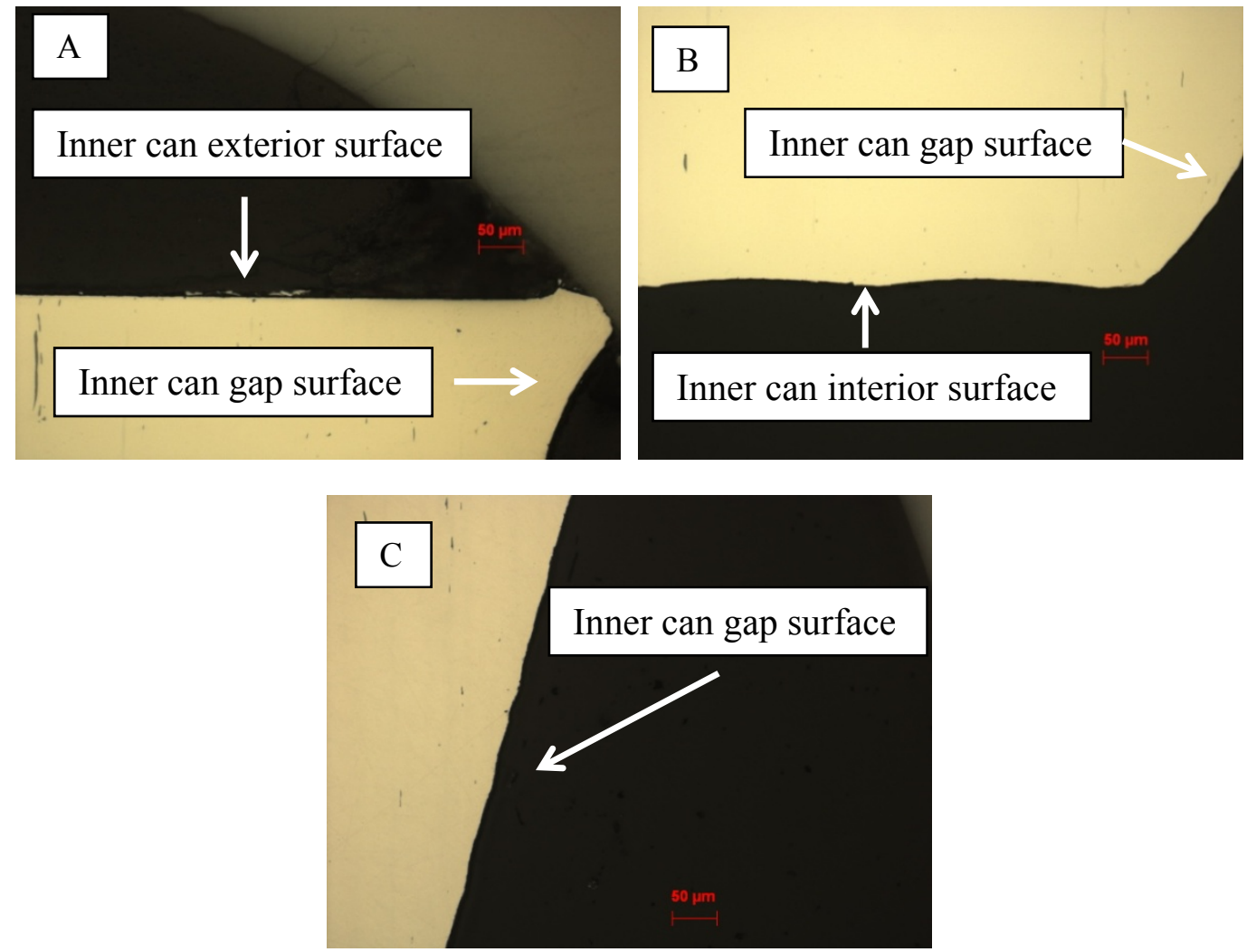

Figure 4-16 Cross sectional micrograph (200x) of the inner container lid for FY12 DE4 showing no degradation along the gap and bottom surfaces for the first (A), second (B), and third (C) planes

For the sidewall, a limited amount of pitting was observed during the serial metallography. The surfaces near the top of the gap were very irregular as can be seen in the three planes shown in Figure 4-17 (A), (B) and (C). The surfaces irregularity may be associated with the welding process, i.e. the melting and dendritic solidification of the base metal. Suspect pits are shown in (B) and (C) with the white arrows. The pit identified in (C) is shown at a higher magnification in (D). Oxides can be seen in the pit, which is approximately a $20 \mu \mathrm{m}$ hemisphere. The oxides have not been analyzed to identify the formation mechanism. Due to its shape the pit is probably the result of two or more pits growing together. The remainder of the interior surface of the sidewall did not show any pitting. 

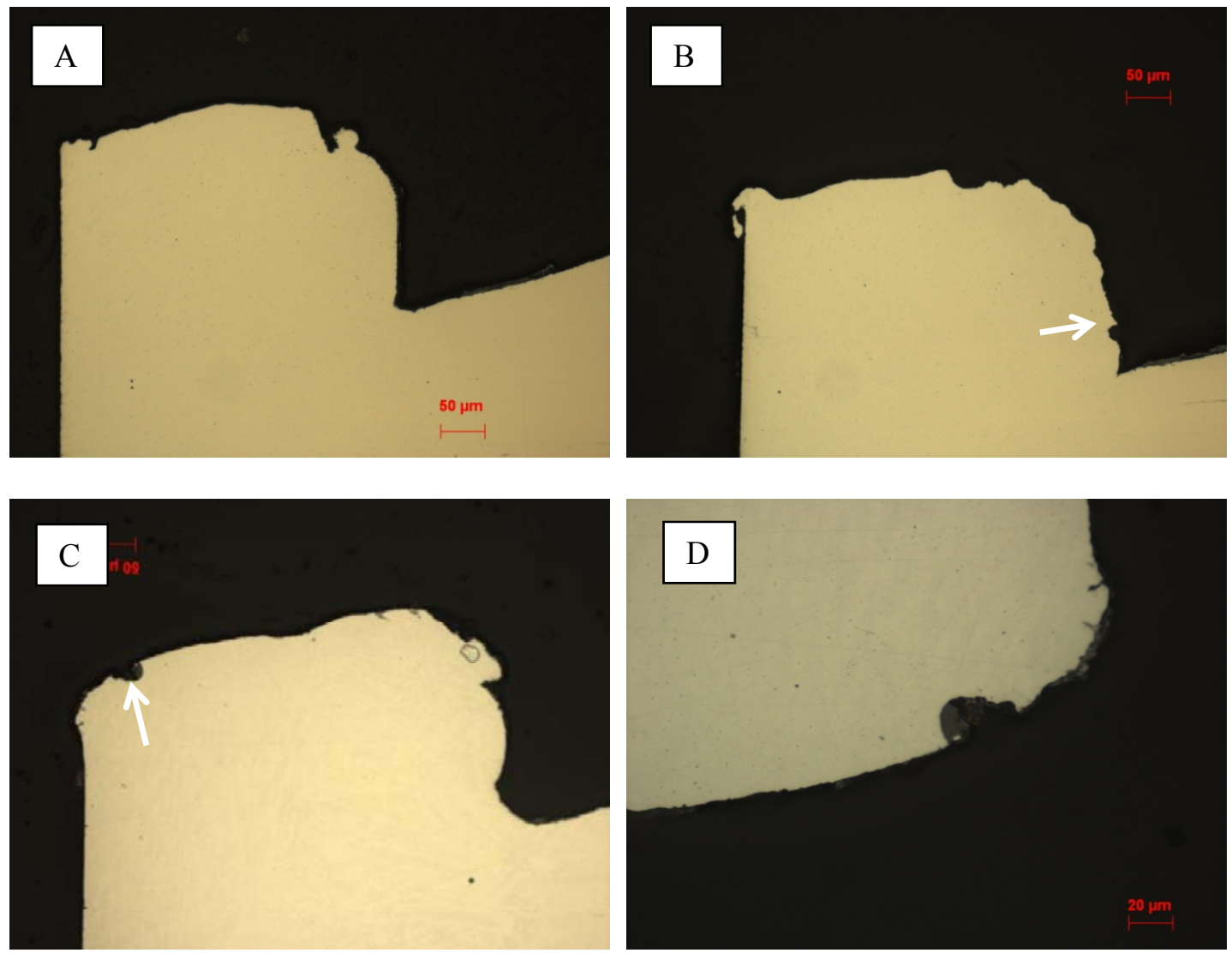

Figure 4-17 Cross sectional micrographs of the sidewall piece for FY12 DE4 for the first (A, $200 x)$, second $(B, 200 x)$, and third $((C, 200 x)$ and $(D, 500 x)$ planes of observation

\subsection{FY12 DE6}

For FY12 DE6, the inner container was noted to have no corrosion (See Figure 2-5) and the convenience container had a light coating that could be wiped. The analysis consisted of several microscopic techniques to characterize the surfaces within the inner container closure weld gap: 1) SEM/EDS to evaluate the type of degradation and the elemental species associated with features on the sidewall surface from the $0^{\circ}$ pie section; 2) stereomicroscope to document the overall surface appearance including color characteristic; and 3) an examination of the cross section of both the lid and sidewall pieces from the $0^{\circ}$ and $90^{\circ}$ pie sections to assess the pit geometry and depth and to determine if any cracks were initiating from the pits. Three different planes were examined using serial metallography.

The surface of the sidewall had a banded appearance as shown in Figure 4-18 with a heavily oxidized (weld and corrosion) surface near the weld (See Figure 4-19 (A)), and then a particlefree surface near the start of the machine marks, and finally a surface with particle/oxide build up near the gap opening. Both oxides were found to be both chromium and iron rich. Figure 4-19 shows the locations that EDS spectra were taken and select spectra are shown in Figure 4-20. A comparison of the oxide spectra (Figure 4-20 (A) - (D)) with the baseline spectrum (Figure 4-20 (E)) shows the differences in chromium and iron concentrations. The presence of chloride was found only near the weld (Figure 4-20 (C)) and was associated with a large oxygen peak. 


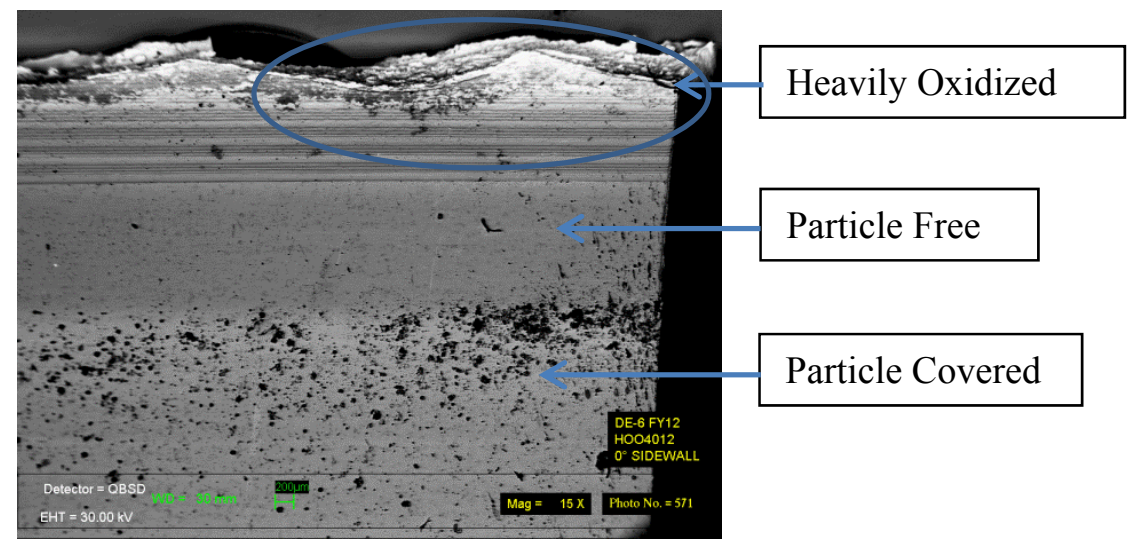

Figure 4-18 SEM micrograph (backscattered electron image, 15x) of the surface of FY12 DE6 sidewall from the $0^{\circ}$ pie section
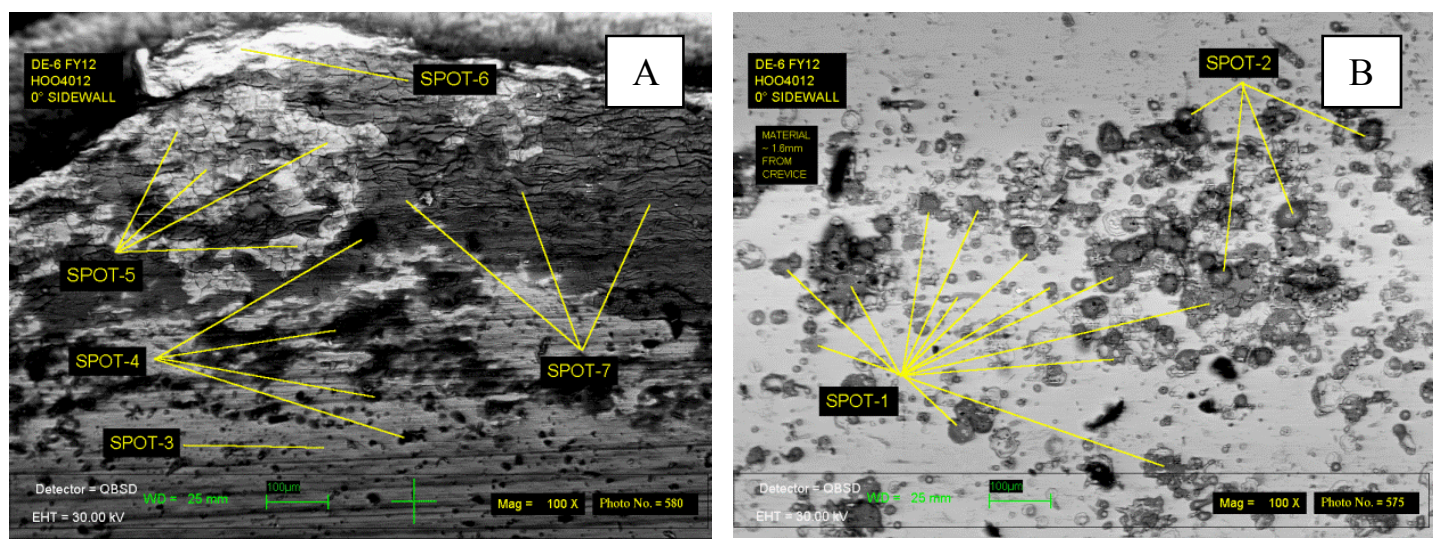

Figure 4-19 SEM micrographs (100x) showing the locations of EDS spectra for the heavily oxidized surface (A) near the weld and the particle-covered surface (B) nearer the gap opening 

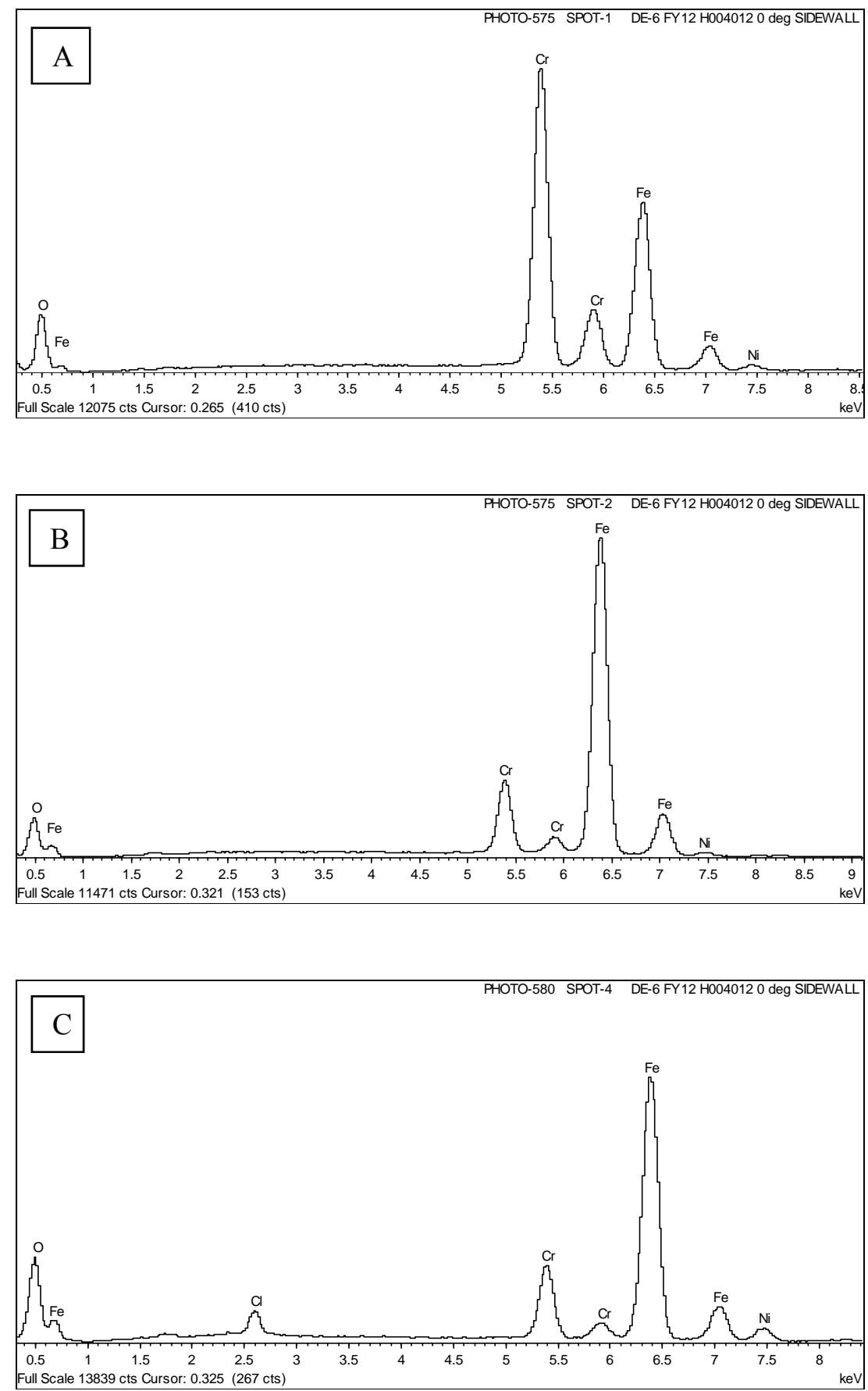

Figure 4-20 EDS spectra of spots shown in Figure 4-19: 1 (A), 2 (B), 4 (C) and 6 (D); and a base metal spectrum is shown in $(\mathrm{E})$ 

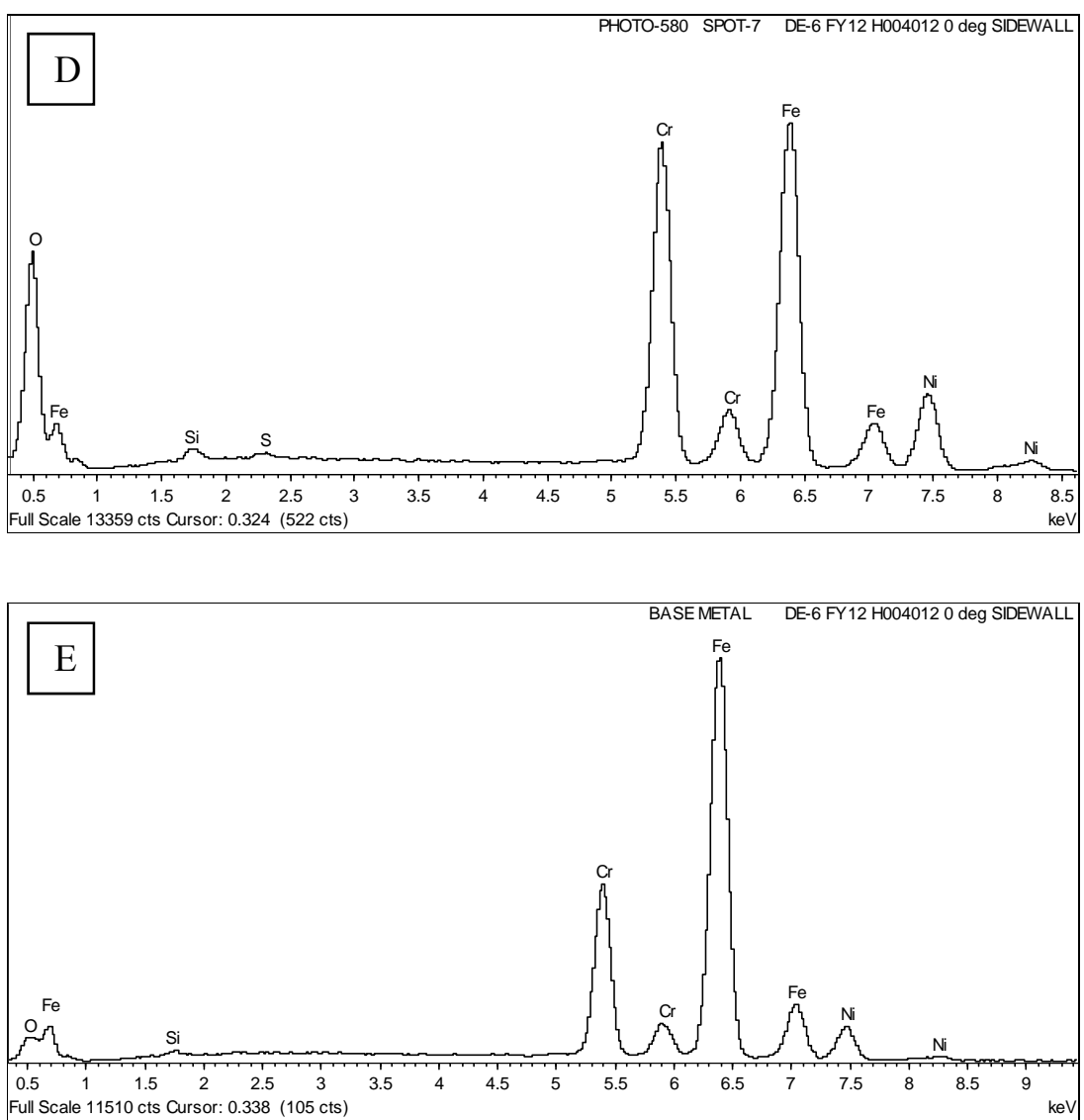

\section{Figure 4-20 (Continued) $\quad$ EDS spectra of spots shown in Figure 4-19: 1 (A), 2 (B), 4 (C) and 6 (D); and a base metal spectrum is shown in (E)}

The stereomicroscope examination was performed for both the sidewall and lid pieces of the $0^{\circ}$ pie section. Corroded areas, as indicated by the non-uniform rust-colored surface, were observed on both the side wall and lid as shown in Figure 4-21. The circled area in the SEM micrograph shown in Figure 4-18 is the same as shown in the stereomicroscope image in Figure 4-21 (A). Higher magnification pictures shown in Figure 4-21 (C) and (D) show the corrosion at higher magnification.

Both the $0^{\circ}$ and $90^{\circ}$ pie sections were mounted and examined in cross section using serial metallography. When preparing the pie sections for observation, the closure weld is removed just above the end of the gap so that the lid and sidewall container can be separated. In some cases, however the sidewall will break below the top of the gap, which keeps intact the top of the closure weld gap. Figure 4-22 shows photographs of the mounted samples for the $0^{\circ}$ pie section where the sidewall broke below the top of the gap and the $90^{\circ}$ pie section where the sidewall and lid pieces separated cleanly. The arrow in Figure 4-22 (B) shows the sidewall ligament remaining connected to the lid. 

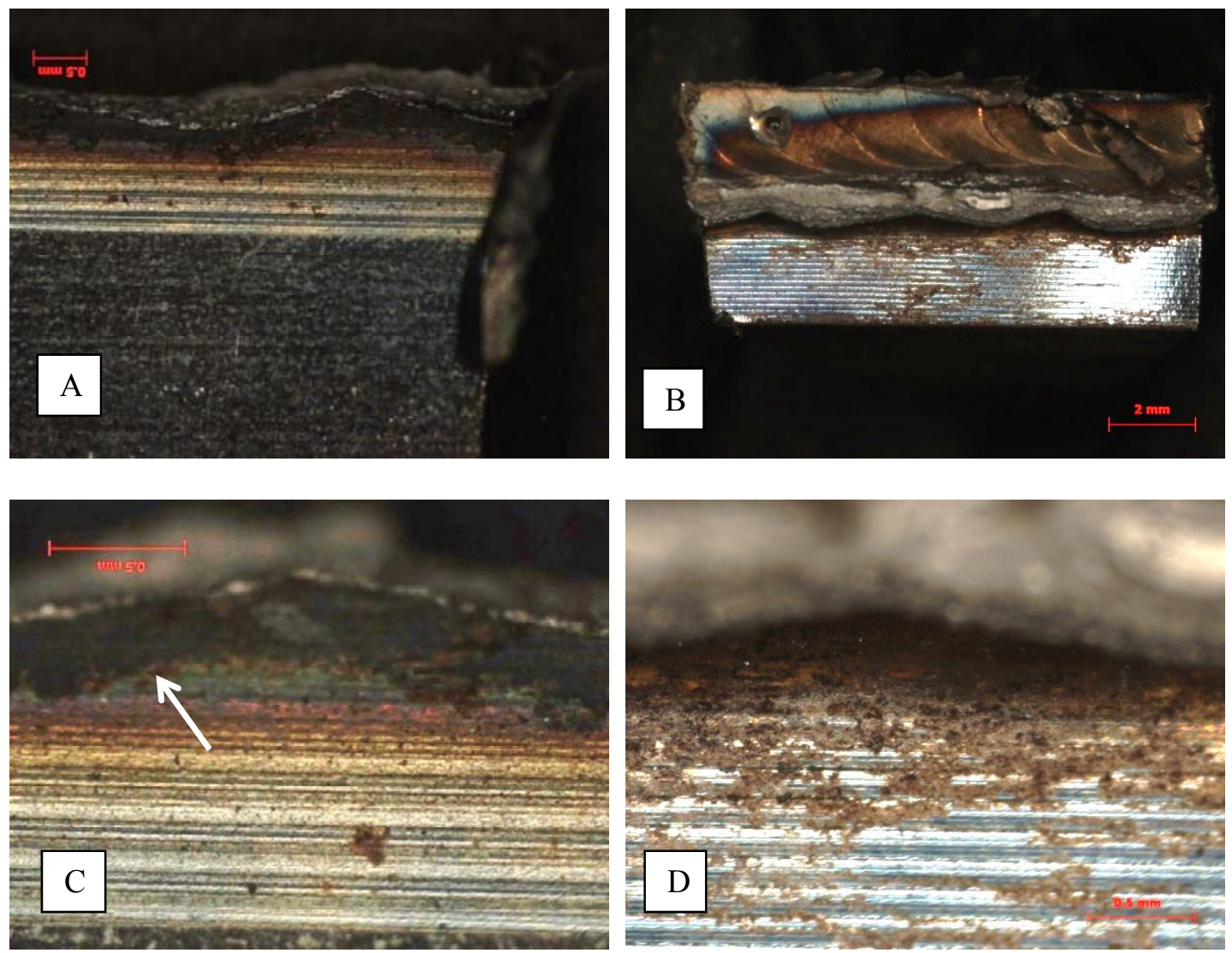

Figure 4-21 Stereomicroscope images of the sidewall (A, 25x and C, 63x) and lid (B, 10x and D, $50 x$ ) pieces from the $0^{\circ}$ pie section of FY12 DE6 

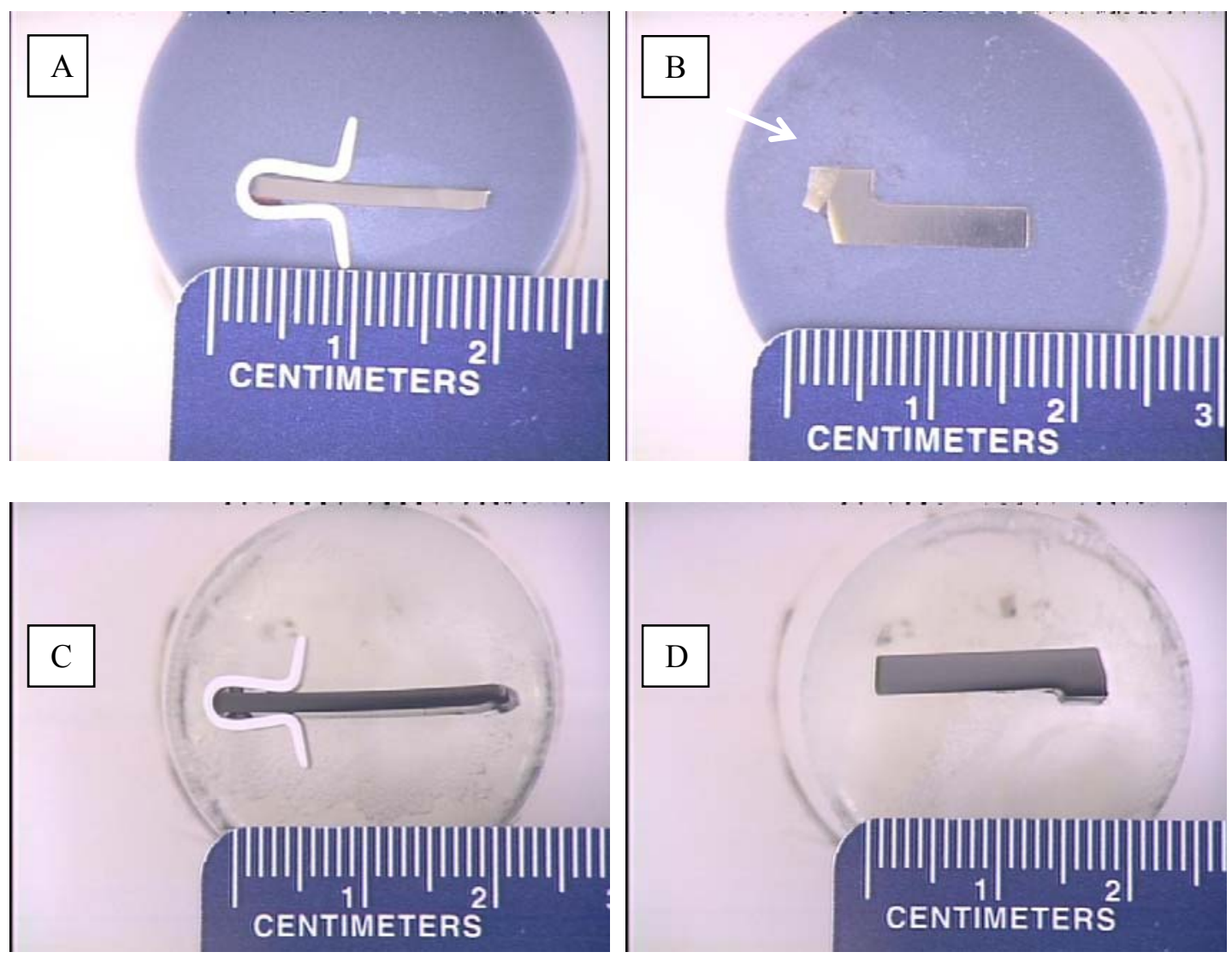

Figure 4-22 Mounted sidewall and lid pieces from the $0^{\circ}$ (A and $B$, respectively) and $90^{\circ}$ (C and D, respectively) pie sections of FY12 DE6

For the $0^{\circ}$ pie section, a crevice was found at the top of the gap as shown in Figure 4-23. Some small pits were observed in this region as shown in Figure 4-23 (A and B), but they are superficial $(<5 \mu \mathrm{m})$. The crevice is characterized by the narrow opening $(<5 \mu \mathrm{m})$ with a longer path $(\sim 20 \mu \mathrm{m})$. No other degradation was observed on the sidewall or the lid pieces. 

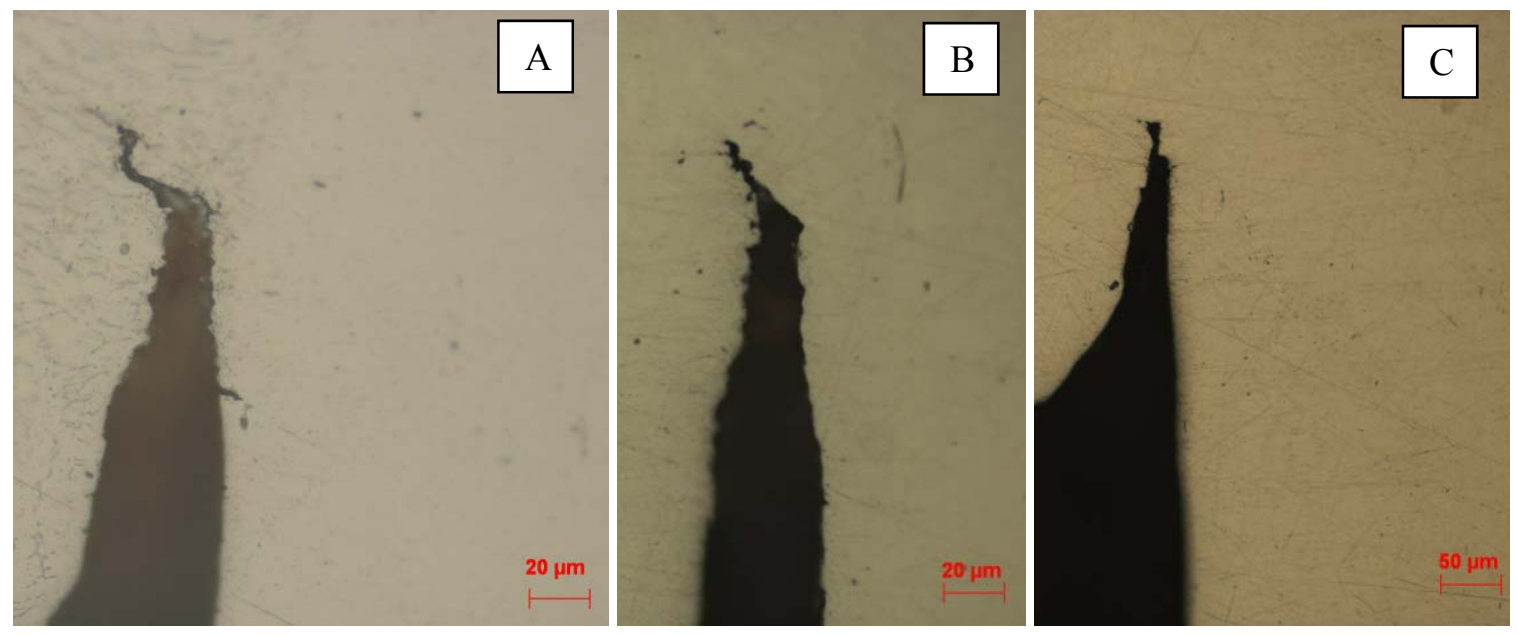

Figure 4-23 Progressive changes with grinding and polishing in the crevice at the top of the $0^{\circ}$ pie section from the inner container closure weld gap for FY12 DE6; (A), (B), and (C) are different planes with (A) being closest to the edge of the pie section, 200x

For the $90^{\circ}$ pie section, pitting was observed on the sidewall as shown by the micrographs in Figure 4-24. Figure 4-24 (A) - (C) shows different locations near the top of the gap. The large pit shown in Figure 4-24 (C) has an approximate width (or diameter) of $200 \mu \mathrm{m}$ and a depth of $80 \mu \mathrm{m}$. The pit had an oxide layer which appears to be associated with corrosion as noted by the morphology shown in Figure 4-24 (C) and (D). The other pits are on the order of 5-10 $\mu \mathrm{m}$. The large pit location was slightly different on the next observed plane during the serial metallography as shown in Figure 4-24 (E). Figure 4-24 (F) shows that the oxide and smaller pits are still present. In the third plane (Figure 4-24 (G) and (H)), the large pit is gone and only small pits remain $(<20 \mu \mathrm{m})$. 

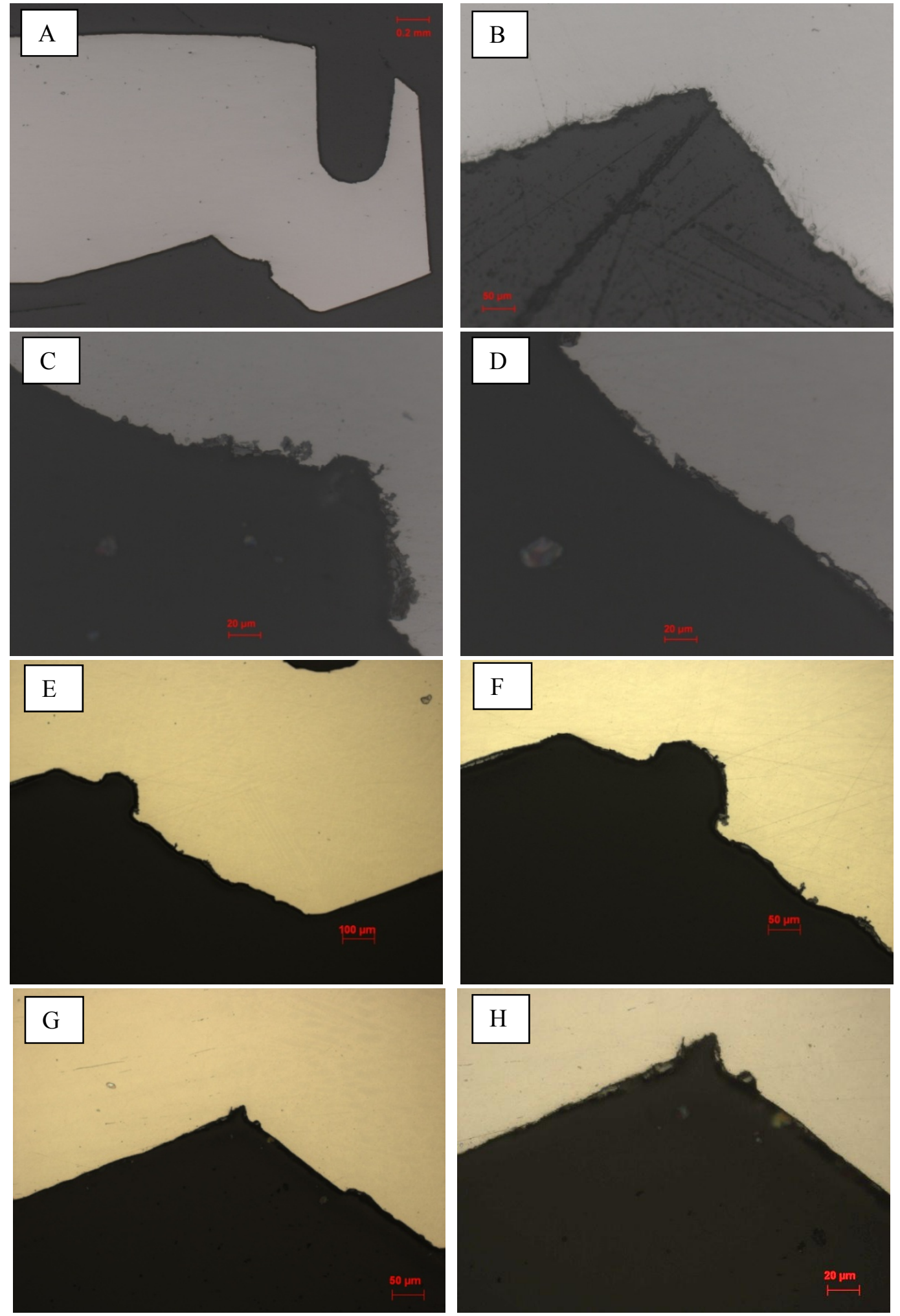

Figure 4-24 Pitting observed in the sidewall surface of the $90^{\circ}$ pie section from the inner container closure weld gap for FY12 DE6 (A-D, first plane; E-F, second plane; G-H, third plane): (A) 50x; (B) 200x; (C) 500x; (D) 500x; (E) 100x; (F) 200x, (G) 200x, and (H) 500x 
The large pit may be associated with the observed corroded area indicated by the white arrow in Figure 4-21 (C), which has a waviness associated with the welding process. Although the corrosion was not severe at the $0^{\circ}$ pie section, a similar surface morphology, as shown by the SEM and stereomicroscope observations, could be expected for the $90^{\circ}$ pie section since previous observations of multiple pie section from the HHMC and FY12 DE4 showed surfaces with similar surface morphologies.

A discussion with a welding SME at SRNL was held to determine if the large pit was an anomaly from the welding process [7]. Based on that discussion and a review of the microstructure as shown in Figure 4-25, unusual solidifications patterns which would have resulted in such a pit being formed were not identified.

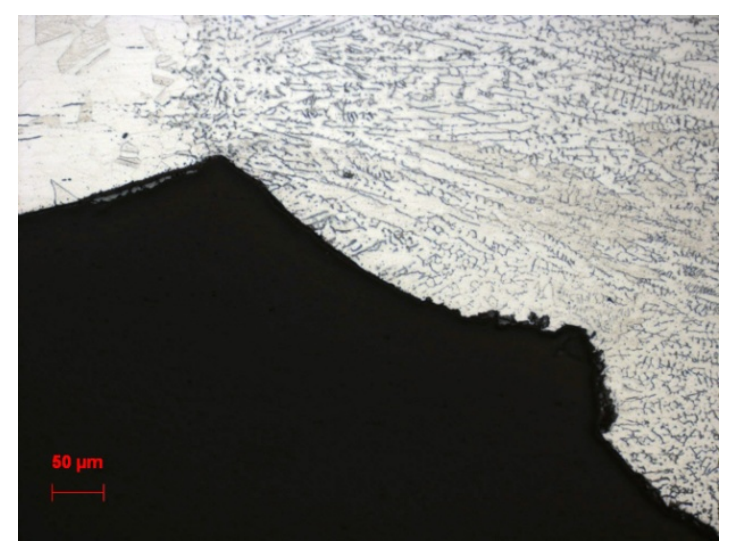

Figure 4-25 Microstructure near the pit observed in the sidewall of the $90^{\circ}$ pie section for FY12 DE6 (200x, electrolytically etched $10 \%$ oxalic acid)

\subsection{FY12 DE7}

For FY12 DE7, the inner container was noted to not have any corrosion (See Figure 2-5). The convenience container had a light coating of particulate that appeared to be easily removable. Localized surface breakdown was found on convenience container threads. The analyses were similar to those used for FY12 DE6 and consisted of several microscopic techniques to characterize the surfaces within the gap: 1) SEM/EDS to evaluate the type of degradation and the elemental species associated with features on the sidewall surface from the $0^{\circ}$ pie section; 2) stereomicroscope to document the overall surface appearance including color characteristic; and 3 ) an examination of the cross section of both the lid and sidewall pieces from the $0^{\circ}$ and $90^{\circ}$ pie sections to assess the pit geometry and depth and to determine if any cracks were initiating from pits. Three planes were examined.

The stereomicoscope photographs of the $0^{\circ}$ pie section showed that both the sidewall and lid had corroded as shown in Figure 4-26. The sidewall had features that appeared to be pits (Figure 426 (B) and (D)) while the lid piece showed general surface breakdown. Near the edge of the fractured weld as shown by the white arrows in Figure 4-26 (B) and (D), some areas of the surface showed a trough like feature since their focus plane laid below that of the image. This trough does not run down the length of the sample. 

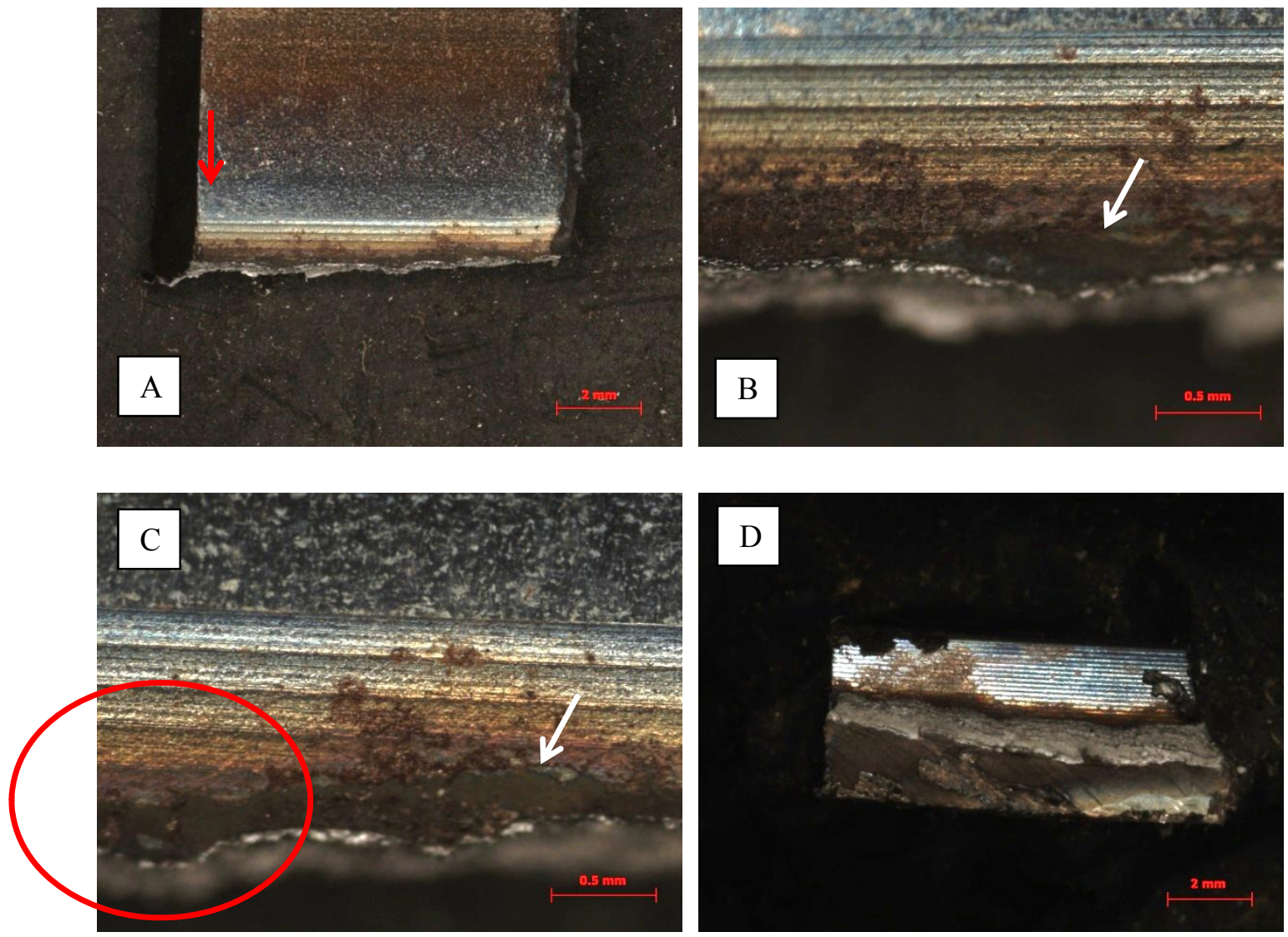

Figure 4-26 Stereomicroscope photographs of the sidewall and lid pieces from the $0^{\circ}$ pie section for FY12 DE7: (A) sidewall, 10x; (B) sidewall, 50x; (C) sidewall, 50x; and (D) lid, 10x

The SEM analysis showed that the sidewall from the $0^{\circ}$ pie section was similar to that observed for FY12 DE6. The surface had a banded appearance with three areas (See Figure 4-27): close to the weld had oxides and corrosion products, an area free of particulate and closer to the gap opening a heavy density of particulate on the surface. Pitting, if present, was obscured by the presence of corrosion oxide and particulates. 

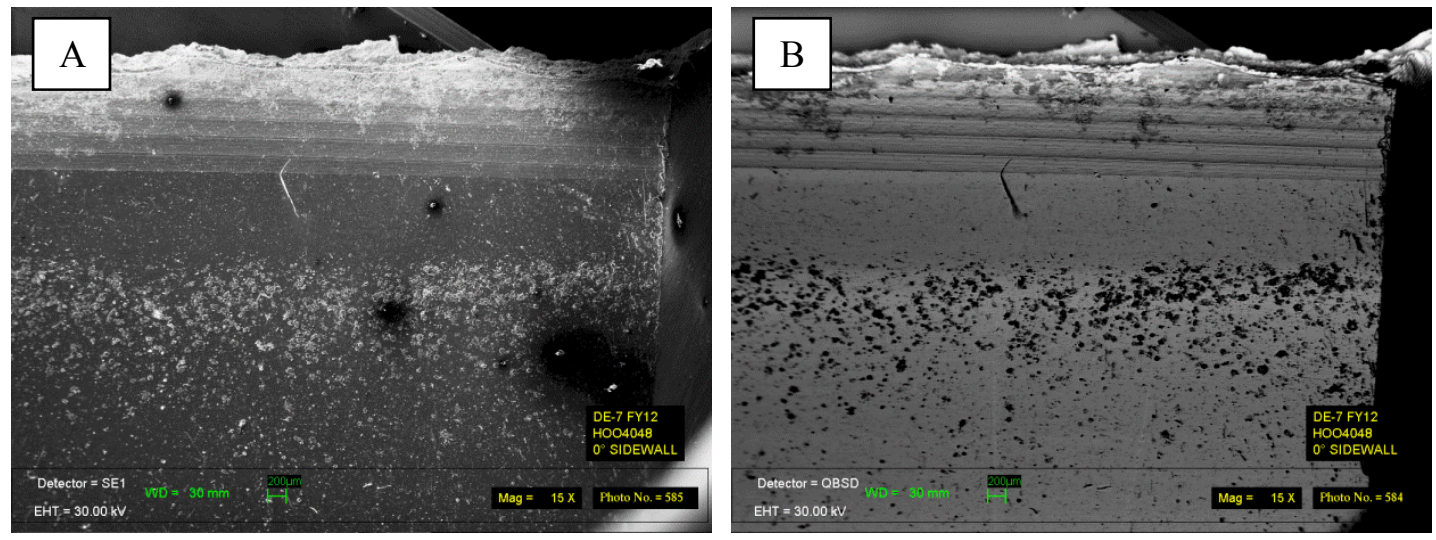

Figure 4-27 SEM micrographs (15x) of the sidewall from the $0^{\circ}$ pie section for FY12 DE7: (A) secondary electron image and $(B)$ backscattered image

The EDS spectra showed that the oxides were a combination of chromium-rich, iron-rich and nominal composition (as compared to a base metal scan). The locations of the spot analyses are shown in the micrographs in Figure 4-28, which were taken near the weld (A) and near the gap opening (B). The spectra are shown in Figure 4-29. The area near the weld shown in Figure 428 (A) is the same as that shown by the red circle in Figure 4-26 (C). Figure 4-29 (A) shows the spectra for the base metal taken as a raster scan of the sidewall away from the gap region. Chromium-rich oxides were observed in both locations (spots 2 and 9), while iron-rich oxides were only identified near the weld (spot 8 ). The presence of the $\mathrm{Al} / \mathrm{Mg} / \mathrm{Si} / \mathrm{Ca}$ compound was identified only near the gap opening.
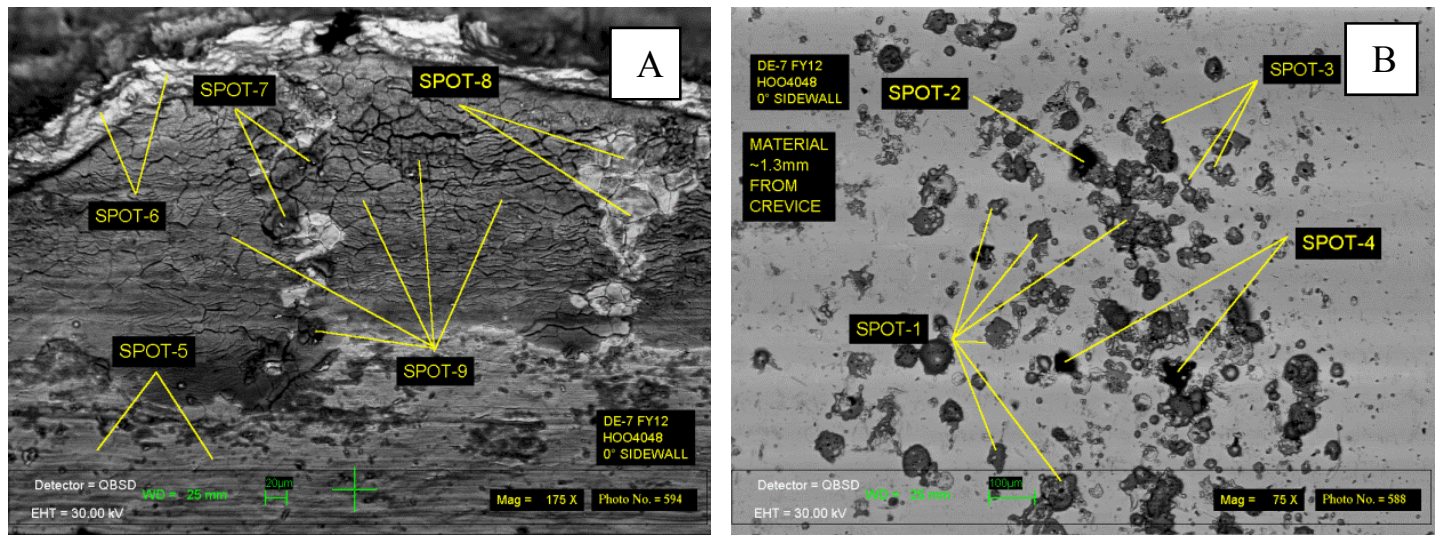

Figure 4-28 SEM micrographs showing the locations of EDS spectra for the heavily oxidized sidewall surface near the weld $(A, 175 x)$ and the particle-covered surface close to the gap opening $(B, 75 x)$ from the $0^{\circ}$ pie section for FY12 DE7 

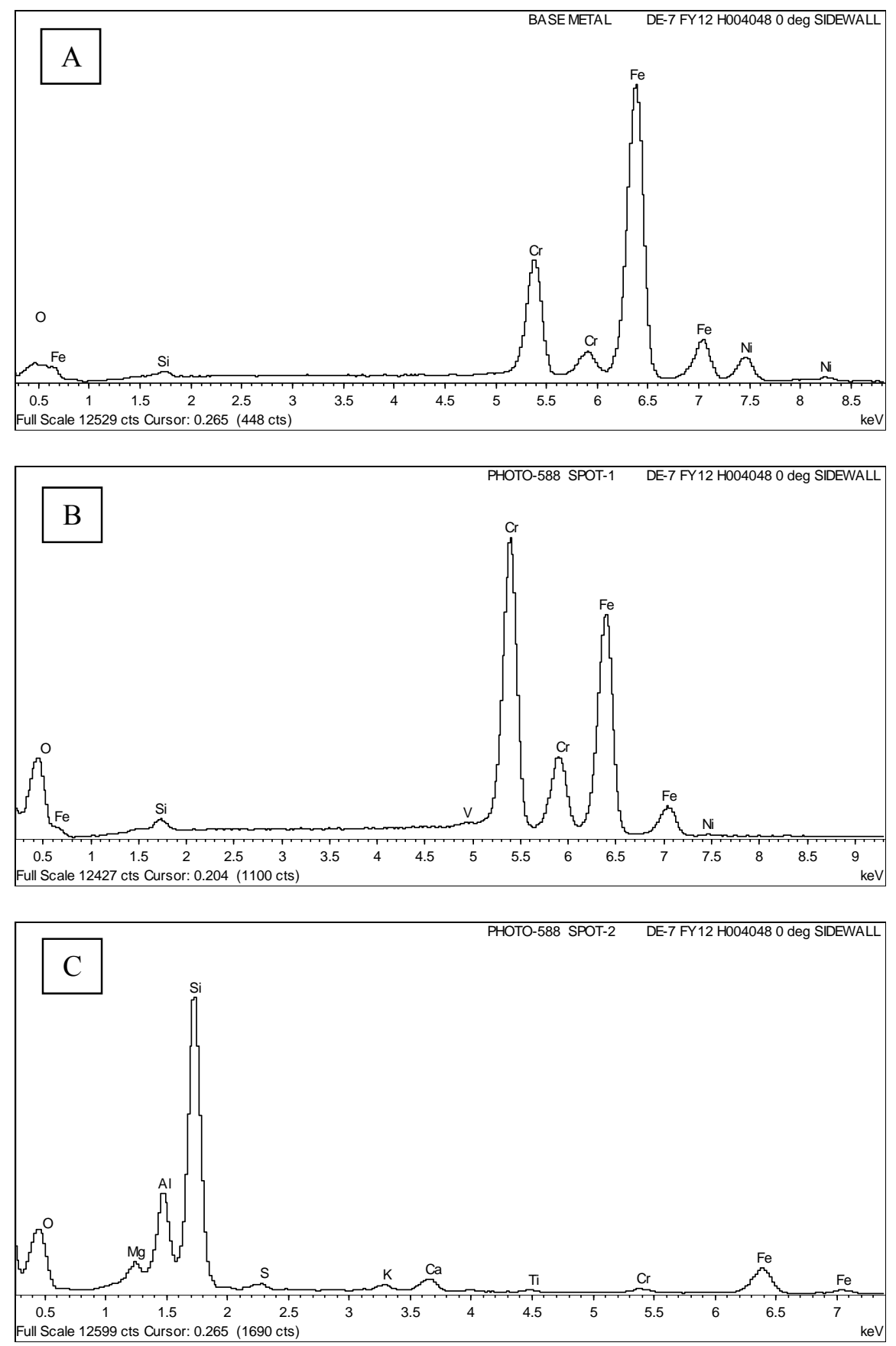

Figure 4-29 EDS spectra of the sidewall from the $0^{\circ}$ pie section for FY12 DE7; spots identified in Figure 4-28: (A) base metal raster scan; (B) spot 1, Cr-rich oxide; (C) spot 2, $\mathrm{Al} / \mathrm{Si} / \mathrm{Mg} / \mathrm{Ca}$ from particulate heavy area; (D) spot 7, Fe-rich oxide; (E) spot 8 oxide of nominal composition (compare to base metal scan) 

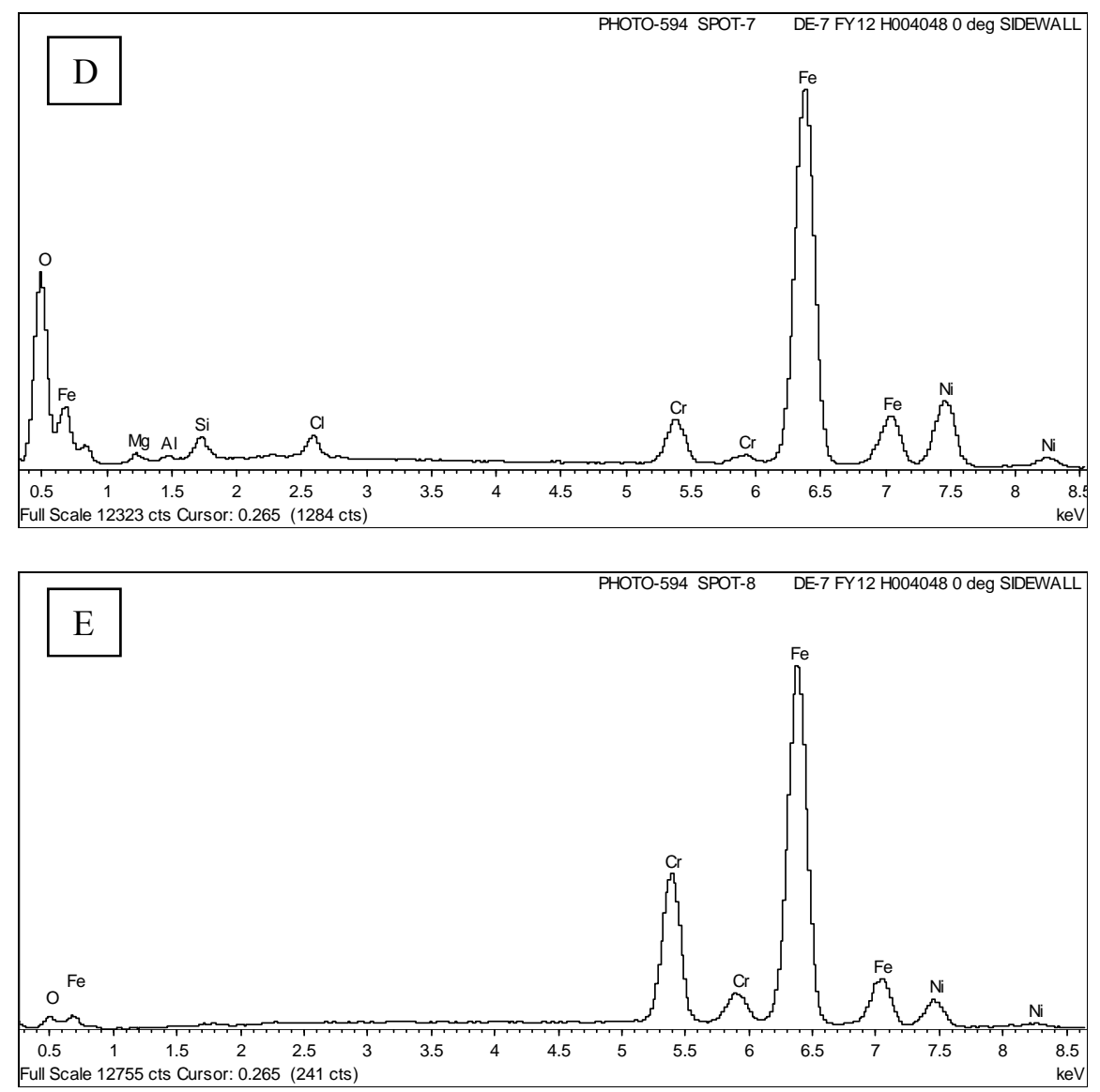

Figure 4-29 (Continued) $\quad$ EDS spectra of the sidewall from the $0^{\circ}$ pie section for FY12 DE7; spots identified in Figure 4-28: (A) base metal raster scan; (B) spot 1, Cr-rich oxide; (C) spot 2, Al/Si/Mg/Ca from particulate heavy area; (D) spot 7, Fe-rich oxide; (E) spot 8 oxide of nominal composition (compare to base metal scan)

During the preparation of samples for the serial metallography, the pie sections from both the $0^{\circ}$ and $90^{\circ}$ pie sections broke such that the sidewall piece did not cleanly separate from the lid piece, similar to the FY12 DE6 $0^{\circ}$ pie section (See Figure 4-22 (A) and (B)). This left intact the upper most part of the inner container closure weld gap.

For the $0^{\circ}$ pie section, pitting was observed only in the top of the gap where a crevice is located. The morphology of the crevice is shown for the three planes investigated in Figure 4-30. The first plane was etched to reveal the microstructure. Some small pits were observed in this region as shown in Figure 4-30 (A and C). An oxidized layer was not observed in this region. For the three planes that were investigated, the remainder of the sidewall and the lid pieces did not have any pitting. 

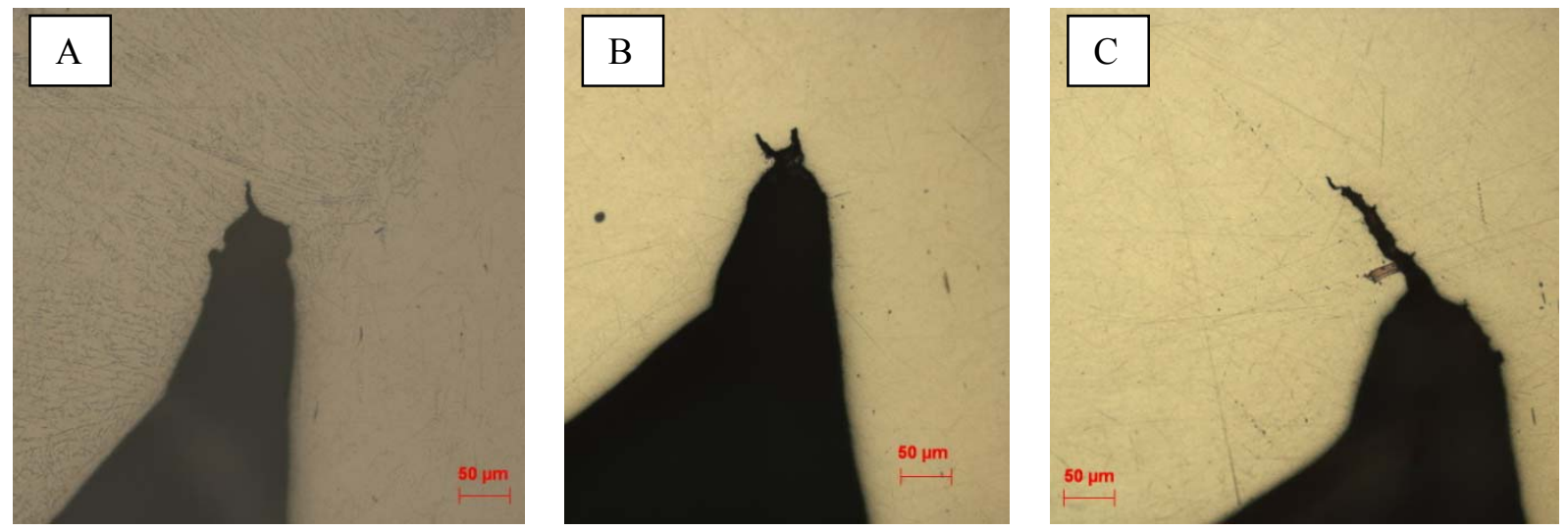

Figure 4-30 Micrographs (200x) showing progressive changes with grinding and polishing in the crevice at the top of the $0^{\circ}$ pie section closure weld gap for FY12 DE7; (A), (B), and $(C)$ are different planes with $(A)$ being closest to the edge of the pie section (shown by red arrow in Figure 4-26 (A))

For the $90^{\circ}$ pie section, the top of the gap showed a crevice that changed in dimensions for the three planes investigated. The first plane shown in Figure 4-31 (A) had a crevice (75 $\mu \mathrm{m}$ long, $10-20 \mu \mathrm{m}$ wide) with some small pits. The next plane the crevice was bigger $(\sim 200 \mu \mathrm{m}$ long, variable width) but without any significant pits. In the third plane (Figure 4-31 (C)), neither a crevice nor pitting was observed. No pitting was observed on the separate sidewall piece or the lid outside of the crevice area.
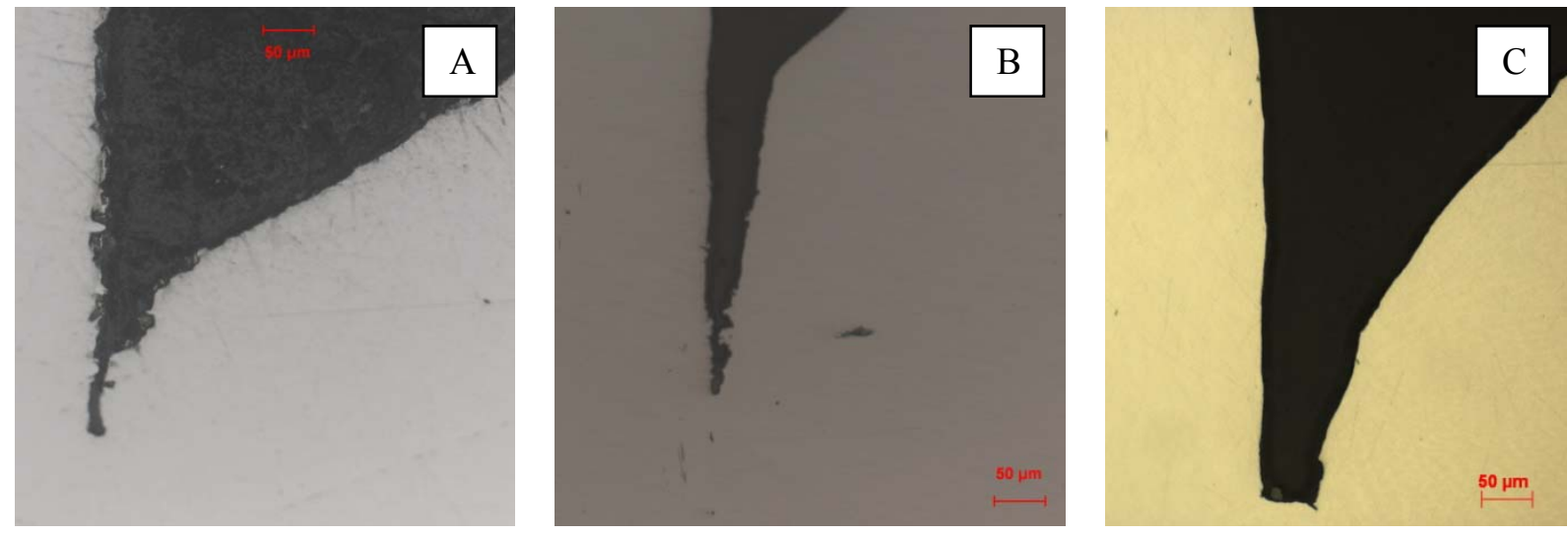

Figure 4-31 Micrographs (200x) showing progressive changes with grinding and polishing in the crevice at the top of the $90^{\circ}$ pie section closure weld gap for FY12 DE7; (A), (B), and (C) are different planes with (A) being closest to the edge of the pie section

\subsection{FY09 DE2}

For FY09 DE2, the inner container had a halo of pits on the interior bottom surface of the lid (See Figure 2-6 (B)). These pits were approximately $20 \mu \mathrm{m}$ in depth [3]. The analysis thus far consisted of several microscopic techniques to characterize the surfaces within the gap: 1) $\mathrm{SEM} / \mathrm{EDS}$ to evaluate the type of degradation and the elemental species associated with features on the sidewall surface for all pie sections; 2) stereomicroscope to document the overall surface appearance including color characteristic for the $90^{\circ}, 180^{\circ}$ and $270^{\circ}$ pie sections; and 3) an 
examination of the cross section of both the lid and sidewall pieces from the $180^{\circ}$ pie section to assess the pit geometry and depth and to determine if any cracks were initiating from pits.

Sectioning of the inner container lid during DE was performed for the first time with FY09 DE2 to get a better depth analysis of pits in the halo. The sidewall and lid pieces from the pie sections were not separated by removing the closure weld as was done for the HHMC, FY12 DE4, DE6 and DE7. The pie sections cut from the inner container lid for FY09 DE2 are shown in Figure 432. The cutting of the pie sections into separate pieces was not done the same for all pie sections. The cut lines are shown schematically in Figure 4-33. The $90^{\circ}$ pie section was the only sample cut through the closure weld which allowed the gap to be opened and the surfaces examined. The other pie sections kept the gap intact.
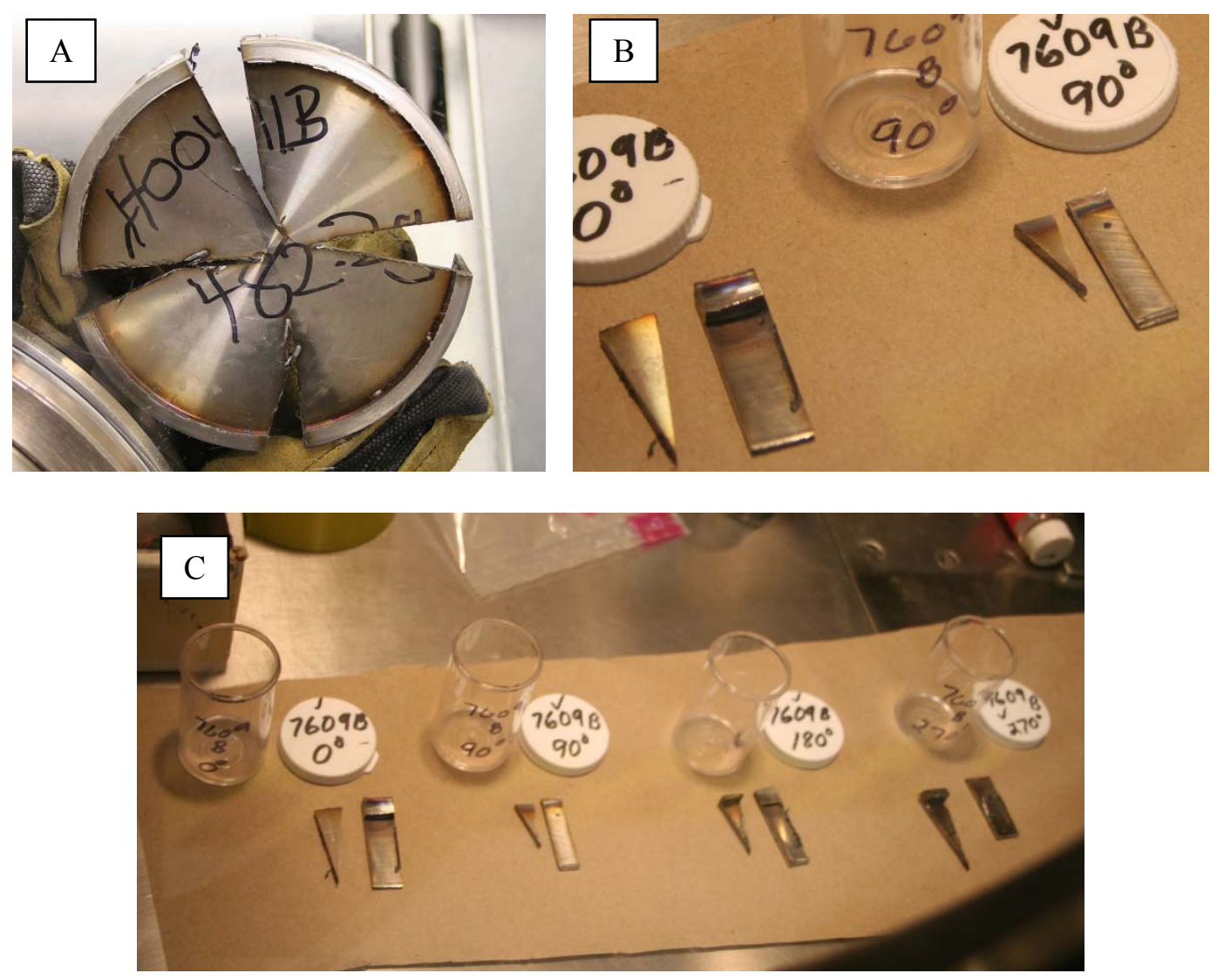

Figure 4-32 Sectioning of the FY09 DE2 inner container closure weld region: (A) remainder of sectioned lid; (B) $0^{\circ}$ and $90^{\circ}$ pie sections; (C) all pie sections 
SRNL-STI-2013-00527

Revision 0

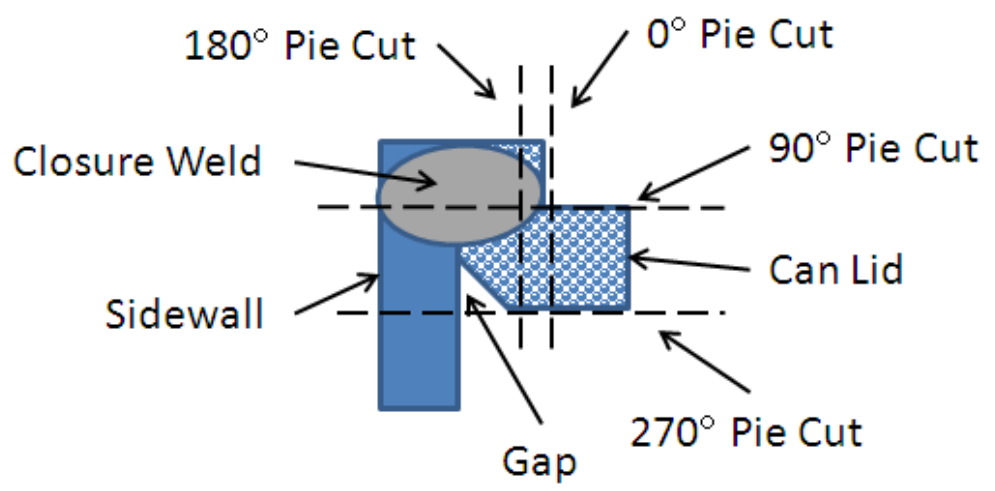

Figure 4-33 Schematic drawing showing the different cut lines used for removing pieces of the sidewall from the pie sections for FY09 DE2

The lid and sidewall surfaces within the gap were examined using the SEM and stereomicroscope for the $90^{\circ}$ pie section. Micrographs from both these analyses are shown in Figures 4-34 and 4-35. Figure 4-34 shows three SEM micrographs placed together showing the entire sidewall surface within the gap region (Note: there is some overlap in each micrograph). In Figure 4-35, a stereomicroscope micrograph of similar magnification is shown of the center of the sidewall gap surface and is the same as that shown in Figure 4-34 (B). From the micrograph in Figure 4-35, rust-colored corrosion products are seen on top of the weld oxide. Rust-colored corrosion products were also observed on the lid surface within in the gap as well as outside the gap region on the both the lid and sidewall (See Figure 4-36). All pie sections showed these types of corrosion products on both the sidewall and the lid for surfaces just outside the gap. All gap surfaces have not been examined at this time because of the way the initial cuts were made as shown in Figure 4-33.
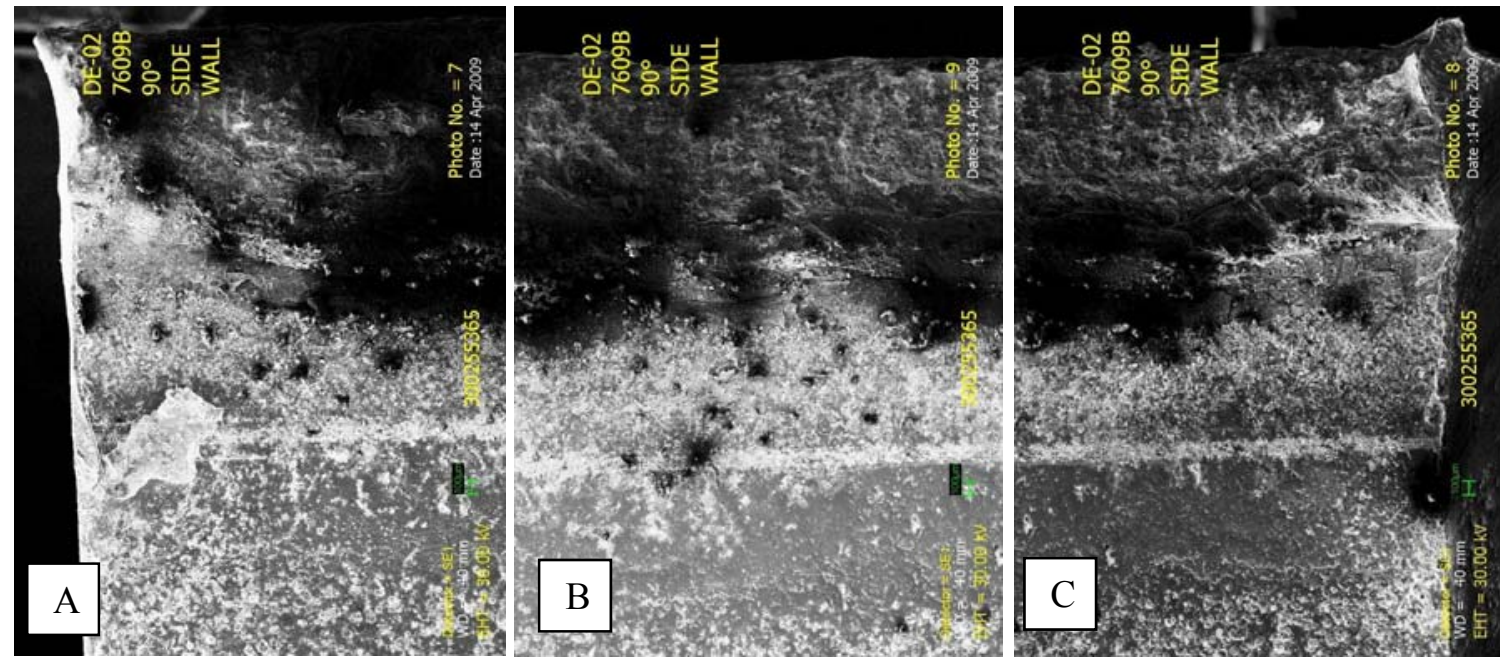

Figure 4-34 SEM micrographs (25x) of the sidewall surface from the inner container closure weld gap for the $90^{\circ}$ pie section from FY09 DE2 
SRNL-STI-2013-00527

Revision 0

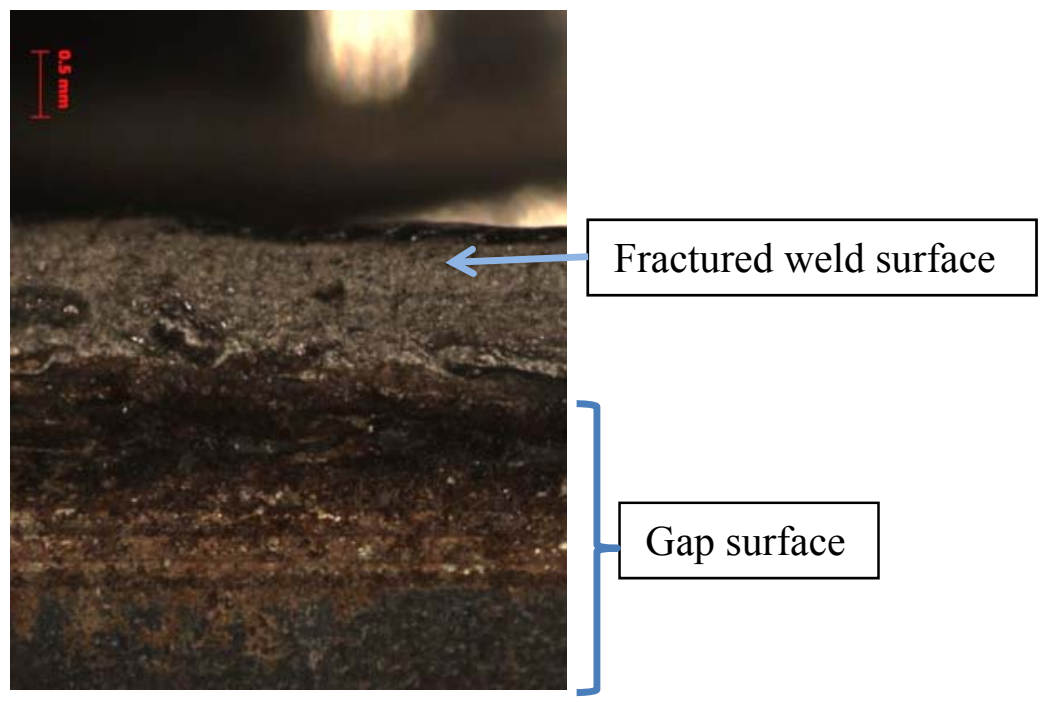

Figure 4-35 Stereomicroscope micrograph (25x) of the sidewall surface from the inner container closure weld gap for the $90^{\circ}$ pie section from FY09 DE2 (same as that shown in Figure 4-34 (B)) 

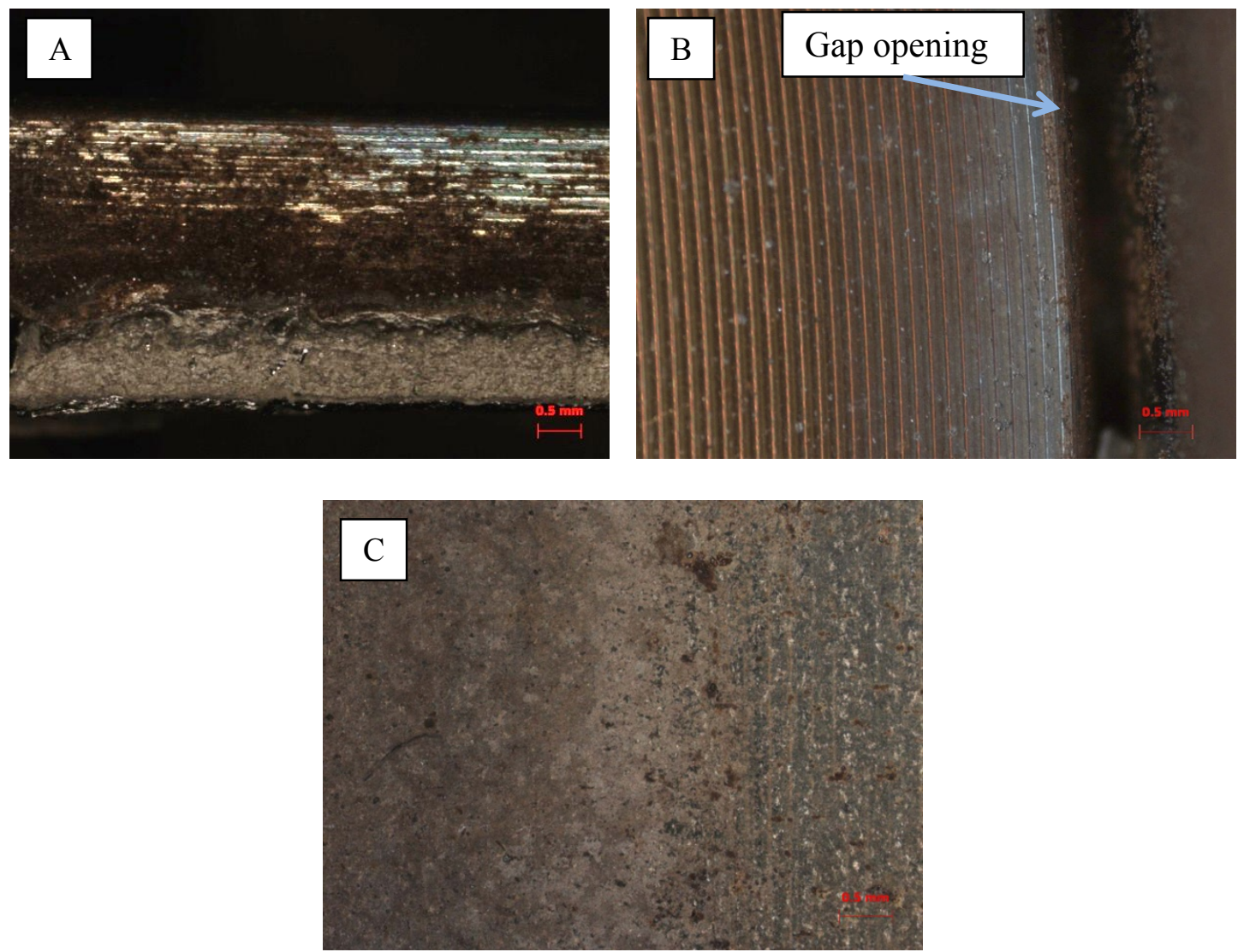

Figure 4-36 Stereomicroscope micrographs of the inner container closure weld region for FY09 DE2: (A) gap surface of the lid from the $90^{\circ}$ pie section, $20 x$; (B) lid outside the gap from $180^{\circ}$ pie section, $25 x$; and $(C)$ sidewall surface outside the gap from the $180^{\circ}$ pie section

During the SEM investigation of the $90^{\circ}$ pie section sidewall, EDS analyses were also performed on the surface oxides and particulate (See Figure 4-37). Iron-rich and chromium-rich oxides were found indicative of the weld oxide (Figure 4-38 (A) and (B)). Corrosion products were also identified and contained a significant chloride peak (Figure 4-38 (E)). Other compounds found on the surface contained $\mathrm{Al} / \mathrm{K} / \mathrm{Si} / \mathrm{O}$ (Figure 4-38 (D)), which were also identified on the lid surface just outside the gap. The halo of pits on the lid section of the $0^{\circ}$ pie section was also analyzed by EDS, which showed that all analyzed corrosion products were associated with Al, Si and $\mathrm{Cl}$. A base metal scan is shown in Figure 4-38 (C) for comparison. 


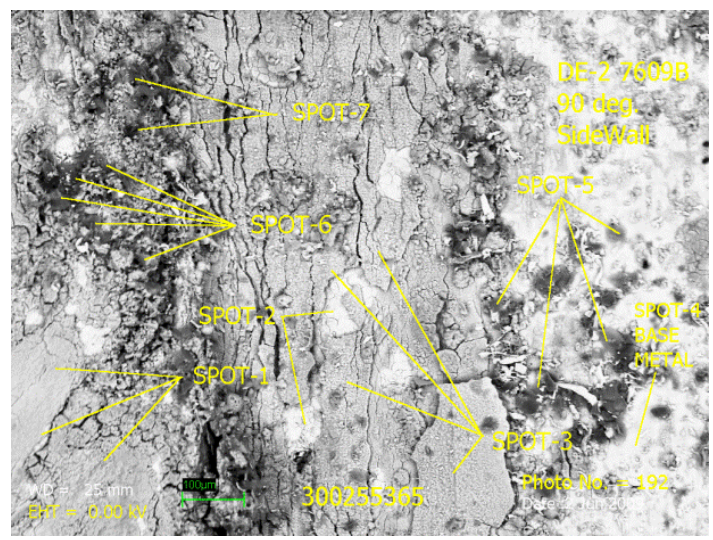

Figure 4-37 SEM micrograph (100x) showing the location of EDS point analysis for the sidewall surface for FY09 DE2 $90^{\circ}$ pie section (spectra are shown in Figure 4-38)
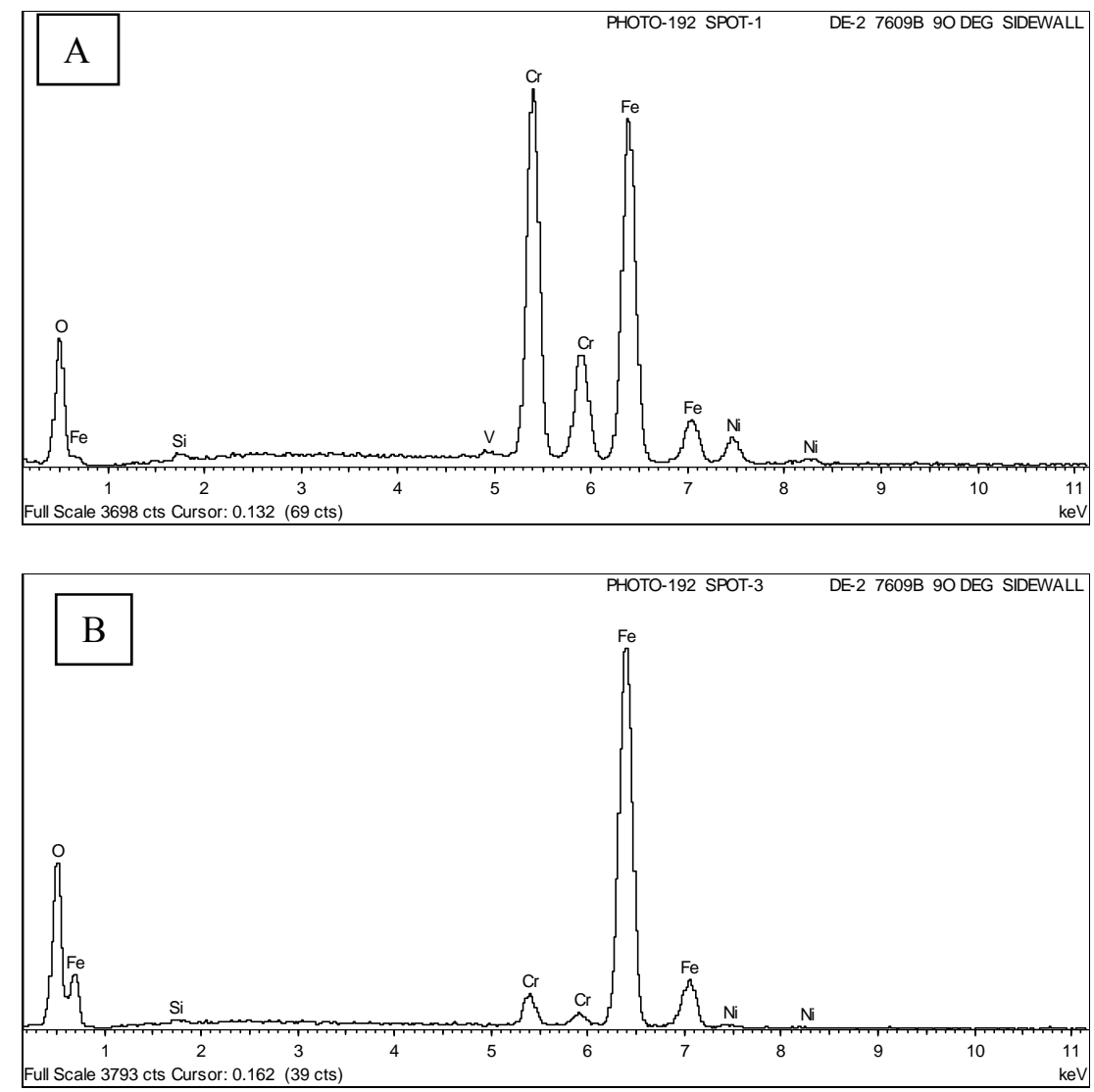

Figure 4-38 EDS spectra from spot analysis of the sidewall gap surface for the $90^{\circ}$ pie section from FY09 DE2 (see Figure 4-37 for location of spots): 1 (A), 3 (B), 4 (C) and 5 (D); and $6(\mathrm{E})$ 

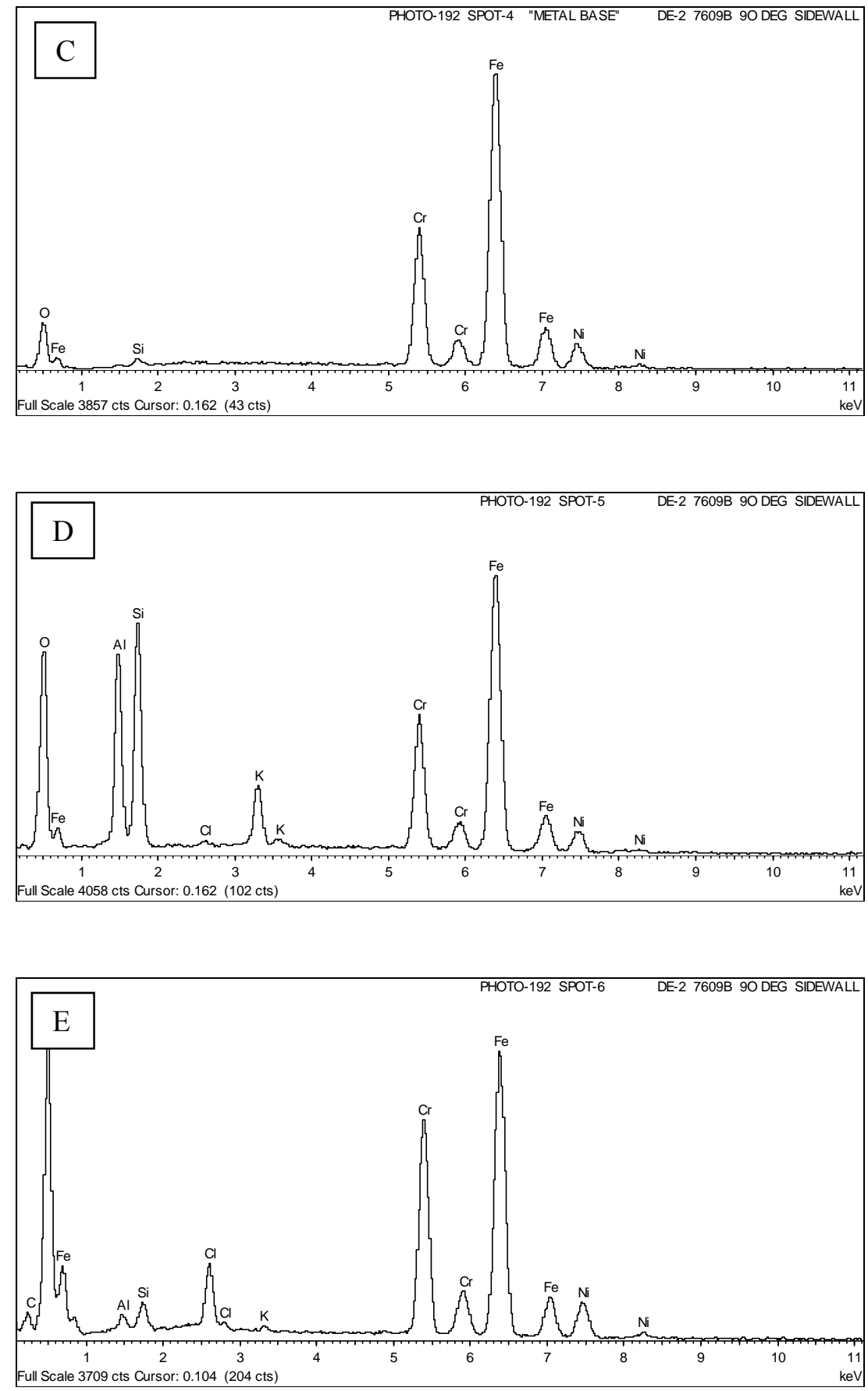

Figure 4-38 (Continued) $\quad$ EDS spectra from spot analysis of the sidewall gap surface for the $90^{\circ}$ pie section from FY09 DE2 (see Figure 4-37 for location of spots): 1 (A), 3 (B), 4 (C) and 5 (D); and 6 (E)

The sidewall piece of the $180^{\circ}$ pie section was mounted in cross section and evaluated for pitting. This sample maintained the gap because of the way it was cut (See Figure 4-33). The gap region was approximately $2.7 \mathrm{~mm}$ long (See Figure 4-39 (A)). A crevice (approximately $0.3 \mathrm{~mm}$ long) was found at the top of the gap as shown by the micrograph in Figure 4-39 (D). A buildup of oxide is seen at the mouth of the crevice. Pitting was found along the sidewall and lid surfaces. 
Pits were generally $5 \mu \mathrm{m}$ or less although a few were slightly larger. Oxide and rust-colored corrosion products were observed on the surface just outside the gap.
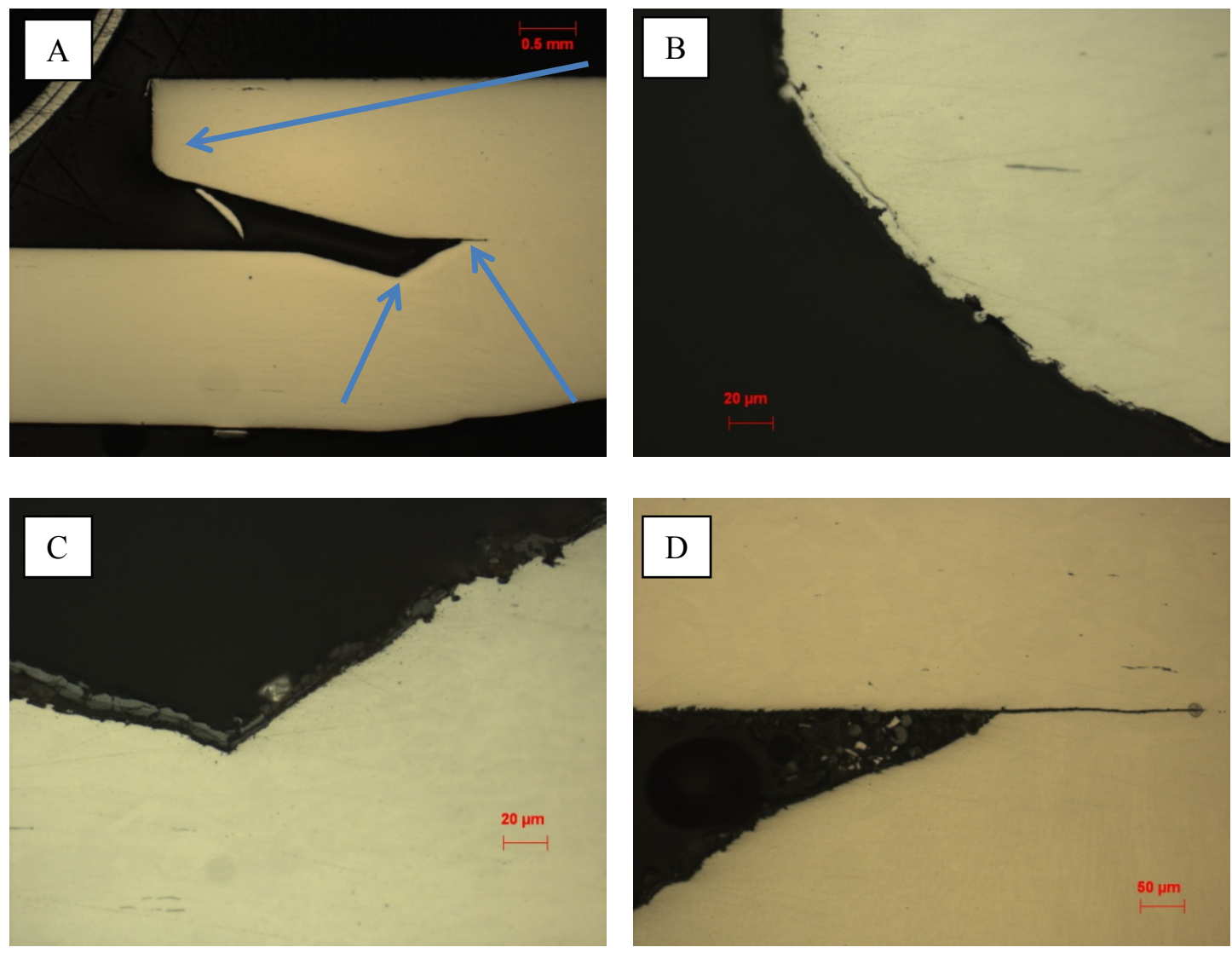

Figure 4-39 Closure weld gap region for the $180^{\circ}$ pie section from FY09 DE2: (A) gap region, $12.5 x$; (B) pitting at the gap opening on the lid, 500x; (C) pitting on the sidewall, 500x; and (D) top of gap showing a crevice, 200x (arrows in A show the location of the other micrographs)

\subsection{SRNL Shelf Life Corrosion Test Results Summary}

The SRNL shelf life corrosion testing was established to evaluate the corrosion of both 304L and 316L stainless steels to different conditions within a 3013 container. The primary factors of interest have been the type of chloride salt, salt concentration, and moisture levels or resulting relative humidity. The test cells are structured so that a stressed coupon (teardrop-shaped coupon) are in contact with both the salt and vapor space above the salt. This testing has been conducted in two phases. Phase I is complete while Phase II, which consists of three test series, is currently underway with the first test series completed and the second series ongoing.

In Phase I, small-scale test vessels were used to evaluate the effects of chloride salt composition and the attendant radiation of plutonium oxide on the corrosion of 304L and 316L [8]. SCC and pitting were found in 304L teardrop coupons after 166 days in a high moisture environment $(0.6$ $\mathrm{wt} \%$ water content for oxide/salt mixture) while in contact with a plutonium oxide/salt mixture that contained $0.3 \mathrm{wt} \%$ calcium chloride. The 316L coupons showed pitting but no cracking. Pitting, however, was also found on surfaces exposed only to the vapor space for both 304L and 
316L coupons. Maximum pit depths after 166 days exposure were $60 \mu \mathrm{m}$ and $100 \mu \mathrm{m}$ for $316 \mathrm{~L}$ and $304 \mathrm{~L}$, respectively. Cracking was not found in 304L teardrop coupons after exposure for 496 days to a plutonium oxide/salt mixture containing $0.92 \mathrm{wt} \%$ calcium chloride and a $0.6 \mathrm{wt} \%$ water content. These results indicated that the incidence of pitting and cracking on the steel surface were a function of the moisture content and salt concentration.

In Phase II, the testing was designed to determine a threshold $\mathrm{RH}$ for SCC and evaluate the dependence on configuration (direct contact with plutonium-bearing material or vapor exposure only) needed for SCC initiation and propagation. The first test series of this phase was set up to duplicate the Phase I testing, although the moisture content was lower at approximately $0.5 \mathrm{wt} \%$ [9]. Small cracks were observed after 85 days with a maximum pit depth of $74 \mu \mathrm{m}$. Pit depths did not appear to increase with time beyond the 85 days, but a crack grew through wall after 340 days. Cracks generally appeared to be associated with pits, although whether they initiated at pits was not determined. Figure 5-1 shows the observed cracking and pitting after 85 and 175 days. Cracking was not observed for pits in the vapor space.
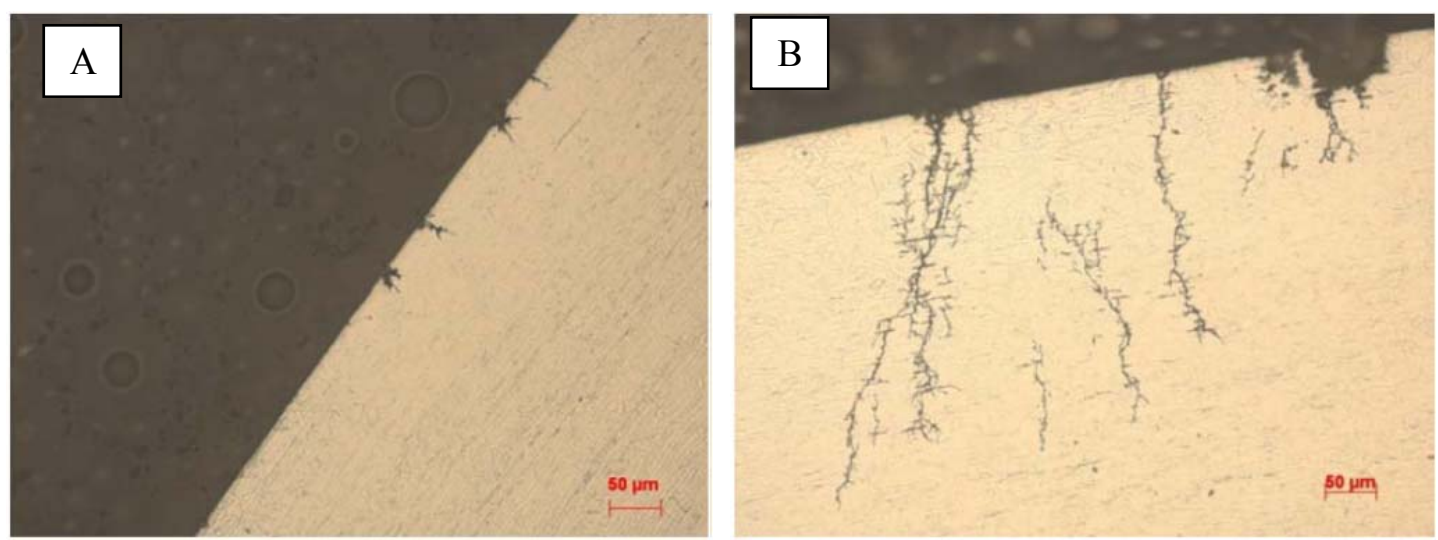

Figure 5-1 Cross-sectional micrographs (200x) showing pit morphology for teardrop-shaped coupon after exposure to plutonium oxide/chloride salt mixture loaded with 0.5 wt \% water: A) 85 days and B) 175 days

The teardrop coupon is fabricated by bending a strip around a mandrel and welding the ends together. The same process used in closing the inner container, tungsten inert gas (TIG) welding, was the technique used to weld the coupons. Similar to the surfaces of the inner container after welding, the welded end of the teardrop coupon had weld oxides. This area of the sample was always found to be covered with corrosion products for both Phase I and Phase II testing. At closer examination, the surface was found to be pitted with the pits appearing strung together as a circuit. The deepest pit measured had a depth of $15 \mu \mathrm{m}$, although all pits were not measured. Figure 5-2 shows SEM and cross-sectional micrographs of pitting observed in the closure weld region of a tear-drop shaped coupon after 85 and 340 days of exposure as well as a teardropshaped coupon after 85 day exposure in vapor only. 

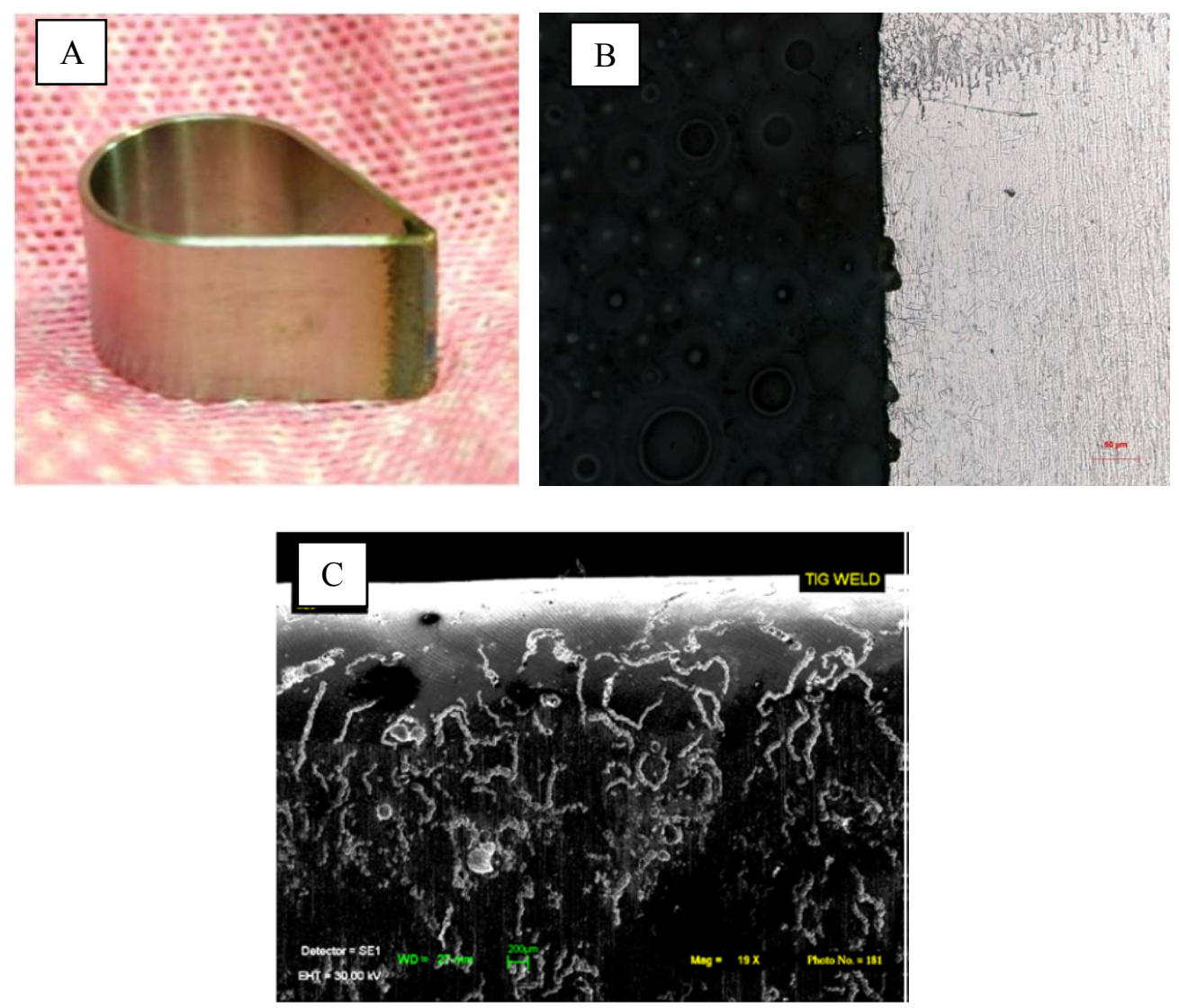

Figure 5-2 Corrosion observed in the closure weld region of teardrop-shaped coupons after exposure to a plutonium oxide/chloride salt mixture with $0.5 \mathrm{wt} \%$ water: A) teardrop-shaped coupon exposed to vapor only after 85 days; B) cross-sectional micrograph (200x) of pitting in coupon after 85-days exposure; and C) SEM micrograph (19x) of pitting on TIG weld surface after 340-day exposure, sample was cleaned

\subsection{Discussion}

The Hanford 3013 inner containers were all welded with parameters within a specified range, which would result in some expected variability within the closure weld region. The corrosion evaluation of the 3013 inner container closure weld region has shown that there is some variability in the surface features (oxide, particulate, etc) and the physical structure (dimensions, presence of crevice). However, the impact of this variability on the overall corrosion resistance, especially to pitting and stress corrosion cracking has not been determined. Additional testing and evaluation would be required to determine if the surface features and physical structure impact the integrity of the inner container.

The physical size of the gap that is formed by the lid and sidewall is generally about the same but can vary in length. The gap lengths are difficult to determine with the separation of the lid and sidewall, but for the $90^{\circ}$ pie section from FY09 DE2 the gap length was measured at $2.7 \mathrm{~mm}$. The gap size measured for mounted pie sections from FY08 DE7, which were archived from baseline metallography, varied from approximately $4.8 \mathrm{~mm}$ to $5.8 \mathrm{~mm}$. Figure $6-1$ shows cross- 
sectional micrographs of the inner container closure weld region for FY08 DE7 and shows the difference in length.
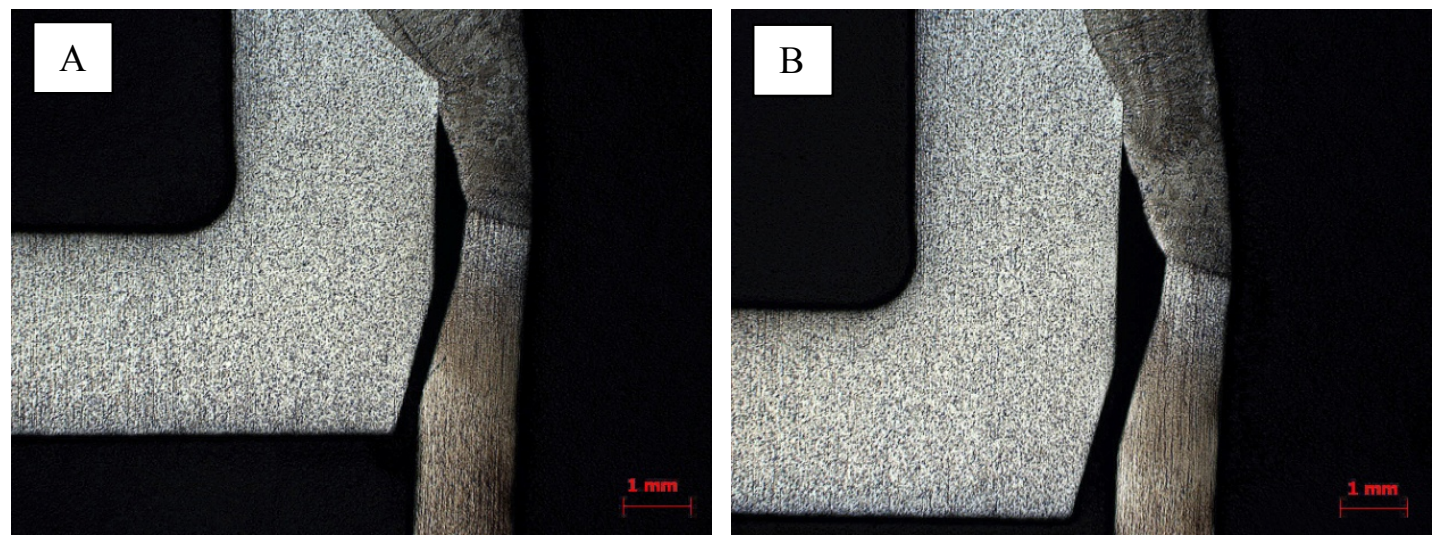

Figure 6-1 Cross-sectional micrograph (12x) of the inner container closure weld region for FY08 DE7: A) $90^{\circ}$ pie section and B) $270^{\circ}$ pie section

The overall shape of this gap region is similar but the top of the gap varies. A crevice may be present and vary in shape as well as dimensions as was seen for FY12 DE 6 and DE7 and FY09 DE2 (Compare Figures 4-23, 4-30, 4-31 and 4-39). This crevice is not uniform around the closure weld region as observed for FY12 DE6 and DE7. Crevice dimensions impact the likeliness of corrosion [10]. The pitting observed in the gap thus far has been outside the crevice, which may be due to a limited amount of moisture deposited in this region.

The sidewall surfaces from all the DE containers examined to date show a similar banded appearance. Close to the TIG closure weld near the top of the gap, the surface is covered with oxides resulting from the welding process. These oxides vary in composition with some being chromium or iron rich while others are closer to the base metal composition. In this region also is where most of the corrosion has been observed. Below this band along the top of the gap is an area that is free of particulate and does not have a heavy oxide build up. The next band which is closest to the gap opening has a heavy deposit of particulate. Some corrosion has been observed in this area of heavy particulate although the investigations have not been exhaustive.

The pitting was most advanced on the HHMC. The pit morphologies were both hemispherical as well as irregular. In the other containers, the pits generally were hemispherical. Other than the large pit observed on FY12 DE6, the pits were less than $20 \mu \mathrm{m}$ with most being less than $5 \mu \mathrm{m}$. These pits are smaller than those observed on the teardrop coupon that was exposed in the oxide/salt mixture for 85 days where the pit morphology varied from broad shallow pits to deep narrow pits. Widths as measured from cross sectional micrographs ranged from 3 to $550 \mu \mathrm{m}$ and depths ranged from 6 to $74 \mu \mathrm{m}[9]$.

From this analysis, the HHMC and FY09 DE2 with the halo of pits on the inside lid bottom were observed with the most corrosion for the inner container. The correlation of corrosion with packaging variables, such as moisture and chloride content, is not a simple relationship. Table 1 shows the variables that have been considered. Both the HHMC and FYO9 DE2 have similar total actinide concentrations as well as chloride concentrations, although not the highest. If the 
corrosion is due to gaseous transport of $\mathrm{HCl}$ as the corrosive agent, then perhaps the higher radiation from more actinides is necessary for sufficient volatilization of the corrosive species [11].

Table 1. Measured Parameters for Packaged 3013 Containers

\begin{tabular}{|l|l|l|l|l|l|l|}
\hline \multirow{2}{*}{ Container } & \multicolumn{2}{|c|}{ Moisture } & \multicolumn{1}{c|}{$\begin{array}{c}\text { Actinides } \\
(\%)\end{array}$} & \multicolumn{2}{c|}{ Concentration $(\boldsymbol{\mu g} / \mathbf{g}) * *$} \\
\cline { 2 - 7 } & \multicolumn{1}{|c|}{ TGA* } & TGA/MS** & & \multicolumn{1}{c|}{ Cl } & \multicolumn{1}{c|}{ Ca } & Mg \\
\hline FY12 DE4 & 0.183 & $0.34 / 0.14$ & 60.86 & 2945 & 526 & 333 \\
\hline FY12 DE6 & 0.238 & $0.56 / 0.31$ & 62.93 & 112500 & 5.55 & 3520 \\
\hline FY12 DE7 & 0.336 & $1.14 / 0.54$ & 56.46 & 135500 & 384 & 3195 \\
\hline FY09 DE2 & 0.399 & $0.6 / 0.28$ & 71.75 & 58,100 & 499.5 & 840 \\
\hline HHMC & 0.225 & $0.9 / 0.24$ & 75.11 & 32,150 & 3540 & 310 \\
\hline
\end{tabular}

* Packaging information

** DE data

The data from the shelf life study has provided some correlation with the corrosion observed in the DE inner container closure weld region. For the shelf life study teardrop coupons, pitting and cracking were observed in a high moisture environment $(>0.5 \mathrm{wt} \%)$ for coupons exposed to the salt/oxide mixture, i.e. direct contact. For coupons exposed only to the vapors in that environment pitting was observed only on the TIG closure weld for the teardrop. These pits were of the same order of magnitude as those observed in the TIG closure weld region of the inner container. Cracking has also not been observed for either of these vapor-exposed surfaces nor the vapor-exposed portions of the teardrop coupon exposed to the salt/oxide mixture. For the teardrop coupons, the stress levels in this region are well below those typically associated with SCC [12], while those in the inner container closure weld region are sufficient to cause SCC [13]. A shelf life test where the TIG weld oxide is sufficiently stressed and exposed to a nominal inner container environment would provide additional insight.

\subsection{Conclusion}

As a result of $3013 \mathrm{DE}$ additional analysis, the area near the inner container closure weld has been identified as being a region of increased corrosion susceptibility which may provide a pathway for corrosive gases to the outer container.. This area has a higher residual stresses, an altered microstructure, and less corrosion resistant weld oxides as a result of from the welding process as well as lower temperature than other areas of the container, which may increase the absorption of moisture on the surface. These conditions have led to pitting corrosion via a vapor/gas transport mechanism and may result in SCC.

During FY2013, the inner container closure weld area was more closely evaluated on several archived samples from DE containers. These containers include FY09 DE2, FY12 DE4, FY12 DE6 and FY12 DE7. The container designated the HHMC was also examined since the convenience container was heavily corroded. The additional examinations included visual observations with a stereomicroscope, SEM/EDS, and serial metallography of this inner container closure weld region. 
Pitting was observed in all the samples taken from the closure weld regions of the examined inner containers. This pitting was generally less $20 \mu \mathrm{m}$ with most less than $5 \mu \mathrm{m}$. These pits were similar in depth to those observed in the vapor exposed surfaces of teardrops in the shelf life testing. Cracking was not observed on either the vapor-exposed surfaces of the teardrop coupons or the inner container closure weld region. Further testing is necessary to determine if the conditions in the welded inner container could support SCC during the 50 year life time for the 3013 container.

\subsection{References}

1. "Stabilization, Packaging, And Storage of Plutonium-Bearing Materials", DOESTD-30132004, U. S. Dept. of Energy, 2012

2. J. Berg et al, "Test Plan for Assessing Potential for Stress Corrosion Cracking in the 3013 Inner Container Closure Weld Region (FY 2014)", in draft

3. Kelly, E.J., Graves, T. L., Veirs, D. K., Duque, J. G., Berg, J. M., Worl, L.A., Mickalonis, J. I., 2013, "A General Statistical Model for Corrosion Pit Depth Analysis for Threshold Data," Los Alamos National Laboratory, LA-UR-13-25127

4. L. Garverick, Corrosion in the Petrochemical Industry, ASM International, OH, 1994, p 136

5. N. Sato, "The Stability of Localized Corrosion," Corr. Sci, V. 37 (12), 1995, pp1947-65

6. J. D. Sedriks, Corrosion of Stainless Steels, $2^{\text {nd }}$ edition, Wiley, New York, 1996

7. Personal communication with S. L. West, SRNL

8. P. E. Zapp and J. M. Duffey, "Status Report for the SRNL 3013 Corrosion Tests," SRNLSTI-2008-00093, October 2008

9. J. I. Mickalonis and J. M. Duffey, "SRNL Phase II Shelf Life Studies - Series 1 - Room Temperature and High Relative Humidity, SRNL-STI-2012-00530, Revision 0, September 2012

10. Qian Hu et al, "The Crevice Corrosion Behaviour of Stainless Steel in Sodium Chloride Solution," Vol 53, pp 4065-4072, 2011

11. D. K. Viers et al, "Evidence of Corrosive Gases Formed by Radiolysis of Chloride Salts in Plutonium-bearing Materials," Vol 38 (3), pp 25-31, 2010

12. P. S. Lam, P. E. Zapp, and J. M. Duffey, "Stress Corrosion Cracking in Tear Drop Specimens," Proceedings of the ASME 2009 Pressure Vessels and Piping Division Conference, July 2009

13. J. I. Mickalonis and K. A. Dunn, "Residual Stresses in 3013 Containers," Journal of Nuclear Material Management, Vol 38 (2), pp 39-46, 2010 